\title{
Optimized Surface Roughening by Pulsed Waterjet

\author{
for Suitable Adhesion Strength of Plasma
}

\section{Transferred Wire Arc Coating}

by

\section{Nicholas O’Neil}

A thesis submitted to the Faculty of Graduate and Postdoctoral Affairs in partial fulfillment of the requirements for the degree of

Master of Applied Science: Materials Engineering

\author{
Carleton University \\ Ottawa, Ontario \\ June 2020 \\ (C) Nicholas O'Neil
}




\section{Abstract}

This study utilized a high-pressure pulsed waterjet process and paired it with the plasma transferred wire arc technology to develop a novel technique to remanufacture worn-out engine cylinder bores and give the engine new life. The plasma transferred wire arc technology is currently being used for the engine remanufacturing process by major auto-industries to deposit the wear resistant top-coat. One of the steps during the remanufacturing process is to chemically deposit a nickel-aluminum pre-bond coat for a better top-coat bond strength. The idea behind this project is to eliminate the need for the expensive pre-bond coat step by optimizing the surface roughness profile of the substrate to provide acceptable mechanical bonding between the coating and the substrate. The desired outcome is a coating-substrate adhesion strength greater than $30 \mathrm{MPa}$, which is required for engine cylinder bore liners application. In this study, low carbon stainless-steel was plasma spray coated on a wide range of pulsed waterjet roughened surface profiles generated on grey cast iron and cast aluminum A380 alloy, two commonly used engine materials. The roughened surfaces greatly increased the adhesion strength between the substrates and stainless-steel coating. The increase in adhesion strength is a result of the formation of favourable mechanical anchoring points. Limitations exist on the surface roughness profile produced by the pulsed waterjet, such that, if the roughness profile generated was copious the coating mirrored the roughened surface profile. Additionally, if the roughness profile produced by the pulsed waterjet was insignificant the coating was removed in its entirety during detachment-based failure. 


\section{Acknowledgments}

Firstly, I would like to thank my supervisor, Dr. Kabir, for guiding me and sharing his knowledge and experience throughout the project.

I would also like to thank Mr. Andrew Tieu and Dr. Mohan Vijay from VLN Advanced Technologies Inc., Ottawa for their assistance during the project.

Additionally, I would like to acknowledge the financial supports from the Natural Sciences and Engineering Research Council (NSERC) of Canada and the Ontario Centers of Excellence (OCE).

Finally, I would like to thank my family for their continuous love, help, and support throughout my educational career. 


\section{Table of Contents}

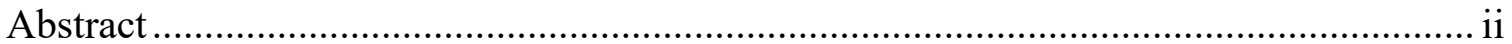

Acknowledgments.............................................................................................. ii

List of Tables .................................................................................................... vii

List of Figures .............................................................................................. viii

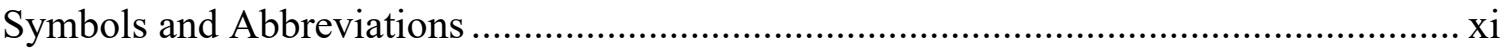

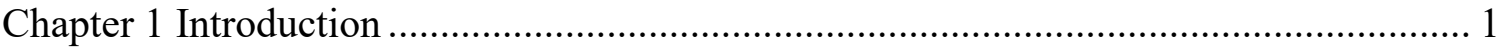

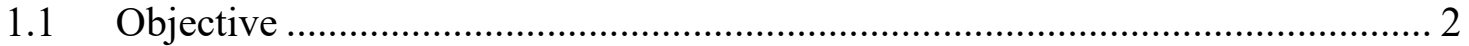

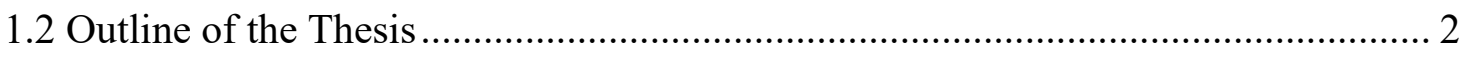

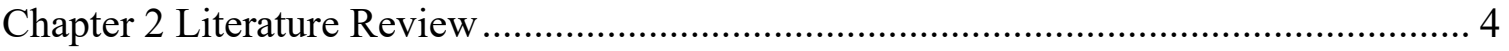

2.1 Pulsed Waterjet Roughening Process .................................................................. 4

2.1.1 Introduction to Waterjet Process....................................................................... 4

2.1.2 Pulsed Waterjet Processes.......................................................................... 7

2.1.3 Application Procedures for Pulsed Waterjet Surface Roughening ................. 10

2.1.4 Parameters that Influence Pulsed Waterjet Surface Characteristics ................ 12

2.2 Properties of Waterjet Roughened Cast Aluminum and Cast Iron Surfaces .......... 15

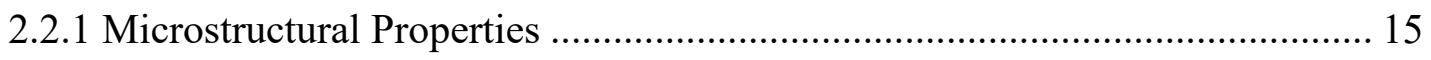

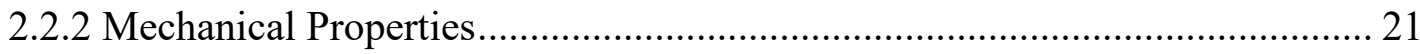

2.3 Plasma Transferred Wire Arc Deposition Process................................................. 25

2.3.1 Introduction to the Thermal Spray Coating Process ...................................... 25

2.3.2 Plasma Transferred Wire Arc (PTWA) Process .......................................... 27

2.3.3 Application Procedure of Plasma Transferred Wire Arc Coating ................... 31

2.3.4 Parameters that Influence Plasma Transferred Wire Arc Coatings ................. 34

2.4 Properties of Plasma Transferred Wire Arc Coating ........................................... 39

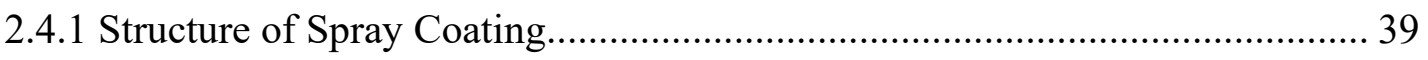

2.4.2 Spray Coating Mechanical Properties........................................................ 40

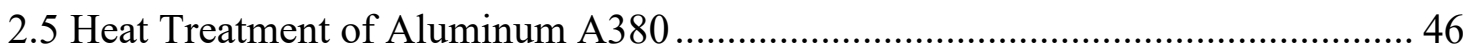

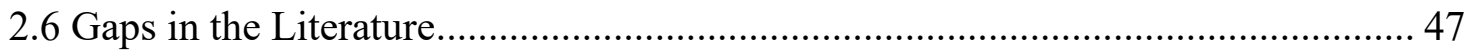

Chapter 3 Materials and Experimental Procedure ................................................. 48

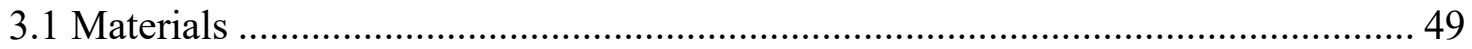


3.1.1 Substrate Material 49

3.1.2 Plasma Transferred Wire Arc Coating Material ........................................... 50

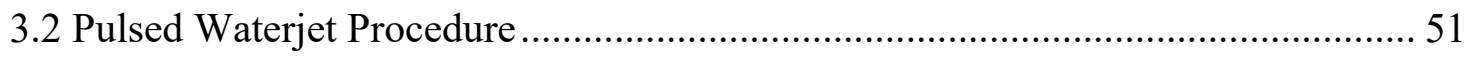

3.2.1 Pulsed Waterjet Test Setup ...................................................................... 51

3.2.2 Parameters of Pulsed Waterjet Process ........................................................ 52

3.3 Measurements of Substrate Dimensional Changes.............................................. 53

3.4 Stylus Profilometer Surface Roughness Measurements .................................... 53

3.4.1 Stylus Profilometer System Overview ........................................................ 54

3.4.2 Parameters Selected for Stylus Profilometer ............................................ 54

3.5 A380 Heat Treatment Procedure ........................................................................... 55

3.5.1 Cast Aluminum T4 Heat Treatment Process ................................................ 56

3.5.2 Cast Aluminum T6 Heat Treatment Process .................................................... 56

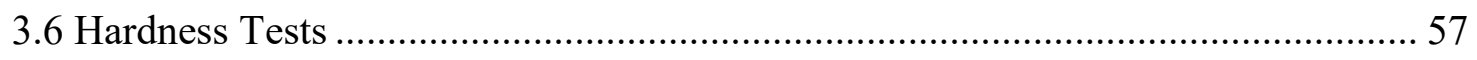

3.8 Plasma Transferred Wire Arc Coating Procedure ............................................ 58

3.9 Pull-off Adhesion Strength Measurements ......................................................... 58

3.9.1 Pull-off Adhesion Strength Procedure ...................................................... 59

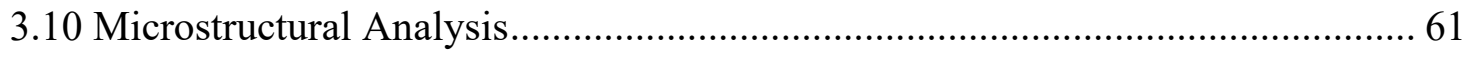

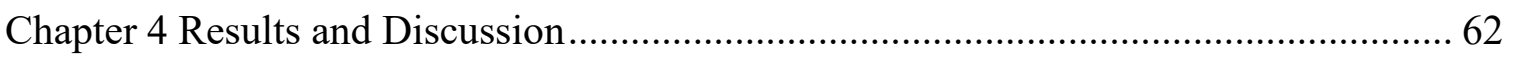

4.1 Stylus Profilometer Surface Roughness Results ............................................... 62

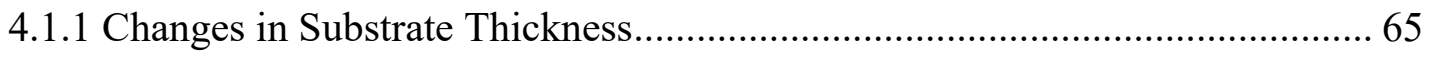

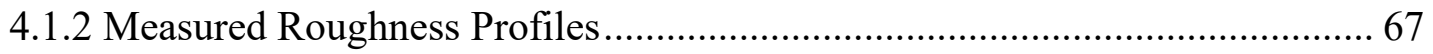

4.1.3 Change in Roughness with Transverse Speed ............................................ 72

4.1.4 Microstructural Features Responsible for Roughness Profiles ...................... 73

4.1.5 Assessment Heat Treated A380 Roughness Profiles ................................... 76

4.2 Subsurface Hardness Results ........................................................................... 78

4.2.1 Change in Subsurface Hardness with Depth............................................... 79

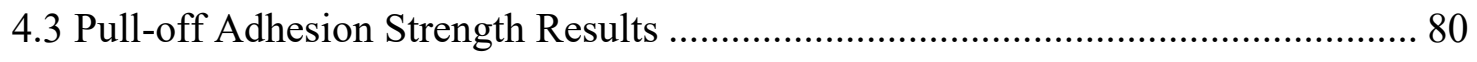

4.3.1 Relationship between Substrate Average Surface Roughness and Adhesion

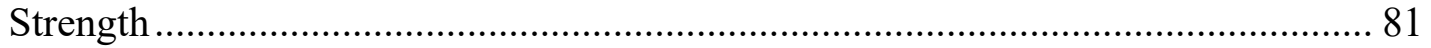

4.3.2 Coating System Failure and Surface Profile ............................................. 83

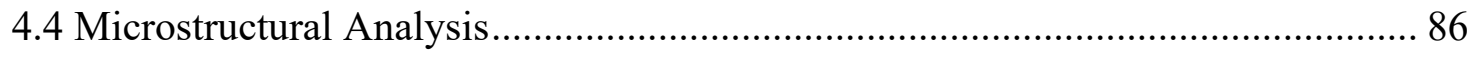

4.4.1 Cross-sectional microstructure of SS 420 Plasma Spray Coating .................. 86

4.4.2 Interlocking of Pulsed Waterjet Substrate and Plasma Spray Coating ............ 87 


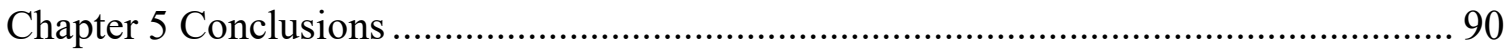

Chapter 6 Contributions and Future Work............................................................ 93

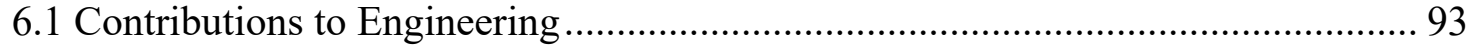

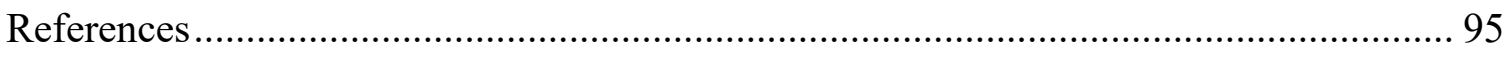




\section{List of Tables}

Table 1: Substrate materials and composition provided by suppliers................................ 50

Table 2: A380 and GCI mechanical properties............................................................. 50

Table 3: Pulsed waterjet parameters used to roughen the A380 and GCI. ....................... 53

Table 4: GCI and A380 adhesion strength measurements and failure modes. ................. 84 


\section{List of Figures}

Figure 2.1 Variety of applications and improvements for waterjet technology [8].......... 6 Figure 2.2: Pulsed water-jet nozzle schematic [17] ...................................................... 7

Figure 2.3: Development of a pulsed waterjet stream [18] ......................................... 9

Figure 2.4: Schematic of the drop test setup [15] .................................................... 11

Figure 2.5: Mass loss versus tip position ('a') for $\mathrm{L} / \mathrm{d}$ ratios of $2: 1$ and $1: 1$ [15] ............ 14 Figure 2.6: Mass Loss versus standoff distance at constant pressure (96.6MPa) for two tip positions [15].

Figure 2.7: Optical microscope image of cut out at an operating pressure of: a) 20MPa, b $30 \mathrm{MPa}, \mathrm{c}) 40 \mathrm{MPa}[21]$

Figure 2.8: SEM images for a deformed AW-6060 sample using pulsed waterjet with a frequency of $20 \mathrm{kHz}$ and varying standoff distances from $5 \mathrm{~mm}$ to $55 \mathrm{~mm}$ [23].

Figure 2.9: SEM image of removed material on gray cast iron surface. (A) is the broken abrasive grains and (B) is the removed cast iron [28].

Figure 2.10: Change in hardness with depth for tests with: a) low roughness, b) moderate

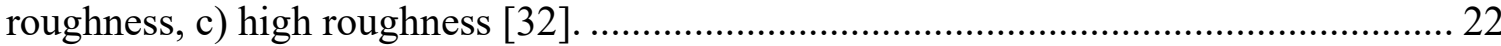
Figure 2.11: Crack formation below the surface for instances of high erosion [32]....... 23 Figure 2.12: Surface and subsurface hardness values at a transverse speed of and pressure of: a) $5 \mathrm{~mm} / \mathrm{s}$ and $40 \mathrm{MPa}$, b) $5 \mathrm{~mm} / \mathrm{s}$ and $60 \mathrm{MPa}$, c) $5 \mathrm{~mm} / \mathrm{s}$ and $80 \mathrm{MPa}$ [31] ............... 24

Figure 2.13: Schematic of a general thermal spray process [34] ................................ 26

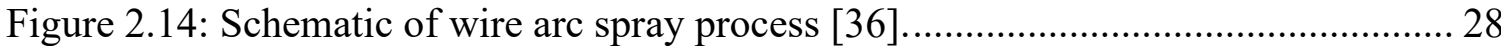

Figure 2.15: Schematic of plasma spray process [37]. ............................................. 29

Figure 2.16: Schematic of plasma transferred wire arc spray process [41] .................... 30

Figure 2.17: The effect of particle speed and substrate temperature on degree of splashing and frequency of disk shaped splat formation for AISI 304L substrate [52]................. 37 Figure 2.18: Different surface activation profiles to modify coating bond strength: 1) dove tail profile, 2) mechanical roughening, 3) grit blasting, and 4) laser texturization

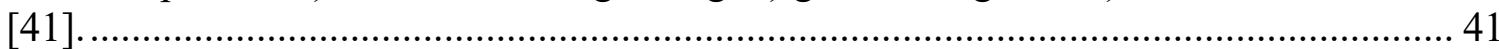

Figure 2.19: SEM images taken at a $20^{\circ}$ angle to the surface showing morphology of a a) polished b) grit blast and c) pulsed waterjet surface [17].

Figure 2.20: Adhesion strength values as a function of surface roughness for multiple surface preparation techniques [17].

Figure 2.21: Surface profiles of the a) pulsed waterjet b) IWF MRP and c) IWF MRP dove tail [39].

Figure 2.22: Bond strength of PTWA sprayed low carbon streel on mechanically roughened aluminum Al-6060 substrates [45].

Figure 2.23: Schematic of different failure modes present in bond strength testing [59]. 46 Figure 2.24: Hardness curves for A380 comparing samples given a T5 and T6 aging treatment at $150^{\circ} \mathrm{C}$ for $24 \mathrm{hrs}$ to a T4 aged sample at $25^{\circ} \mathrm{C}$ for $25 \mathrm{hrs}$. the heat treatment parameters were $490^{\circ} \mathrm{C}$ at 15 minutes [60].

Figure 3.1: Flow chart outlining the methodology used to determine the optimal surface roughness for adhesion of plasma transferred wire arc coating .................................. 48 Figure 3.2: Images of substrate material coupons: (A) A380, (B) GCI.......................... 49 Figure 3.3: Pulsed waterjet test system containing the test cell, control system, and pump system. 
Figure 3.4: Pulsed nozzle and sample holding fixture used during the experiment. ....... 52

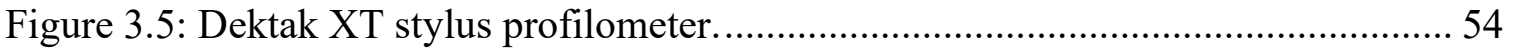

Figure 3.6: Furnace used for T4 and T6 heat treatment of A380 samples...................... 56

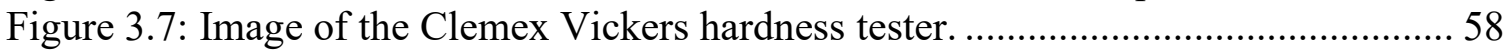

Figure 3.8: Images of a) Dolly adhesion test setup and b) Pull Tester Set On Sample.... 60

Figure 4.1: Images of pulsed waterjet A380 roughness. The corresponding nozzle speed

and average roughness values are presented on each image....................................... 63

Figure 4.2: Images of pulsed waterjet GCI roughness profiles. The corresponding nozzle

speed and average roughness values are presented on each image. 64

Figure 4.3: Decrease in A380 substrate thickness with nozzle transverse speed for a pulsed waterjet system with a constant pressure of $34.5 \mathrm{MPa}$ and a constant standoff

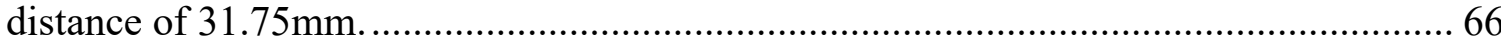
Figure 4.4: Decrease in GCI substrate thickness with nozzle transverse speed for a pulsed waterjet system with a constant pressure of $34.5 \mathrm{MPa}$ and a constant standoff distance of $25.4 \mathrm{~mm}$. 66

Figure 4.5: Pulsed waterjet A380 roughness profiles for a $10 \mathrm{~mm}$ by $10 \mathrm{~mm}$ area. The corresponding nozzle speed and average roughness values $\left(\mathrm{R}_{\mathrm{a}}\right)$ are presented on each image.

Figure 4.6: Pulsed waterjet GCI roughness profiles for a $10 \mathrm{~mm}$ by $10 \mathrm{~mm}$ area. The corresponding nozzle speed and average roughness values are presented on each image.

Figure 4.7: The effects of nozzle transverse speed on surface roughness of A380 ........ 72 Figure 4.8: The effects of nozzle transverse speed on surface roughness of GCI........... 73 Figure 4.9: SEM image of the A380 surface. ............................................................ 74

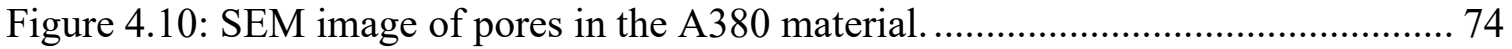
Figure 4.11: SE image of GCI showing the dispersion of graphite flakes normal and

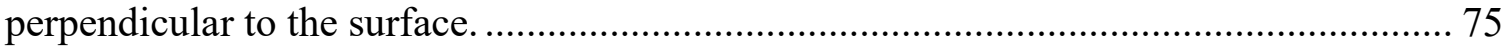
Figure 4.12: SE image of pores in the GCI material.................................................. 76 Figure 4.13: Pulsed waterjet as-cast, T4, and T6 A380 roughness profiles for a $10 \mathrm{~mm}$ by $10 \mathrm{~mm}$ area where: a)is the as-cast sample b) is the T4 heat treated sample and c) is the T6

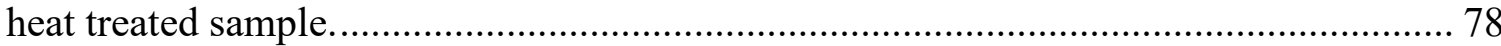
Figure 4.14: Hardness as a function of subsurface depth for pulsed waterjet roughened A380. The sample letter corresponds with the images in Figure 4.1 ........................... 79 Figure 4.15: Hardness as a function of subsurface depth for pulsed waterjet roughened GCI. The sample letter corresponds with the images in Figure 4.2 ............................. 80 Figure 4.16: Images of A380 and GCI samples prepared for pull-off strength testing. ... 81 Figure 4.17: The adhesion strength of the SS 420 plasma spray coating on the A380

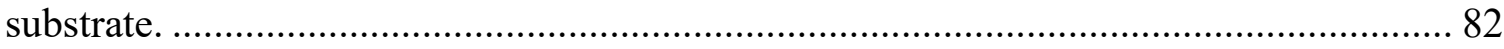
Figure 4.18: The adhesion strength of the SS 420 plasma spray coating on the GCI

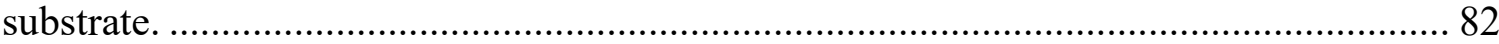
Figure 4.19: Surfaces after pull-off test of the SS 420 plasma spray coating on the a) GCI and b) A380 substrates showing complete coating removal and partial splat layer

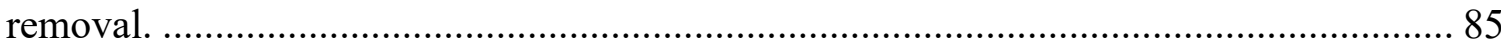
Figure 4.20: T4 and T6 heat treated samples coated with the SS 420 plasma spray....... 86 
Figure 4.21: SE image of SS 420 coating showing the cross-sectional microstructure. The scan was conducted using a WD of $20.5 \mathrm{~mm}$, EHT of $20.00 \mathrm{kV}$, and a magnification of 1000X.

Figure 4.22: SE images showing pit interlocking between cast aluminum substrate with an average surface roughness of $19.36 \mu \mathrm{m}$ and the SS 420 coating............................. 88 Figure 4.23: SE images showing pit interlocking between cast iron substrate with an

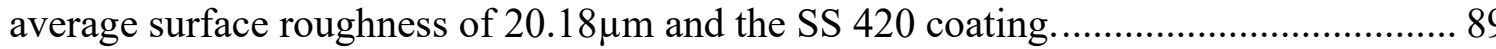




\section{Symbols and Abbreviations}

$\begin{array}{ll}\text { ASTM } & \text { American Society for Testing and Materials } \\ \text { EDX } & \text { Energy Dispersion X-ray Spectroscopy } \\ \text { PTWA } & \text { Plasma Transferred Wire Arc } \\ \text { SE } & \text { Secondary Electron } \\ \text { SEM } & \text { Scanning Electron Microscope } \\ \text { WD } & \text { Working Distance }\end{array}$




\section{Chapter 1 Introduction}

Nowadays fuel efficiency and emission control have changed the way diesel and gasoline engines have been designed and remanufactured in automotive industries. In many cases, older and less fuel-efficient models of auto-engines are being upgraded to better operating functionality. In doing so, automakers are remanufacturing and giving a new life to the engines that would otherwise be decommissioned and scrapped at a cost [1]. The $\mathrm{CO}_{2}$ emission produced during remanufacturing of a worn-out engine is up to $80 \%$ less than those generated to manufacture a new engine [2]. While decreasing $\mathrm{CO}_{2}$ emissions during engine manufacturing may seem insignificant compared to the total emissions produced during an engine life cycle, if we consider that tens of millions of cars are produced per year this becomes a substantial reduction. Engine manufacturers such as Fiat, Ford, and Caterpillar are currently remanufacturing worn-out engine cylinder bores by using the plasma transferred wire arc (PTWA) coating process to give new life to these engines. To improve the coating-substrate bond strength, the process also involves the deposition of an expensive Ni-Al pre-bond coat. On one side, the pre-bond coat is important to ensure the coating-substrate bond strength in the engine bore is high enough to be used under engine operating conditions. On the other hand, the process complexity and high price-tag associated with this pre-bond coat on many occasions result in the removal and replacement of the worn-out engines [3]. This research project focuses on the removal of the need for the expensive conventional $\mathrm{Ni}-\mathrm{Al}$ bond coat by developing an optimized surface profile using pulsed waterjet, a simpler, cheaper, and environmentally friendly technique, as a coating bond strength enhancer before the PTWA final coating. 


\subsection{Objective}

The goal of this research project is to optimize the surface roughness of cast iron and cast aluminum substrates using high-pressure pulsed waterjet technology to produce a coating- substrate adhesion strength greater than $30 \mathrm{MPa}$, which is required for cylinder bore liners [4]. With the optimized surface roughness of the cast iron and aluminum substrates using the high-pressure pulsed waterjet technology, old worn engine blocks can be remanufactured using this technique. Not only the reduced production costs will draw the automotive industry to implement this new technique, but also the development of a more sustainable remanufacturing process will assist in the reduction of the environmental footprint by the automotive industry.

\subsection{Outline of the Thesis}

The literature review for this paper will discuss the pulsed waterjet process and its applications and operating parameters. Then we will review the capabilities of the pulsed waterjet technique to roughen a material and improve adhesion strength between the substrate and top coating. The next topic covered in the literature review is the plasma transferred wire arc deposition process including its applications and operating parameters. This is followed by a section on the properties of the plasma transferred wire arc coating. Next, is the heat treatment techniques for cast aluminum A380 alloy to improve its hardness and ductility. Finally, a segment on how this work fills in the gaps in the literature.

The materials and experimental procedure section of this paper outlines the materials used for the substrate and plasma transferred wire arc coating. The setup and parameters used for the pulsed waterjet processes. Measurement techniques for the change in substrate thickness, surface roughness profile, Vickers hardness, and pull-off adhesion 
testing. The heat treatment techniques used on the cast aluminum A380 alloy. Lastly, the SEM parameters used for the microstructure analysis of the substrate, coating, and interlock.

The results and discussion section summarises the data collected and examines the significant findings. The first set of data mentioned is the results obtained during the stylus profilometry measurements. The next set is the subsurface Vickers hardness measurements. This is followed by the pull-off adhesion strength results and defining of the relationship between average surface roughness and adhesion strength. Lastly, microstructural analysis of the coating-substrate system.

The major findings of this paper are outlined and summarized in the conclusion section and contributions to engineering and considerations for future work are also mentioned. 


\section{Chapter 2 Literature Review}

This chapter consists of a literature review on the pulsed waterjet and plasma transferred wire arc (PTWA) technology. Parameters which influence substrate surface roughening and spray coating are discussed. As well as, the microstructural characteristics of the pulsed waterjet and spray coated surface are studied. Finally, a review of heat treatment processes which could potentially improve adhesion performance of cast aluminum when pulsed waterjet.

\subsection{Pulsed Waterjet Roughening Process}

In this section, the history and development of the waterjet process leading up to pulsed waterjet will be discussed. Additionally, the modern pulsed waterjet processes and parameters will also be reviewed. Lastly, the influence pulsed waterjet parameters have on surface roughening characteristics will also be examined.

\subsubsection{Introduction to Waterjet Process}

Waterjet technology offers a versatile process with capabilities of manufacturing techniques such as cutting, cleaning, and surfacing on a wide variety of materials. The basis of the waterjet technology is the deliverance of high energy water to an extremely small area $[5,6]$. As the high energy water impacts the surface of the target area it disintegrates the material. As a result of the broad industrial capabilities of the waterjet process and the additional environmental benefits, several different waterjet techniques have been developed to accommodate a wide variety of applications. These techniques include 
continuous, abrasive, and pulsed waterjet. The following section will review the history and advancements of waterjet technology.

The modern waterjet process has been around for almost a century and was first recorded being used in 1853 by the California Gold Country [7]. The waterjet technique was used to remove soft rocks surrounding gold and this method became known as hydraulic mining [8]. In parallel with the developments made to the increased pressure of the waterjet systems used in hydraulic mining, the waterjet technology was then being adopted as a cleaning process. An example of a handheld device is the lances used in car washes [8].

In the 1960's Professor Robert Franz found that high pressures waterjet could be used to cut through materials such as wood at high speeds with little damage to the material [9]. A collaboration with McCartney Manufacturing Company brought the development of the first high pressure waterjet cutter. The first waterjet cutter had an operating pressure of 400MPa and paved the way for another waterjet cutter developed by Flow Industries [8].

The next breakthrough in waterjet technology was the addition of abrasive particulate matter to the stream of water. This idea came from the metal cleaning industry which introduced sand into the cleaning water stream. The sand increased cleaning rates which were amplified as pressure increased. Flow Research scientists used this information and determined that adding abrasive material to the high pressure waterjet solution would result in the cutting of materials such as metal and ceramics [10].

In 1986 a development was made by British Hydromechanics Research Association which provided the ability to inject abrasive material between the pump and the nozzle [11]. This advancement reduced operating pressure almost tenfold to about 35MPa. 
The next big break in the waterjet industry came in 1994, Vijay and Foldyna developed the forced pulsed waterjet nozzle which contained a vibrating tip [12]. This vibrating tip broke up the continuous stream and produced slugs of water [13]. The developed slugs were full of cavitation bubbles which resulted in a much larger impact pressure and much lower operating pressure than the continuous stream alone. Pulsed waterjet operating pressures were similar to that of abrasive waterjet. The pulsed waterjet process further improved waterjet technology as components within the waterjet system had a longer service life, and there were no abrasive contaminants in the water which need to be recycled or disposed of.

Although not everything about waterjet technology is understood, simulations and experimental studies are enough to continue to drive its industrial development. The diagram in Figure 2.1 outlines some of the current and potential improvements to waterjet. As the waterjet technology continues to advance, new applications will be determined for this flexible process. This thesis will cover a new application for the pulsed waterjet technology that will improve an existing process in the automotive industry by reducing costs and environmental effects.

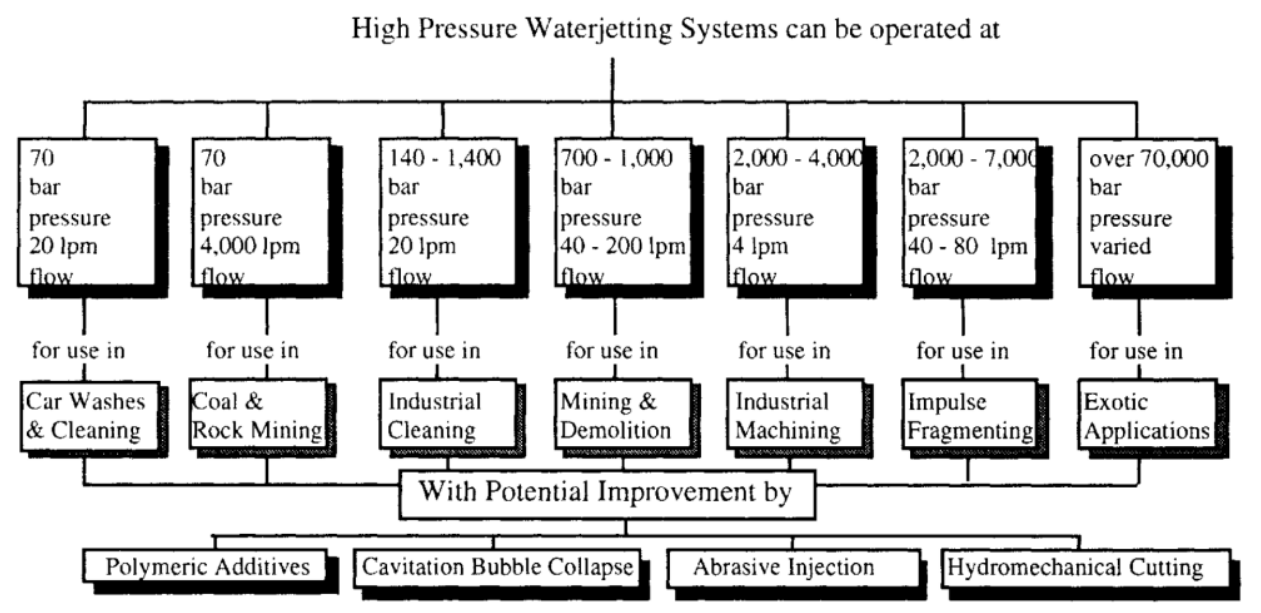

Figure 2.1 Variety of applications and improvements for waterjet technology [8]. 


\subsubsection{Pulsed Waterjet Processes}

The pulsed waterjet process was developed to improve cutting, cleaning, and surfacing capabilities of the existing waterjet processes, to reduce production costs by improving nozzle service life, and to reduce the environmental impact of the manufacturing industry. It can be viewed as an extension of the pre-existing continuous waterjet process. The pulsed waterjet technique is described as the breaking of a continuous stream of water to produce slugs, discrete packets of water responsible for the disintegration of the target material. The greater the energy associated with these slugs the greater the amount of disintegration at the impact surface [14]. These slugs can be generated using highfrequency vibrations produced by an oscillating mechanism. Throughout this study, the pulsed waterjet slugs were generated using a vibrating ultrasonic probe tip (microtip) in the nozzle $[15,16]$. The schematic in Figure 2.2 represents the pulsed waterjet nozzle used in the study.

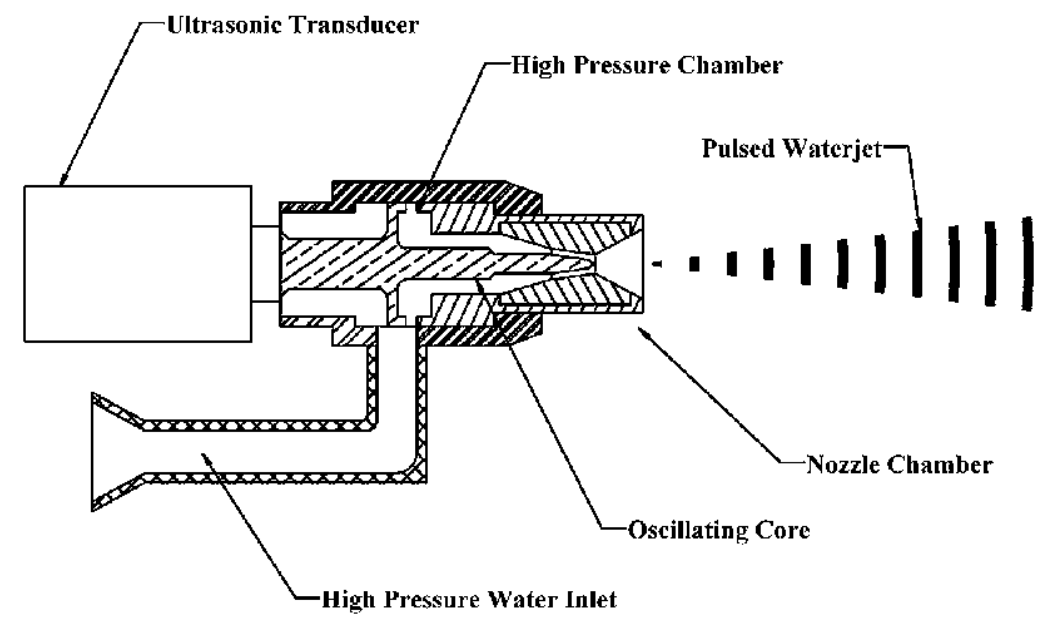

Figure 2.2: Pulsed water-jet nozzle schematic [17].

The pulsed waterjet system is comprised of a high-pressure pump, power supply, ultrasonic generator, transducer, spray nozzle, and control unit. The control unit is 
responsible for controlling all the operating parameters such as the pressure generated by the pump, the standoff distance between the nozzle and target surface, and the speed at which the pulsed water transverses over the target surface. However, the most important components in the system are the ultrasonic generator and transducer. These two components are responsible for the modulation of the stream of water. Currently, the ultrasonic generator which operates at a maximum power of $1.5 \mathrm{~kW}$ at $20 \mathrm{kHz}$ powers the transducer. Gradually increasing the power of the ultrasonic generator from zero results in the water modulation. At zero input power, the waterjet stream is continuous with a diameter almost equal to that of the orifice of the nozzle. As the power starts to increase modulation of the continuous stream begins. Power levels continue to increase until an optimum value is reached such that a well-defined fully developed pulsed waterjet is produced [16]. A fully developed pulsed waterjet can be described as having a mushroom shape, which grows in size as the distance between the nozzle and target surface increases. This is represented in Figure 2.3 which shows the stages leading up to a fully developed mushroom and the growth of the mushroom as distance increases. In the first stage L1, the pulsed waterjet behaves as a continuous stream. As the distance increases the L2 region shows the initial formation of pulses, but they are not yet discrete packets. In the L3 region, discrete pulses begin to form, and in the L4 regions the pulses fan out giving them their mushroom shape [15]. The produced mushroom of water is also referred to as a slug. 


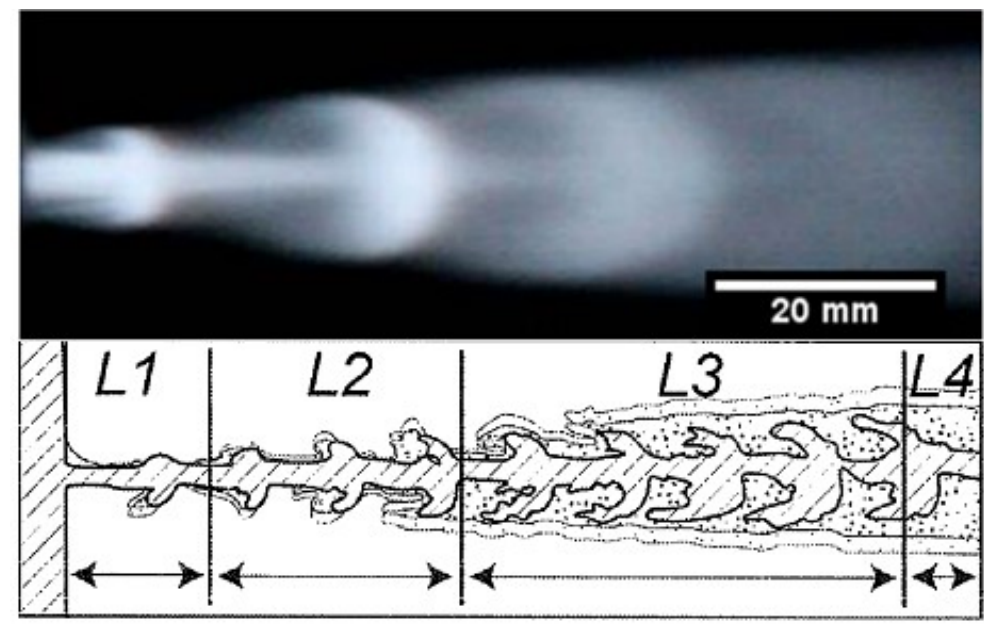

Figure 2.3: Development of a pulsed waterjet stream [18].

The developed mushrooms or slugs act as a water hammer when contact is made with the target surface. A water hammer can be described as the pressure wave generated when a fluids motion is forced to have an abrupt change in direction [17]. This water hammer effect is responsible for the erosion of the material at the target area.

In summary, the efficacy of forced pulsed waterjet derives from large energy transferred to the target area in the form of high impact pressure produced by the water hammer effect, the change in slug diameter with standoff distance which allows for greater target areas compared to regular waterjets which stay a constant size, and the high frequency of impacts which allow for a faster and more violent process. Extensive work has been done to confirm the effectiveness of pulsed waterjet at cleaning, cutting, and surfacing materials [19]. Through continued research and innovation of pulsed waterjet technology new capabilities will be discovered for this system, such as the one to be discussed in this thesis. 


\subsubsection{Application Procedures for Pulsed Waterjet Surface Roughening}

The process of conducting pulsed waterjet roughening on a material includes the following steps, surface preparation through machining in order to obtain a smooth and flat surface, operating parameter selection, parameter optimization by conducting a drop test, cleaning of the roughened surface, and taking final measurements of the surface profile. The first three steps are done before conducting the pulsed waterjet on the target surface with the most important step being the drop test which determines optimal standoff distance for the implosion of cavitation bubbles [15]. Changing the standoff distance will greatly impact the effects the pulsed waterjet has on the target surface and selecting the correct distance will greatly improve the performance of the roughened material surface.

Due to the crudeness of some material processing methods such as casting, the machining of the target material is important before conducting the pulsed waterjet. Obtaining a smooth and flat target area enables the ability to produce a uniform surface roughness. Post machining contaminants such as oil, grease, and debris should be removed using industry cleaning techniques such as ultrasonic baths, brushing, or water jetting [20].

The next step is the determination of operating parameters of the pulsed waterjet system. These parameters include the transverse speed of the nozzle, water pressure, water flow rate, $\mathrm{L} / \mathrm{d}$ ratio between the length of the cylindrical portion of the nozzle and the diameter of the nozzle, the distance between the microtip and exit orifice, the $\mathrm{D} / \mathrm{d}$ ratio between the orifice diameter and the nozzle diameter, and frequency and amplitude of the signal sent to the transducer. The testing parameters used in this thesis follow those outlined by Vijay et al. [15] and will be discussed in more detail in the following section. By selecting optimal operating conditions and nozzle geometry a uniform and predictable 
surface finish can be achieved [15]. These parameters will ultimately affect the surface roughness of the target material and how it performs under processes to be discussed in later sections where adhesion strength of coatings is desirable.

Following this step, the important drop test is conducted to determine the standoff distance between the nozzle and the target area. The drop test helps to simplify the complex interrelationship between operating parameters. The setup of the drop test is depicted in Figure 2.4 and shows the nozzle moves simultaneously in a vertical and horizontal direction at a constant speed. The drop test gets its name from this vertical and horizontal motion. The purpose of the drop test is to find the optimal standoff distance, the effective zone, behaviour of the jet with standoff distance, and determine jet behaviour at different pressures [15].

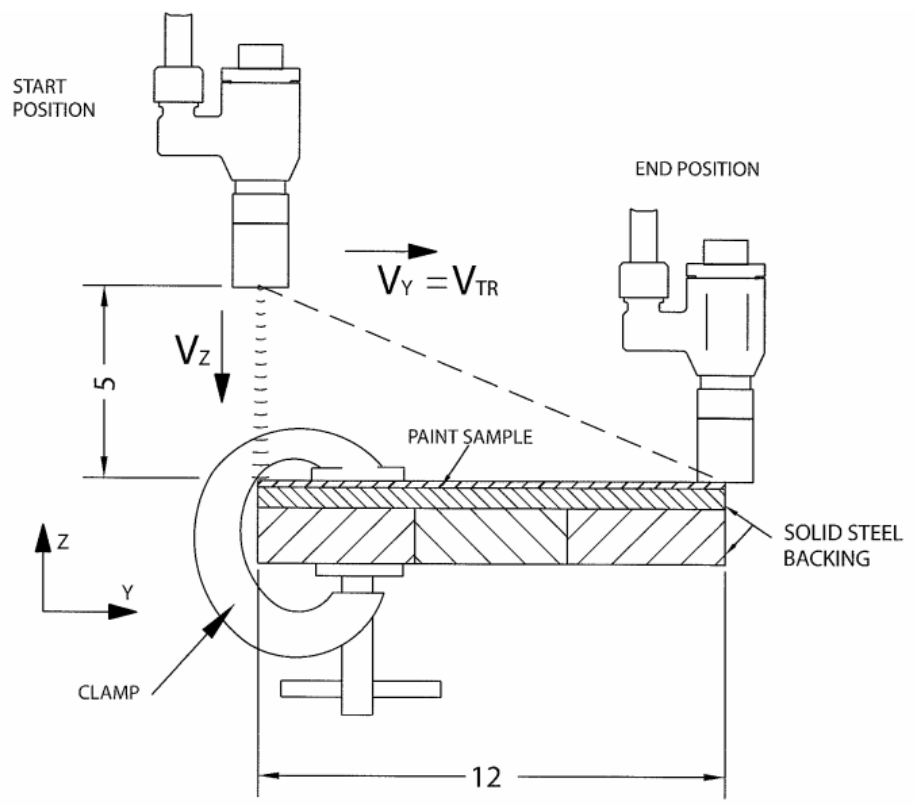

Figure 2.4: Schematic of the drop test setup [15].

However, the determination of the standoff distance by observing the drop test can be subjective. In the case of coating removal, the desirable standoff distance determined 
by the drop test is that which provides peak mass loss or maximum erosion of the material. In the case of surface roughening it is a bit more difficult to determine this distance. Therefore, iterative testing can be conducted to find a balance between pressure, transverse speed, and standoff distance, such that the desired surface roughness can be determined for a given material. Peak performance or speed testing may also be a useful test from a manufacturing standpoint to find the fastest nozzle speed to produce the desired surface roughness.

After the substrate is waterjet roughened measurements are taken of the surface profile. Values such as the peak height, trough depth, and the arithmetic average are determined to assist in the characterization of the surface roughness. Measurements of surface profile characteristics can be taken using a stylus profilometer or optically using a digital microscope [17]. Using the stylus method to determine the surface features will allow for the development of a three-dimensional map of the surface area under study. Both methods, however, are timely processes and can take hours if not days to generate results.

Following this initial roughness measurements, a baseline can be developed for the parameters required to produce such a surface profile. With this baseline, changes to the waterjet process can be made accordingly to obtain a surface finish which suits the application. In most situations, the parameters associated with the waterjet nozzle itself will be fixed but standoff distance, pressure, and speed can all be easily changed using the control unit.

\subsubsection{Parameters that Influence Pulsed Waterjet Surface Characteristics}

The pulsed waterjet method and apparatus parameters which influence surface roughness follow those outlined by Vijay et al. [15]. The parameters are as follows, the L/d 
ratio where $\mathrm{L}$ is the length of the cylindrical portion of the nozzle and $\mathrm{d}$ is the diameter of the exit orifice should preferably be between $2: 1$ and $0.5: 1$ with the best results being achieved at a ratio of 1:1. The standoff distance between the nozzle tip and target material should be no greater than $25.4 \mathrm{~cm}$, with the preferred distance being between $1.27 \mathrm{~cm}$ and $12.7 \mathrm{~cm}$. The standoff distance changes with slug development, to close and the slugs will not fully form while too far the slugs may dissipate. Thus, determining the optimal standoff distance is paramount for attaining the desired surface roughening results. The orifice diameter at the exit of the nozzle should be between $0.5 \mathrm{~mm}$ and $12.7 \mathrm{~mm}$ with a preferred diameter range of $1 \mathrm{~mm}$ to $1.65 \mathrm{~mm}$. The range in water pressure for a pulsed waterjet system should be between $6.9 \mathrm{MPa}$ and $138 \mathrm{MPa}$ with optimal pressures being between 34.5MPa and 69MPa. It should be noted that pressures can be used outside of these ranges but problems such as those associated with ultra-high-pressure systems will begin to develop. In addition to the outlined parameters, optionally, the nozzle configuration can have a $\mathrm{D} / \mathrm{d}$ ratio of 1 to 1.5 where $\mathrm{D}$ is the diameter of the nozzle tip and $\mathrm{d}$ is the diameter of the exit orifice. Furthermore, the high frequency signal applied to the transducer to oscillate the microtip has a frequency in the range of $5 \mathrm{kHz}$ to $40 \mathrm{kHz}$. Finally, independent of the pulsed waterjet nozzle parameters, the transverse speed at which the nozzle passes the target area is limited to the apparatus used to move the nozzle. Typically, the nozzle would be mounted on a gantry or robotic arm to achieve the required transverse motion.

The preferred ranges for the parameters were determined using the drop test method. Comparative testing can be conducted by varying a single influential parameter and then conducting a drop test and comparing the mass loss of each test. Improvements to the waterjet system would be viewed as an increase in mass loss. An example of this was the 
tests conducted to determine the effects of the L/d ratio for a general set of operating parameters. The graph in Figure 2.5 below the mass loss for an L/d ratio of 2:1 and 1:1 with a varied range of ' $a$ ' or distance between microtip and exit orifice was plotted [15]. It is evident in the graph that the mass loss increases from $100 \mathrm{~g} / \mathrm{min}$ to $130 \mathrm{~g} / \mathrm{min}$ as the value of ' $\mathrm{a}$ ' increases from $0.71 \mathrm{~cm}$ to $0.99 \mathrm{~cm}$ and that the $\mathrm{L} / \mathrm{d}$ ratio of $1: 1$ is better than $2: 1$ for all values of 'a'. Additionally, the graph also has operators plotted of mass loss using a continuous waterjet. The mass loss is negligible compared to the pulsed waterjet and shows the true power of the pulsed waterjet system [15].

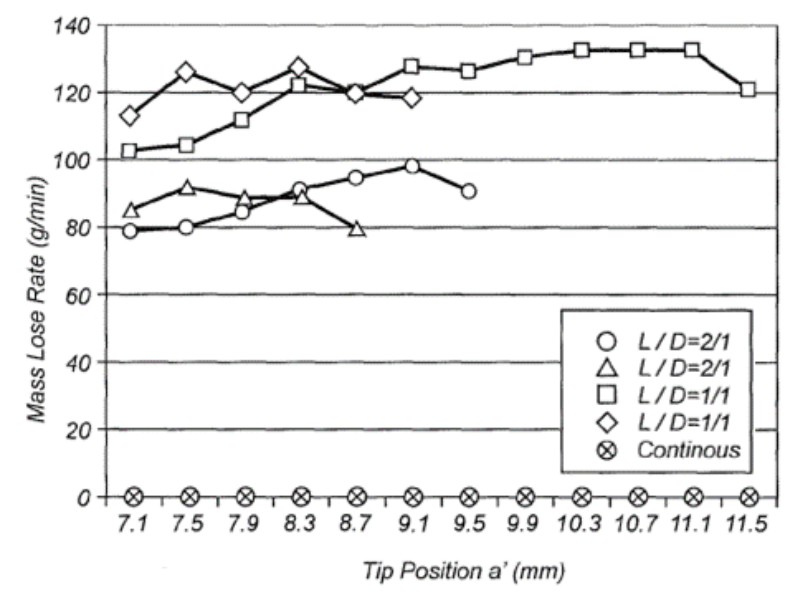

Figure 2.5: Mass loss versus tip position ('a') for L/d ratios of 2:1 and 1:1 [15].

Similarly, to the testing done to determine the ideal L/d ratio, the optimal standoff distance for a pulsed waterjet was also measured for a varied tip position ('a') and a fixed operating pressure. Strictly looking at the influence standoff distance has on the pulsed waterjet system, the results of the testing showed that the slugs produced with these operating parameters were most developed and effective at a standoff distance of $10.2 \mathrm{~cm}$ to $13.3 \mathrm{~cm}$. The data of the test is presented in Figure 2.6 graph. 


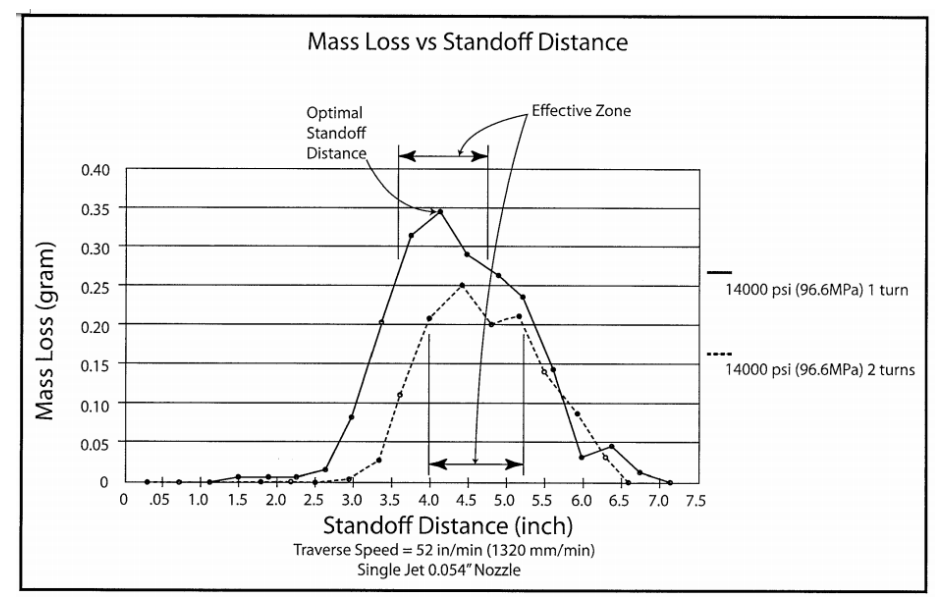

Figure 2.6: Mass Loss versus standoff distance at constant pressure (96.6MPa) for two tip positions [15].

\subsection{Properties of Waterjet Roughened Cast Aluminum and Cast Iron Surfaces}

The pulsed waterjet technique when used to roughen a material is applied to components which require improve adhesion strength between the substrate and top coating. This improved adhesion strength is a result of the increased surface area as well as the mechanical interlocking between the substrate and coating. The cast aluminum and cast iron respond differently when roughened with the pulsed waterjet and this section will review some of the established literature on this topic.

\subsubsection{Microstructural Properties}

The microstructural surface profile of a roughened cast aluminum and cast iron can be viewed by polishing the cross section of the material. Observing the surface profile using optical images will indicate the effects of the repeated impacts from pulsed waterjet on the surface. Analysis of results will assist in determining the mechanisms of surface erosion, plastic deformation, and material disintegration. Comparatively, cast aluminum is 
ductile while cast iron is brittle. This results in the materials behaving differently when the pulsed waterjet surface roughening process is applied.

In the case of pulsed waterjet roughened cast aluminum, there was limited literature available in regard to this topic. However, a literature review was conducted on the effects pulsed waterjet has on other types of aluminum, specifically pure aluminum $(99.5 \%)$ and AW-6060 which has a composition of $97.9-99.3 \% \mathrm{Al}, 0.05 \% \mathrm{Cr}, 0.1 \% \mathrm{Cu}, 0.35-0.5 \% \mathrm{Mg}$, $0.1 \% \mathrm{Mn}, 0.3-0.6 \% \mathrm{Si}, 0.1 \% \mathrm{Ti}$, and $0.15 \% \mathrm{Zn}$ (wt $\%$ ). Even though these materials are not the same, connections can still be made between the deformation mechanisms present in these materials and those found in cast aluminum.

The effects of pulsed waterjet on pure aluminum was studied by Foldyna et al. [21] for a range of system pressures. The image in Figure 2.7 a) is the surface at an operating pressure of 20MPa. It was noticed at this pressure that the pulsed waterjet produced a cut out with many craters on the material surface. The edges surrounding the cut out are bent outwards creating a rim with minimal plastic deformation. This rim is believed to have formed by shear stresses generated by radial flow [22]. Plastic deformation is also present along the cut-out walls and at the base of the cut out [21]. Aluminum particles are also mechanically connected to the base of the cut out and fine cracks are also visible parallel to the original surface. Increasing the pulsed waterjet operating pressure to $30 \mathrm{MPa}$ removes the rims which were visible at 20MPa, this is shown in Figure 2.7 b). There is an increase in the amount of plastic deformation and the depth of the cut out. Further increasing of the waterjet pressure to $40 \mathrm{MPa}$ result in the joining of craters in the cut out, aluminum particles at the bottom of the cut out being torn away, and aluminum particles becoming embedded in the material, seen in Figure 2.7 c). Thus, the behaviour of pure aluminum when subjected 
to increasing pulsed waterjet pressures can be described by the following steps; firstly, craters form due to the impact of water with occasional microcracks being produced at the bottoms of the craters. To follow, the mechanically attached aluminum particles are torn away and microcracks form as a result of shock wave release. Lastly, further deformation results in the joining of craters and embedding of undeformed particles in the material. Detached or worn sections of projections, ridges, and columns are eroded by outward jetting from the surface of the cut out [21].

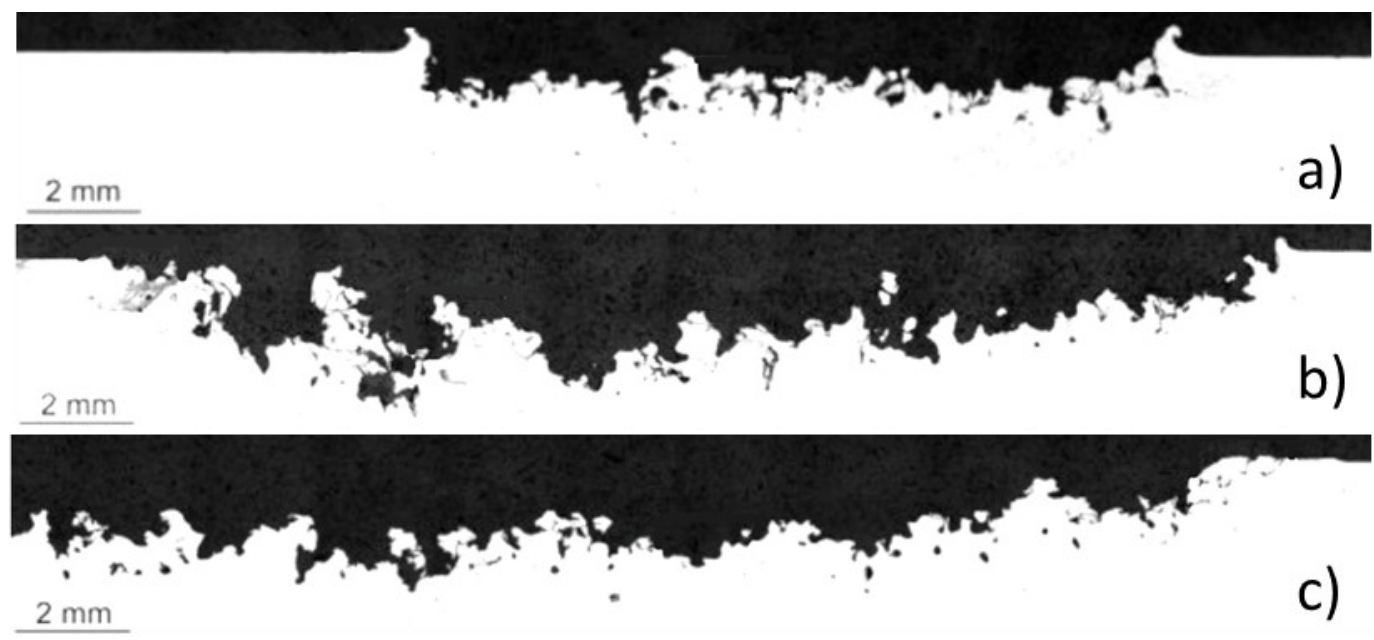

Figure 2.7: Optical microscope image of cut out at an operating pressure of: a) 20MPa, b $30 \mathrm{MPa}$, c) $40 \mathrm{MPa}[21]$.

The study of the effects of pulsed waterjet on the aluminum-based substrate AW6060 was also studied by Hloch et al. [23]. Unlike the previously discussed paper, the pulsed waterjet pressure in this study remained at a constant $100 \mathrm{MPa}$. Instead of a varied pressure, the tests were conducted for a range of standoff distances from $5 \mathrm{~mm}$ to $55 \mathrm{~mm}$, and a constant transverse speed of $10 \mathrm{~mm} / \mathrm{s}$. This technique is similar to the drop test which was discussed in a previous section. At first, with a standoff distance of $5 \mathrm{~mm}$ to $26 \mathrm{~mm}$, shallow and smooth micro pits and dimples formed with no apparent loss of material. As 
the test progressed from $26 \mathrm{~mm}$ to $46 \mathrm{~mm}$ elastic and plastic deformation coexisted with less deformation as the location of observation moved away from the line in which the pulsed waterjet stream made direct contact [24, 25]. As deformation progresses new erosion mechanics appear in the form of craters and voids [26, 27]. Erosion is a result of the shear stress produced by the lateral flow of water left behind after impact. Surrounding the plastic deformation zones, elastic deformation occurs where impact is made by droplets located in the periphery of the main waterjet stream. At a standoff distance of $52 \mathrm{~mm}$ to $55 \mathrm{~mm}$ material folds at the edge of the trace are noticeable [23]. With a standoff distance of this size at a waterjet frequency of $20 \mathrm{kHz}$ individual jet pulses are clearly defined. SEM images for the entire progression of pulsed waterjet induced deformation of AW-6060 aluminum for a standoff distance of $5 \mathrm{~mm}$ to $55 \mathrm{~mm}$ is presented in Figure 2.8. Therefore, for deformation to occur the impact stress produced by the pulsed waterjet exceeds the fracture strength of the material [23]. 


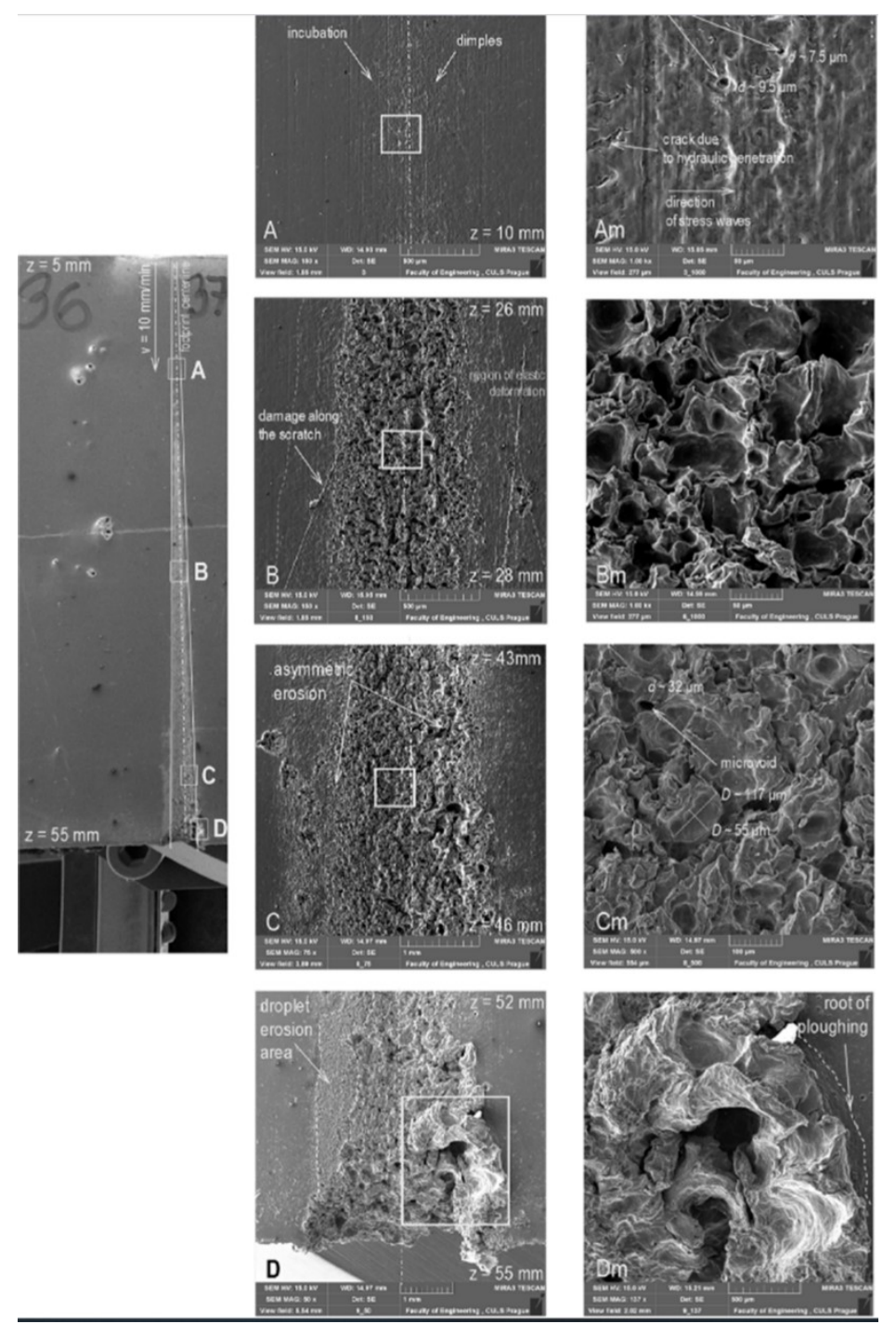

Figure 2.8: SEM images for a deformed AW-6060 sample using pulsed waterjet with a frequency of $20 \mathrm{kHz}$ and varying standoff distances from $5 \mathrm{~mm}$ to $55 \mathrm{~mm}$ [23].

Surface roughening of cast iron material has not been deeply investigated based on the available literature. However, the use of waterjet to cut cast iron has drawn more interest. Using the resources available which discuss the deformation mechanisms in waterjet cut cast iron, connections can be made which help to define the deformation and fracture mechanisms present in surface roughened cast iron. 
The fracture and deformation mechanisms of gray cast iron were studied by Momber et al. for abrasive waterjet cutting [28]. The cast iron behaves like a brittle material and contains two distinct phases, a hard iron matrix, and softer graphite phase. The weak graphite flakes mimic sharp cracks in the material and prevent the deformation of the normally ductile ferrite [28]. This idea is reinforced by Okada et al. [29] who noticed that erosion occurs in gray cast iron due to the notching of the graphite flakes. It has also been proposed that the merging of cracks in pre-existing fractured carbides causes spallation [30]. Figure 2.9 is the surface of gray cast iron subject to abrasive water jetting. It is known that gray cast iron gets its name from the gray colour that is present on its fracture surface. The gray colour is a result of crack formation and propagation through the weak graphite flakes in the material. Thus, it can be assumed that when surface fracture of cast iron occurs during the waterjet process it happens because of the same mechanism, crack formation, and propagation through the graphite flakes.

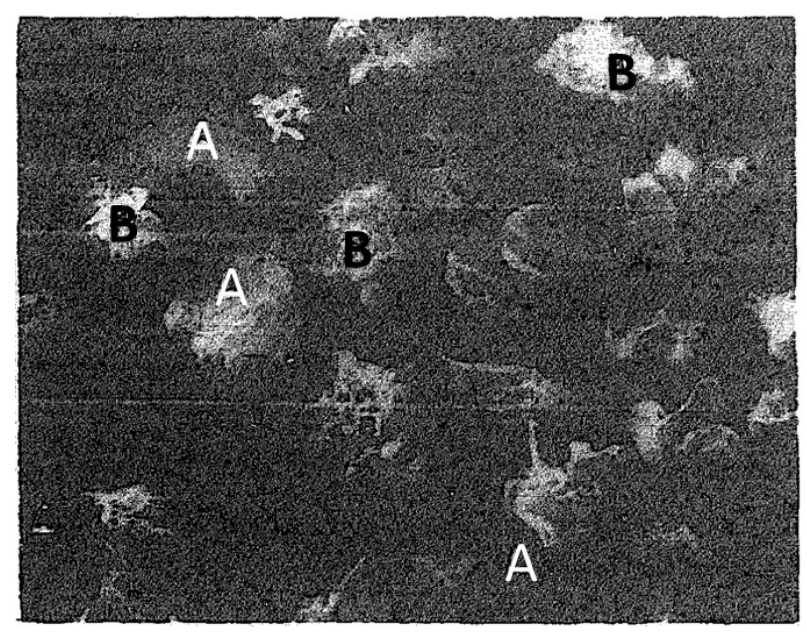

Figure 2.9: SEM image of removed material on gray cast iron surface. (A) is the broken abrasive grains and $(B)$ is the removed cast iron [28]. 


\subsubsection{Mechanical Properties}

The pulsed waterjet process also influences the mechanical properties of materials, specifically surface hardness. Studies have been undertaken to examine if waterjet can be used as a successful means of shot peening [31]. The impact of repeated waterjet pulses causes plastic deformation and higher residual stresses on the surface and in the subsurface. Variations in the pulsed waterjet process parameters will change the surface and subsurface hardness of the material.

Research was conducted by Azhari et al. [32] to determine the effects pulsed waterjet on surface peening of aluminum alloy 5005. During their investigation, surface and subsurface hardness measurements were taken for varied parameters such as number of passes, pressure, standoff distance, and transverse speed to determine the optimal conditions for the maximum hardness value. In summary, the hardness value and erosion of the material increased as the number of passes, pressure, and standoff distance increased, but decreased with increasing transverse speed. The increase in hardness is a result of the introduction of compressive stresses from the repeated waterjet impact force, high kinetic energy associated with waterjet droplets, and the number of droplets which impinge on the contact surface [32]. The amount of material erosion was measured by the surface roughness and was split into three groups. The first group had minimal to no erosion and had roughness values below $1 \mu \mathrm{m}$, while the second group had intermediate erosion with roughness values of $1 \mu \mathrm{m}$ to $10 \mu \mathrm{m}$, and the final group classified as high erosion with roughness values above $10 \mu \mathrm{m}$. Hardness measurements were taken for these three groups and some of the trials were plotted as shown in Figure 2.10. 

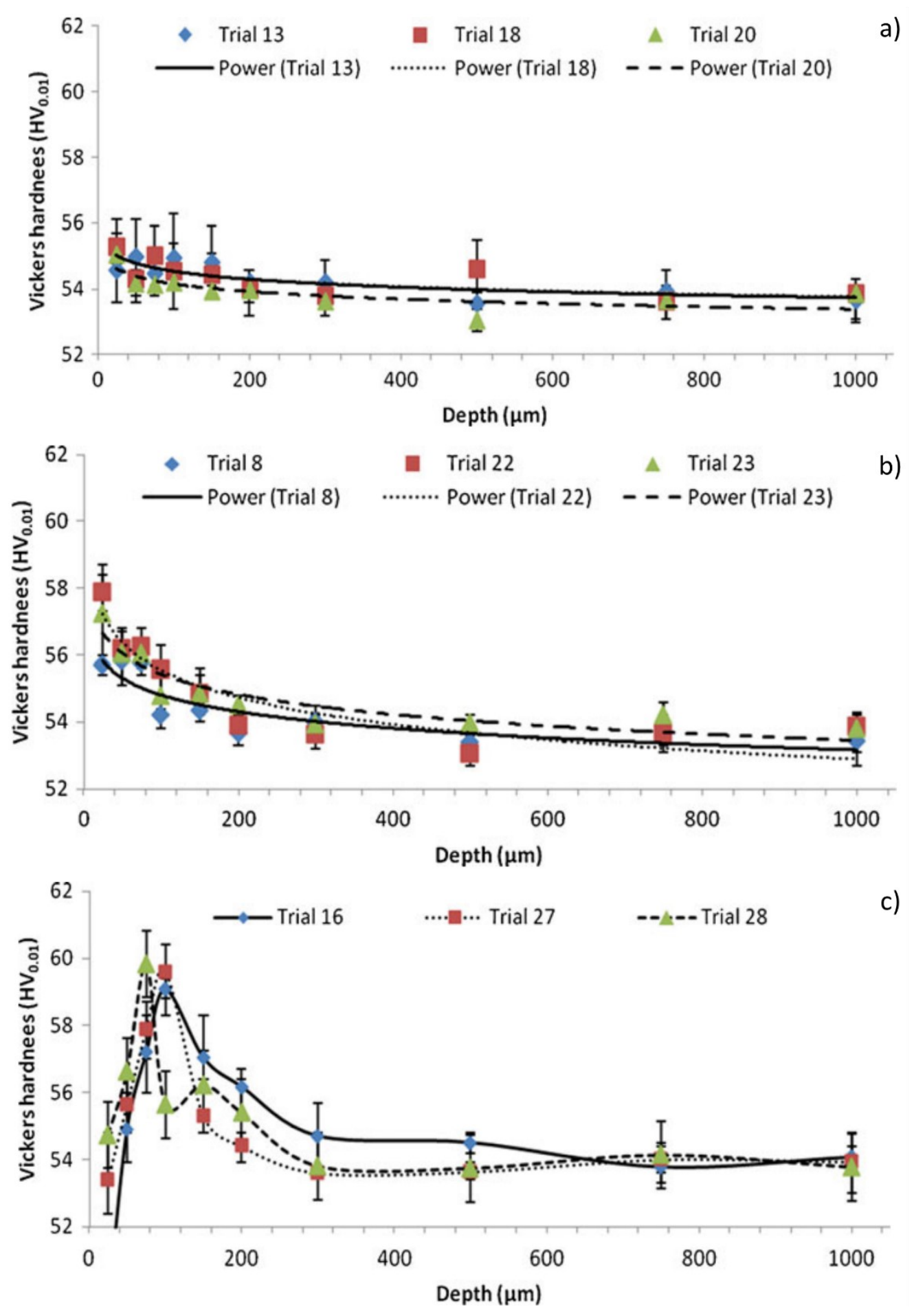

Figure 2.10: Change in hardness with depth for tests with: a) low roughness, b) moderate roughness, c) high roughness [32]. 
Reviewing the trends of these graphs revealed how the hardness value changes with subsurface depth. For instances in which there was low to moderate surface erosion, the maximum hardness was apparent at the surface and moderately decreased with increasing subsurface depth. On the contrary, if the surface erosion was high the maximum hardness was located at a depth $80 \mu \mathrm{m}$ to $120 \mu \mathrm{m}$ below the surface. This occurred because at depths of $50 \mu \mathrm{m}$ to $80 \mu \mathrm{m}$ cracks propagated and weakened the material. Figure 2.11 shows crack propagation below the eroded surface.

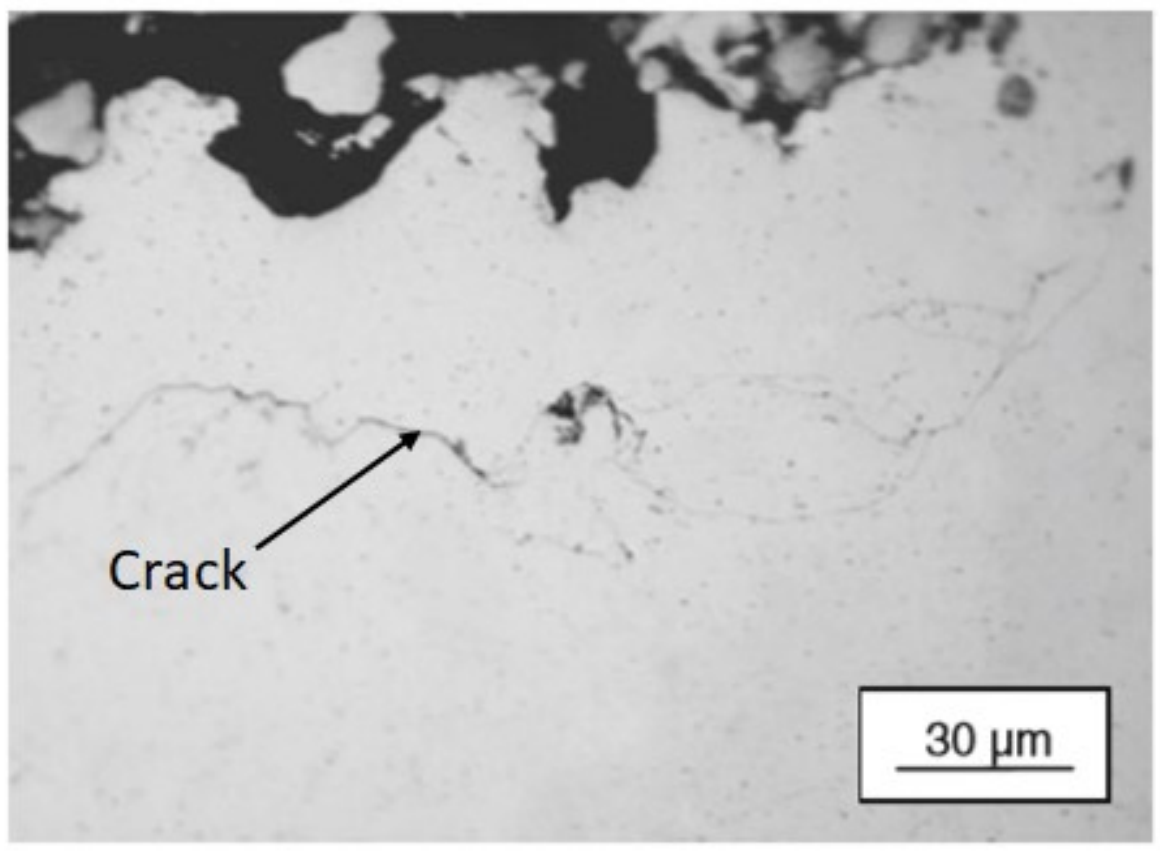

Figure 2.11: Crack formation below the surface for instances of high erosion [32].

Srivastava et al. [31] examined the surface and subsurface hardness for stainless steel peened with pulsed waterjet. The base stainless-steel material had a hardness value of $347 \mathrm{HV}$. In their study, they varied the standoff distance, and pressure from $40 \mathrm{MPa}$ to $80 \mathrm{MPa}$. It was determined for all cases that at subsurface depths of $200 \mu \mathrm{m}$ to $300 \mu \mathrm{m}$, 
hardness returned to the same as the base material. It was also noticed that increasing the standoff distance and lowering the pressure increased hardness. The reason for this is at a higher standoff distance the amplitude of the pulsed waterjet is enhanced which causes elastic and plastic deformation of the surface and subsurface layers [31]. The plastic deformation leads to the motion of dislocations and work hardening. Also, when the pressure is lower the hardness is greater because there is less crack formation in the subsurface. As well as, at lower pressures more discrete packs of water form which produce the water hammer effect that is responsible for strengthening the surface layers [31]. The graphs presented in Figure 2.12 show how at a constant transverse speed of $5 \mathrm{~mm} / \mathrm{s}$ the surface and subsurface hardness values changed with pressure and standoff distance.
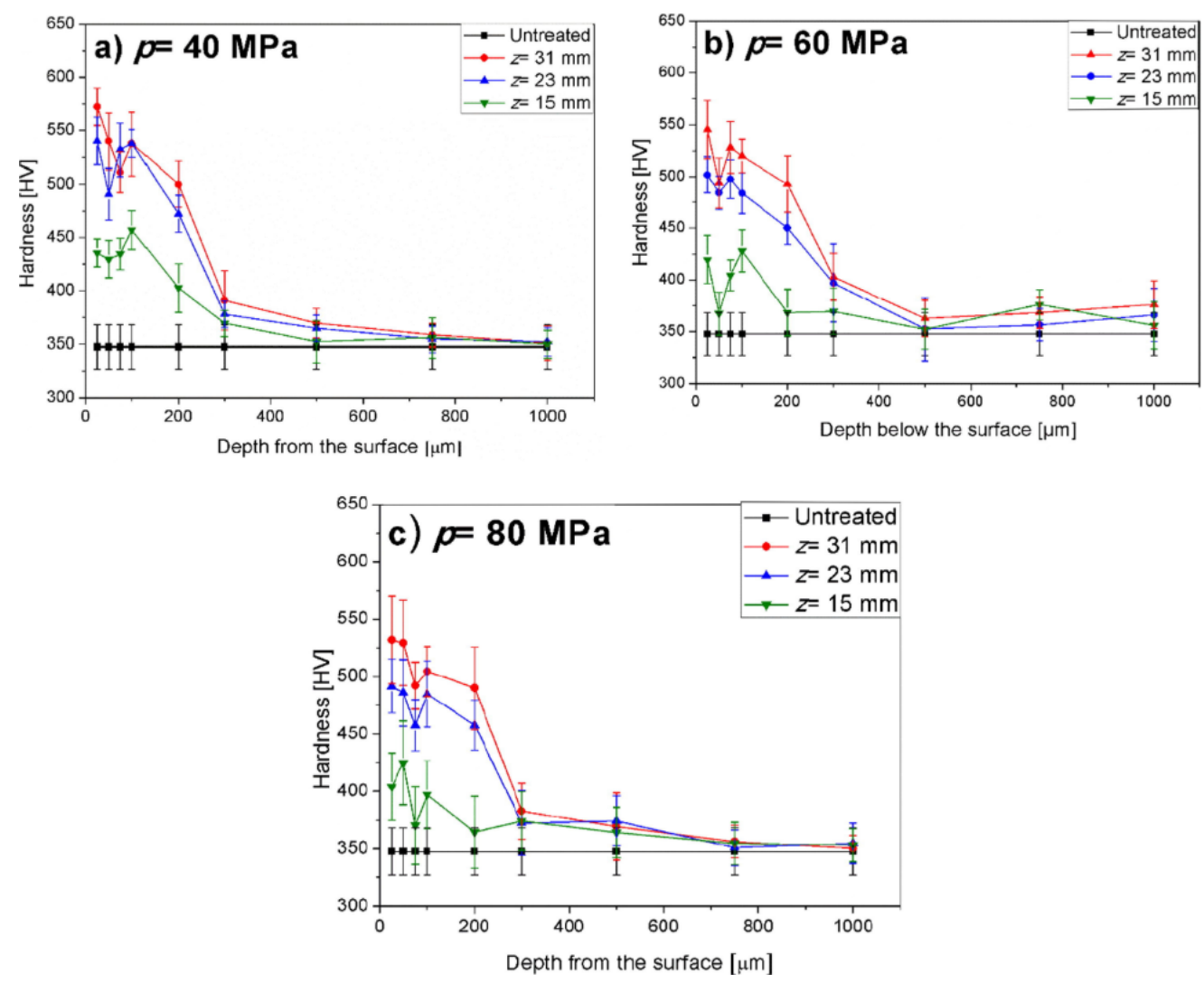

Figure 2.12: Surface and subsurface hardness values at a transverse speed of and pressure of: a) $5 \mathrm{~mm} / \mathrm{s}$ and $40 \mathrm{MPa}$, b) $5 \mathrm{~mm} / \mathrm{s}$ and $60 \mathrm{MPa}$, c) $5 \mathrm{~mm} / \mathrm{s}$ and $80 \mathrm{MPa}$ [31]. 
It should be noted that for the aluminum and steel samples tested in both papers at a subsurface depth of around $80 \mu \mathrm{m}$ to $100 \mu \mathrm{m}$, the hardness was either at a peak value or relatively unchanged. This is because at these depths work hardening still occurred and there was minimal cracking. Therefore, this range of subsurface depths should be a promising starting location to measure the hardness value of pulsed waterjet peened material.

\subsection{Plasma Transferred Wire Arc Deposition Process}

This section will provide background information and an introduction to the thermal spray coating technology. Additionally, the plasma transferred wire arc process and parameters will also be reviewed. Lastly, the influence of plasma transferred wire arc parameters on the surface coating will also be examined.

\subsubsection{Introduction to the Thermal Spray Coating Process}

The general purpose of any coating process is to improve the performance of a component by adding functionality to its surface. The coatings are deposited by a particle stream of metallic or non-metallic materials which when in contact with the surface of study, flatten to form platelets, called splats. These splats bond and build-up on the surface, with several layers of splats forming the spray coating [33]. The final coating thickness depends on the number of layers of splats.

The foundation of the thermal spray coating technology is the build-up of finely divided materials in molten conditions which are propelled onto a substrate [34]. The starting material such as wire or powder which forms the coating is called the feedstock. The feedstock is placed in the gun or flame/jet where it is heated to a molten state and then 
carried by high speed compressed gas to the substrate. The high energy molten particle strikes the surface of the substrate, flatten, and form thin splats. The splats adhere to the substrate surface and build up splat by splat in a lamellar structure which forms the coating. The formed coating has an inhomogeneous microstructure as particles formed and accelerated during the thermal spray process have different sizes, temperatures, and velocities [34]. This results in a final coating containing voids due to poor adhesion between particles. The schematic in Figure 2.13 is an illustration of the thermal spraying process with the lamellar splat build up.

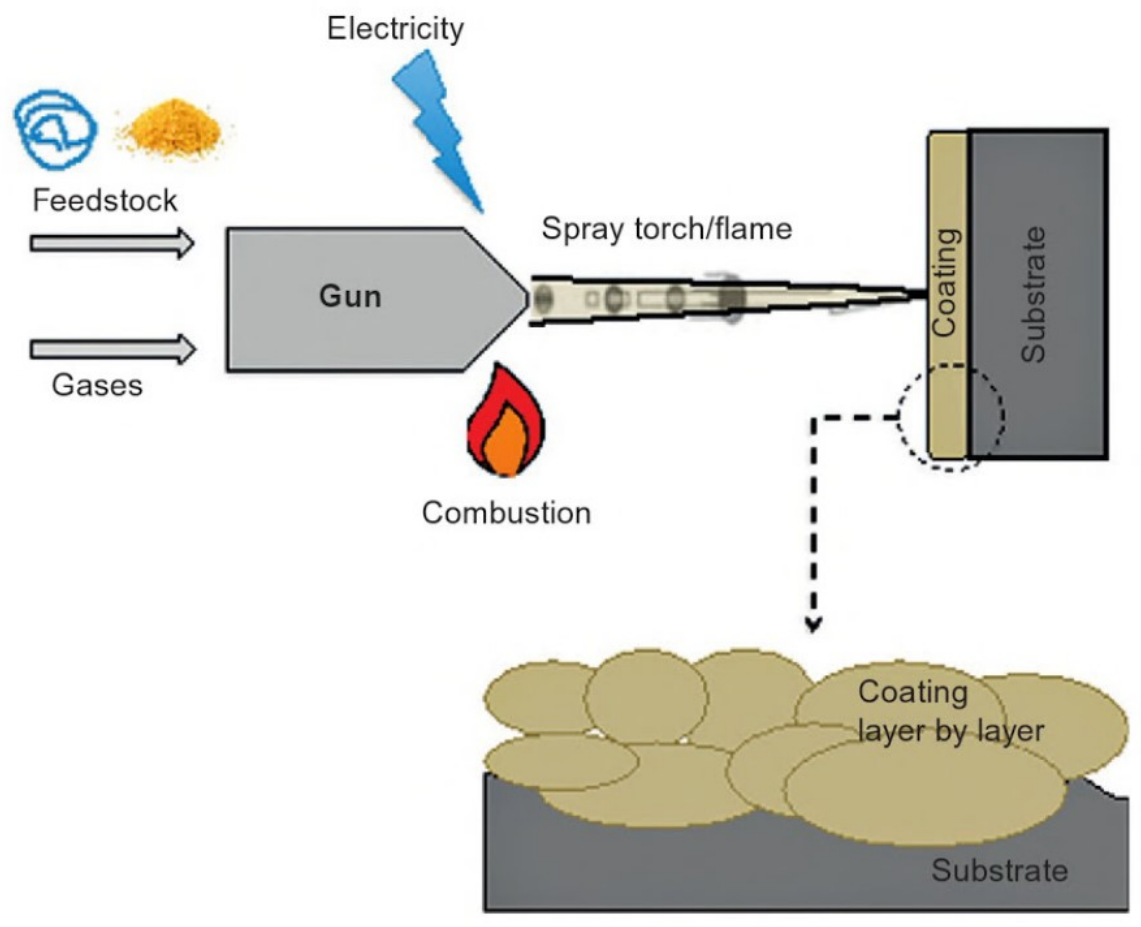

Figure 2.13: Schematic of a general thermal spray process [34].

Nowadays, thermal spray technologies are an integral part of many industries such as aerospace, industrial gas turbine, and automotive. These industries utilize the capabilities of thermal spray coatings to melt a range of materials, recoat damaged surfaces, and coat material with high melting points on substrates without changing substrate 
properties. Thermal spray coatings reduce the costs to manufacture components, may improve wear and corrosion resistance, and can act as an insulator or a conductor [34].

\subsubsection{Plasma Transferred Wire Arc (PTWA) Process}

The plasma transferred wire arc process is one of the most versatile forms of thermal spraying. It was developed by Flame-Spray industries and Ford Motor Company to improve vehicle fuel efficiency by enabling the use of lightweight materials such as aluminum [1]. The process is a combination of the early developed plasma spray and wire arc spray techniques.

The wire arc spray technology was developed and patented by Schoop in 1915 making it the oldest thermal spraying process [35]. The process is shown in Figure 2.14. During the wire arc spraying process, the deposition material is in the form of a wire. The wires are transformed into a molten or semi-molten state when they are connected to a power supply which creates an electric arc between the two wire tips. The plasma gas experiences little heating during the wire arc process, most of the energy is used to melt the deposition material. A few drawbacks of the wire arc process are the molten droplets only experience cooling in flight to the substrate material. Also, the heat transferred rate is less in the wire arc process compared to high temperature gas processes as only the sensible heat of the droplet is transferred to the substrate [33]. This is advantageous for substrates with low melting points but preheating from an additional heat source may be required to improve coating adhesion strength. Furthermore, the plasma spray process is flexible as the dimensions of bore shape and size, angle of material injection, and the distance from the plasma gun to the substrate surface can all be altered until acceptable coating performance is achieved. 


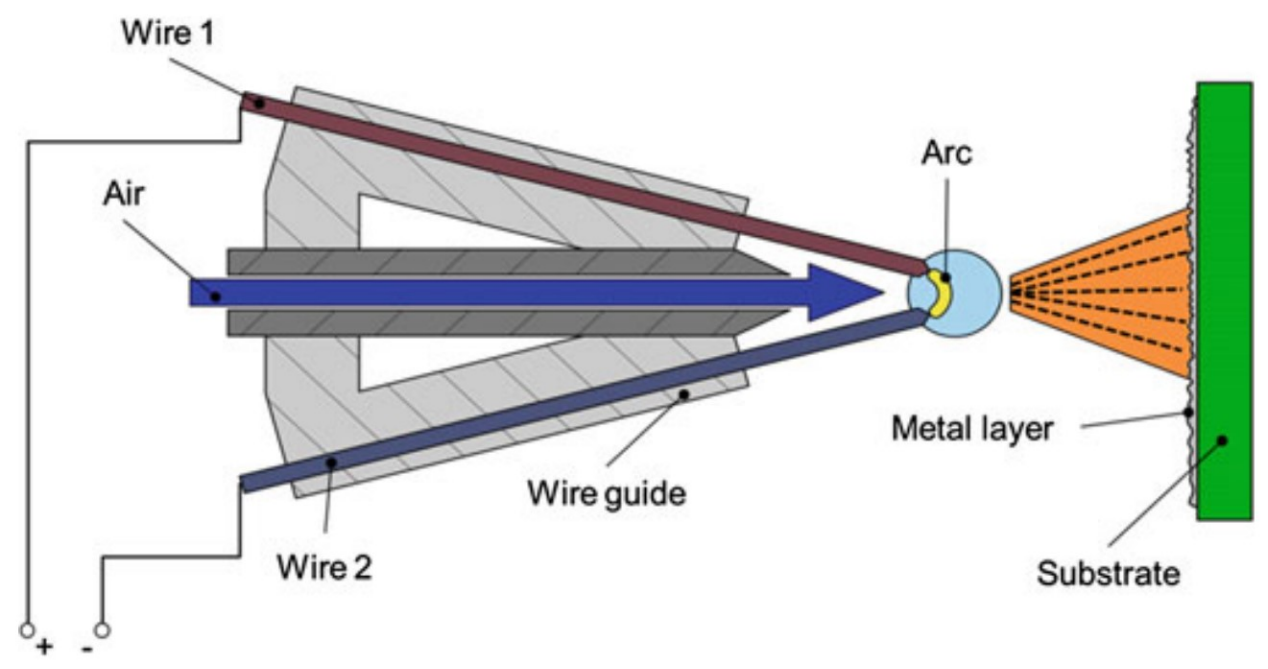

Figure 2.14: Schematic of wire arc spray process [36].

The plasma spray technique uses an electric arc which generates plasma within the plasma torch. The arc occurs between the cathodic rod and an anodic nozzle head. The plasma gas is fed at a high speed from the base of the cathode and heated by the arc. The plasma gas exit speed is between $500 \mathrm{~m} / \mathrm{s}$ to $2500 \mathrm{~m} / \mathrm{s}$ and the temperature ranges from $11700^{\circ} \mathrm{C}$ to $14700^{\circ} \mathrm{C}$. The speed and temperature vary depending on torch design, plasma gas, and operating parameters [33]. The material used for deposition is in powder form and is usually injected in a radial fashion downstream of the arc. The powder is typically fed inside the nozzle as the plasma jet is still confined and can be fed perpendicular, at an angle, or parallel to the jet axis. The spray particles are heated and transported by the plasma to the substrate. The particles form splats on the substrate which build up to form the coating. The movement of the torch or substrate relative to each other results in the deposition of a uniform coating. The coating is constructed with each pass of the plasma jet over the substrate. The schematic in Figure 2.15 represents the plasma spray process. 


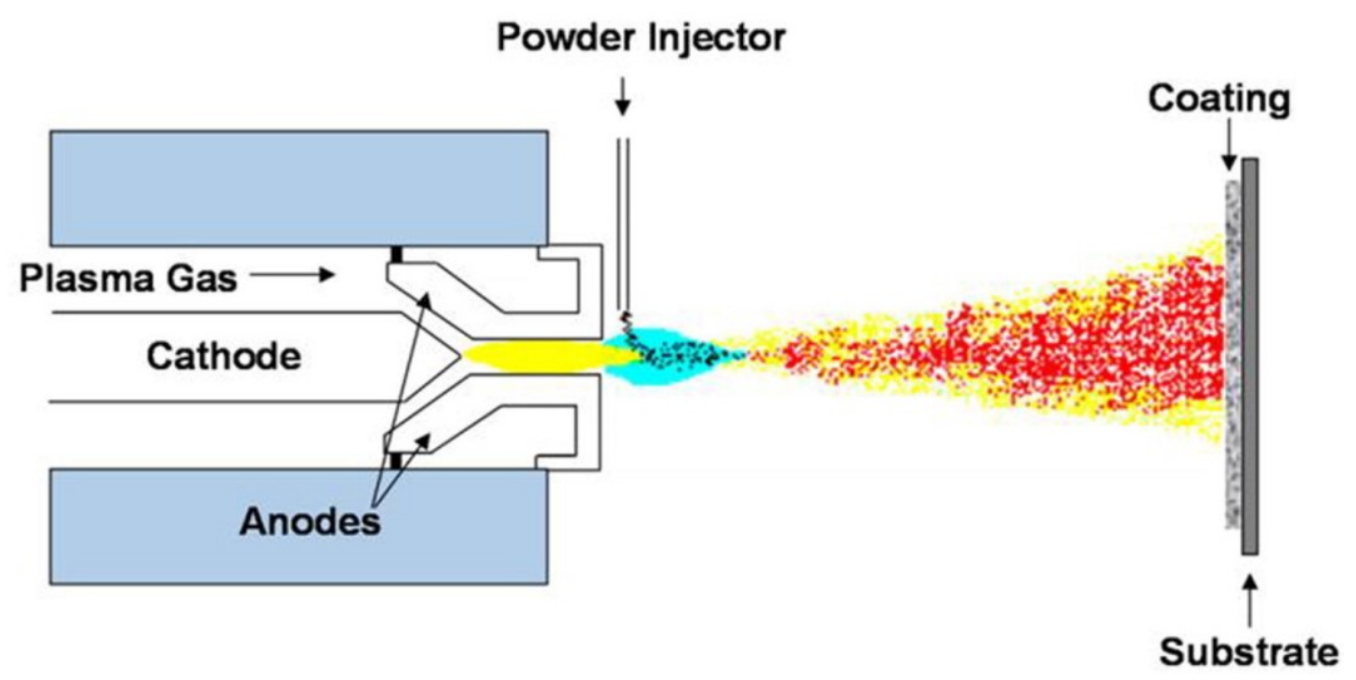

Figure 2.15: Schematic of plasma spray process [37].

Thus, the plasma transferred wire arc system is a combination of the wire arc and plasma spray processes. It is an alternative thermal spray solution and was developed for coating of engine cylinder bores. The established solution is a thermal spray gun small enough to fit and rotate inside of the engine to produce a uniform coating. The thermal spray system is described as a rotating spindle which uses wires deposition material instead of power to reduce costs. All in all; the automotive industry was considered to be the primary user while designing the plasma transferred wire arc coating process.

The plasma transferred wire arc system contains a nozzle, plasma gas supply, air gas supply, a cathode, and a wire of selected material. Figure 2.16 is a schematic representing the plasma transferred wire arc spraying process. The process occurs when a wire is fed perpendicular to the center orifice of the nozzle. A high voltage discharge ionizes and dissociates a gas mixture between the cathode and the nozzle during the process. The plasma gas ( $\mathrm{Ar}, \mathrm{He}, \mathrm{N}_{2}$ or $\mathrm{H}_{2}$ ) is forced out of the pilot nozzle at supersonic speeds [38]. The plasma is elongated and transferred to the anode and wire which completes the electric circuit. A constant current maintains the plasma from the cathode to the wire. The 
tip of the wire is melted and the high pressure plasma gas combined the atomizing gas strips the molten material from the tip of the wire and generates a spray of finely atomized particles [39]. The particles flatten when they reach the surface and solidify. A coating is generated with layers of these solidified droplets. The major benefits of the plasma transferred wire arc thermal spray process are the high temperatures and velocities that can be achieved, and its repeatability. The temperatures can reach $14700^{\circ} \mathrm{C}$ which is high enough to melt any feedstock material required for coating [40]. Ceramics which have very high melting points can even be used as deposition material due to these high temperatures. Also, the high plasma jet velocities result in a dense coating with porosities less than $2 \%$ produced. Finally, the process is repeatable and predictable due to control systems monitoring parameters such as gas flow and applied current in the system.

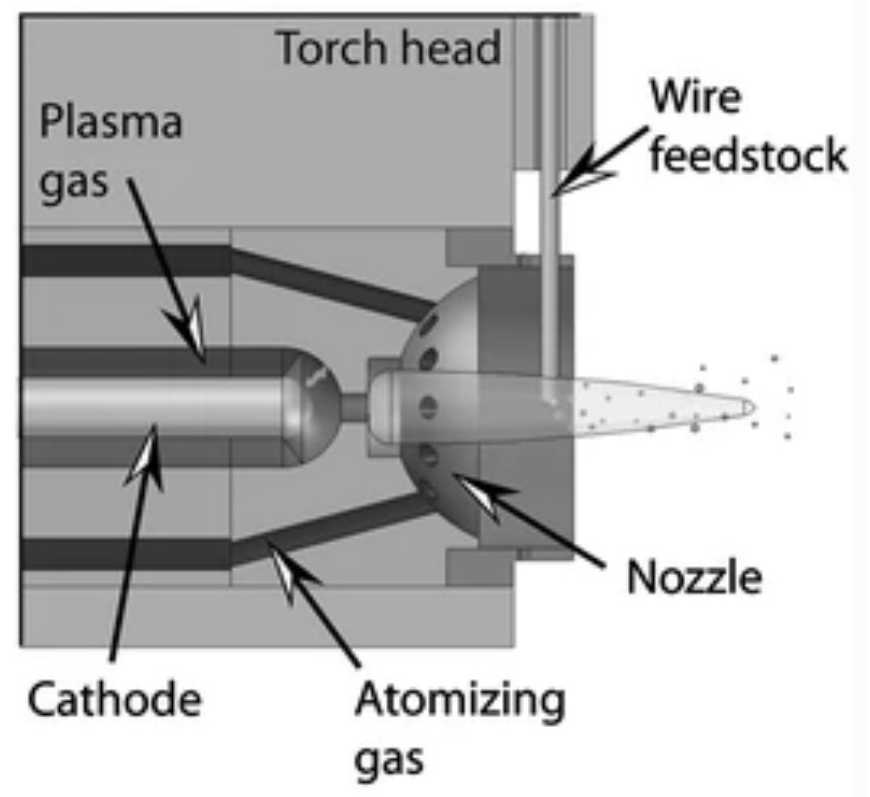

Figure 2.16: Schematic of plasma transferred wire arc spray process [41].

The equipment commonly used in a plasma transferred wire arc system are two DC rectified constant current power supplies. A plasma gun which consists of a tungsten 
cathode and a copper anode in a water-cooled brass casing. A control panel to manage the plasma gas, power, and cooling water. A wire feeder and straightener to regulate the feedstock. The working distance and translation speed of the plasma torch are manually determined and set by the operator [38]. Computerized automation is also used but impractical if not in a production environment.

In summary, the plasma transferred wire arc coating uses a single wire as the feedstock for deposition. The plasma jet is formed when an arc is transferred between the cathode and wire tip, with forced air being used to generate and move the stream. The wire tip is heated into a molten state, atomized, and transported by the high temperature and speed plasma gas to the substrate. The molten droplets splat on the bore wall with their high kinetic energy causing them to flatten on the substrate. The heat loss from the particles to the substrate results in rapid solidification. The final coating is a build-up of these solidified splats along the target surface.

\subsubsection{Application Procedure of Plasma Transferred Wire Arc Coating}

The technique for applying a plasma transferred wire arc coating to a substrate consists of four steps. The first two steps are pre-treatment processes which occur before coating deposition and include surface machining to obtain a flat and smooth finish, and surface activation to achieve a respectable bond strength. The last two steps are posttreatment processes and involve coating deposition, and coating honing. The pre-treatment steps play a more critical role in coating performance. Surface preparation is important as optimal coating adhesion strength is associated with surface cleanliness and roughness [42].

Appropriate machining is required to prepare the samples for plasma transferred wire arc coating. In this project, machining was used to level and remove the crude surface 
finished produced by the casting process. Also, machining assisted in the cutting of small samples for each of the different testing conditions. Surface machining can also be used to produce groves or threads in the substrate to improve adhesion strength by increasing the mechanical interlock between the coating and substrate [38]. Without proper machining, the coating would not correctly adhere to the substrate which would result in poor results.

After machining the substrate surface should be cleaned to remove any possible contaminants. Some common contaminants include oil, grease, paint, and fingerprints. Any surface imperfection could result in inconsistencies of the coating. In industry, some techniques used to remove surface contaminants include laser cleaning, air plasma cleaning, wet or dry blasting, brushing, and ultrasonic cleaning [43, 44].

The next stage in the procedure is surface roughening. The purpose of surface roughening is to improve mechanical interlock between the coating and substrate. The improved interlocking occurs because roughening the surface increases the surface area and produced pits where the coating can anchor. Grit blasting, and surface machining, are commonly used techniques to roughen the substrate surface $[17,38,45]$. This paper will focus on the surfaces roughened by pulsed waterjet. There are many advantages associated with using pulsed waterjet for surface roughening including its environmental friendliness and unlike the grit blasting and machining techniques there is no surface residue that must be cleaned after roughening.

Once all of the pre-treatment steps are completed the substrate is ready for coating. The coating deposition process consists of heating and transporting molten droplets of feedstock material to the substrate surface. Once impact is made with the surface the particles flatten and solidify forming splats. During the plasma transferred wire arc process, 
the molten particles form from melting the wire tip which is fed perpendicular to the spray nozzle. These particles are then transported with high speed plasma gas and atomized. The molten particles accelerate to the substrate surface where on impact flatted into splats that form to the topography of the contact surface. When the molten material makes contact with the substrate it cools rapidly forming a mechanical interlock with the surface. The formation of the coating through flattening and solidification of molten particles has been studied in depth by other researchers [46, 47]. They noticed that splat solidification occurs in $1 \mu \mathrm{s}$ to $2 \mu \mathrm{s}$. They also observed if solidification is very rapid the solid layer formed around the edges of the splat obstructs liquid flow and results in splashing. Splats produced in this manner have a finger like structure. If splats do not solidify on impact they disintegrate when the liquid sheet formed by the spreading droplet ruptures, producing a splat with a small central core surrounded by an annular ring [46].

Once a particle makes impact with the substrate surface the next particle is quick to follow and builds on the previous one. The time between particle impacts is in the tens of $\mu$ s which is ample time for the previous splat to solidify. Coatings are formed by the layering of many splats, with defects such as porosities, semi-melted particles, and oxides present in some coatings. The cause of porosities is the inability of the flattening particle to follow the topography of the previous layer. Parameters which influence the density of porosities include the feeding rate of the feedstock, deposition efficiency, and spray pattern. Oxidation which is another defect occurs when particles are in flight or on the surface. Defects greatly impact coating performance and are strongly related to the parameters used during the coating process. These parameters include working distance and speed, the 
temperature of substrate and coating, cooling rate, preparation of the substrate surface, and the size and shape of the molten coating particles.

After the coating deposition process, post treatment techniques are used to reduce or create residual stresses, decrease pore density, improve bond strength, prevent oxidation or corrosion, better coating homogeneity, assist in chemical modifications, improve particle cohesion, or promote precipitation. A few methods used by industry for post treatment include annealing at atmospheric pressure or under vacuum to reduce stresses, austempering to improve bonding and increase coating hardness, and nitriding to produce a case hardening $[48,49]$. Once this step concludes the coating process is finished and the coating is ready to be used for its desired application.

\subsubsection{Parameters that Influence Plasma Transferred Wire Arc Coatings}

Many parameters influence the quality of the plasma transferred wire arc coating from the material used for feedstock to the equipment used for deposition. The coating microstructure and performance depend on the molten particles impact with the surface, flattening, splat formation, and cooling rates. It is parameters such as feedstock material, equipment, spray speed and working distance, substrate temperature, and coating temperature that affect the formation of this coating. This section will discuss many of the parameters which affect coating performance.

The selected feedstock material has a major impact on coating performance because composition, and particle size and distribution all influence coating formation. Feedstock material composition and particle characteristics can vary between suppliers.

The plasma transferred wire arc process requires that the feedstock material be ductile enough to allow for a smooth and constant feed. It is imperative that the feed rate 
be constant to ensure little change in the arc gap used to produce the plasma spray. Initially, an operating voltage is set, and the electrodes are consumed which results in varying arc lengths. A rectifier is used to control the voltage during this step. In the case of a small wire gap during the arc process then the rectifier will increase the voltage to increase the melt rate. Accordingly, if the arc gap is too large then the voltage will decrease. During this stage, a balance between feed rate and melt rate needs to be determined. Since control systems are responsible for managing the voltage there will be some overcorrection in the system which will cause a fluctuation in arc voltage and current with principle frequencies varying between $500 \mathrm{~Hz}$ and $2000 \mathrm{~Hz}$ [38]. The frequency adjustments can be reduced by fine tuning other aspects of the system such as wire feed rate, plasma gas flow, and atomizing gas flow. The wire must also be precisely aligned to minimize the change in voltage. A wire straightener is also typically present in the system, it consists of a series of rollers which force the wire down a straight path and reduce the curvature in the feedstock material. The wire straightener is crucial in assisting with an even melt of the feedstock material. The density and particle size of the powder or wire based deposition material is also considered.

In flight the molten particles take a spherical shape. Once the impact is made with the surface the molten material flows outwards which causes the material to flatten and solidity in the shape of a splat. The flattening of material deposited on the surface depends greatly on particle properties such as temperature, speed, surface tension, viscosity, chemical composition, and pressure of the system chamber.

The temperature of the in-flight particles affects oxidation as the spray process is conducted in an atmosphere containing air. Oxidization can occur either on the surface of 
the molten material or in the vapor surrounding it. Diffusion and convection are responsible for the oxidation of in-flight particles [38]. Also, oxidation can happen on the coating surface, but this can be controlled by altering operating parameters such as coating temperature. The system pressure and stream composition also affect the spray jet appearance, heat, and momentum transferred to the molten particles. The plasma gas mixes with the gasses in the atmosphere which causes quenching of the particle stream. The rate of quenching increases with increasing humidity in the system and decreases with decreasing pressure. A low pressure also results in decreased heat and momentum transferred from the plasma gas to the molten particle [38].

The substrate temperature also plays a role in splat formation as it is responsible for cooling the molten particles on the surface. It was determined that if the deposition was conducted on a cold substrate the splats would form irregular shapes due to droplet splashing during rapid solidification [50]. Alternatively, if the deposition was conducted on a hot substrate the splats formed were circular and resembled a disk shape [51]. Therefore, a substrate temperature exists to produce splats with a defined shape. A high temperature substrate produces a lamellar layer comprised of disk-shaped splats while a substrate at a low temperature produces an irregular layer comprised of fragmented splats. A coating formed with fragmented splats has a greater probability of containing porosities then one formed with disk shaped splats.

The speed of the particles also plays a role in splat formation. If the speed is too low, the splats cannot fill and form to the surface cavities. This results in porosities as well as poor adhesion and cohesion in the formed layer. On the other hand, if the particle speed is too high then large droplets can break apart and deform on impacting resulting in a 
fragmented layer and poor adhesion between splats. Thus, the ideal operating parameters for splat formation are small particles with high velocities which form a low amount of porosities and produce a well adhered coating. The graphs in Figure 2.17 show that for AISI 304L substrate increasing substrate temperature and particle speed improve the degree of splashing and frequency of disk-shaped splat formation.
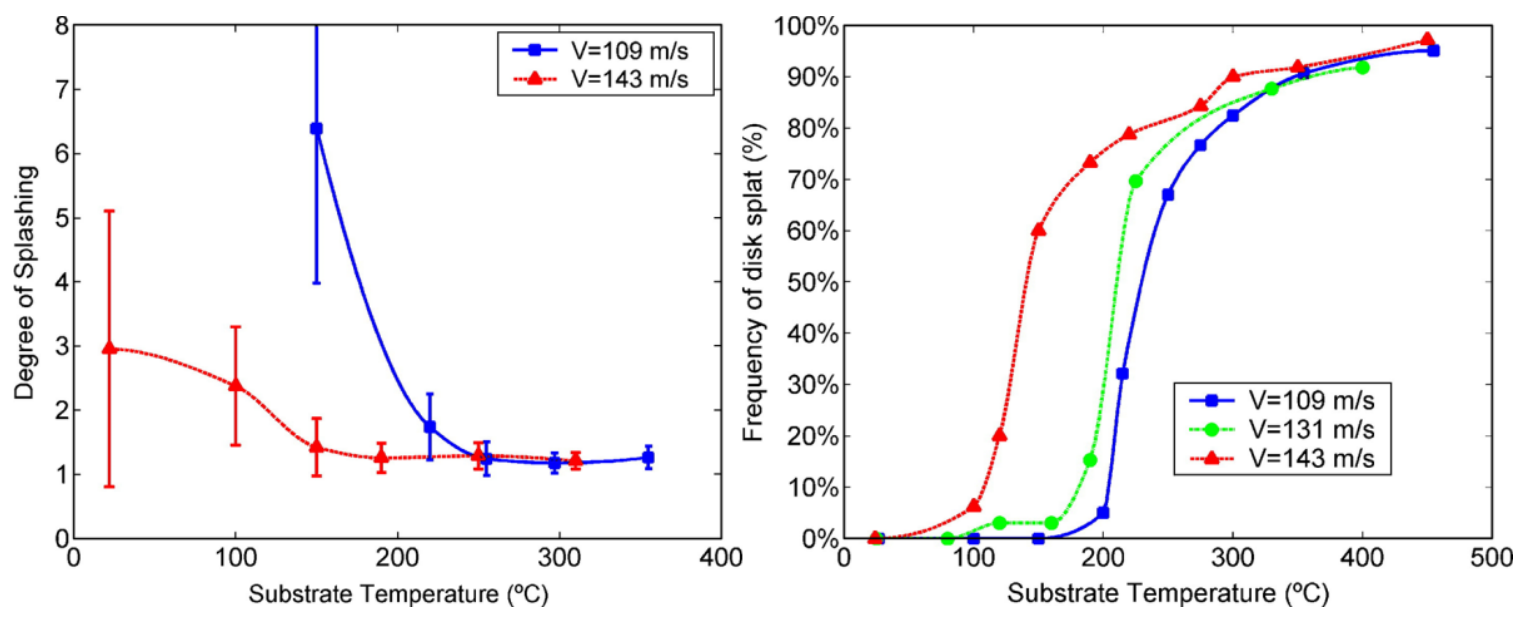

Figure 2.17: The effect of particle speed and substrate temperature on degree of splashing and frequency of disk shaped splat formation for AISI 304L substrate [52].

The working distance also plays a critical role in coating formation. The working distance must be far enough to allow the particles to fully melt and attain high speeds, but close enough so that the particles do not vaporize [38]. The plasma gas is responsible for melting and transferring momentum to the deposition material. This is required to produce a coating that is dense with minimal porosities. If the working distance is too large, then the particles in the stream have the potential to drop out of the spray path and lose temperature and speed. This could result in the particles depositing in the wrong area or missing the substrate entirely. In contrast, if the working distance is to small then the 
particles will not have time to completely melt and un-melted particles will bounce off the substrate while partially melted ones will adhere as inclusion in the coating.

The plasma torch also influences the plasma transferred wire arc spray process. Plasma torches typically operate under constant current. The current remains constant because the voltage of the power supply is adjusted to compensate for changes. A plasma torch can be described by its arc voltage, deviation of voltage, and cooling water temperature change. If these values are known then the efficiency, energy transferred to the plasma jet, enthalpy of the plasma gas, plasma gas speed, and plasma gas temperature can be determined [38]. Additionally, the gas used for plasma and how its injected into the nozzle also influence arc voltage and torch efficiency. A commonly used gas for plasma is argon with trace amounts of hydrogen added to increase arc voltage and torch efficiency. The hydrogen atoms improve voltage and efficiency by rapidly diffusing to the arc column borders which increases thermal conductivity. The plasma gas is injected into the nozzle radially, axially, or by swirling. For instances of lower temperatures typically the plasma gas is injected radially, while for cases with higher voltages the plasma gas is injected axially. The spray torch design also plays a role in arc voltage and torch efficiency, with smaller nozzle diameters resulting in shorter arcs, lower temperatures, and higher velocities at the nozzle exit [38]. Finally, the cathode shape also influences the spray process. A cathode designed with a sharp tip increases plasma gas speed compared to that of one with a round tip. However, the sharp tip becomes molten during operation and is quick to erode and change shape. 
The plasma transferred wire arc pre-treatment and post-treatment processes discussed in the application section also influence coating quality. Modifications to these processes will also change the characteristics of the final coating.

\subsection{Properties of Plasma Transferred Wire Arc Coating}

Thermal spray coatings have been utilized by many industries to resurface and improve wear and corrosion resistance of components in their systems. The improved wear and corrosion resistance can be attained by the thermal spray process without altering the properties of the base material. The automotive industries are one of the major trades which have benefited from thermal spray coatings. Engine cylinder bores have been coated to resurface worn linings and allow for the use of lightweight metals such as aluminum [38] [53]. These new lightweight aluminum engine blocks have their cylinder bores coated with harder materials such as steel. As a result of developed thermal spray coating processes, fuel consumption in vehicles has decreased by 2 to $4 \%$ [53]. To ensure optimal performance the microstructure and mechanical properties of the coating are studied. The characteristics of a high-quality thermal spray coating are discussed in this section.

\subsubsection{Structure of Spray Coating}

The microstructures of thermal spray coatings can be examined under an optical or electron microscope, which provides information about the quality of the coating. The microstructure of the thermal spray coating is layered and can be described as particles flattening, solidifying, and then after a sufficient amount of time another particle impacts the same location such that particles accumulate layer by layer until a continuous coating is formed. A single splat is only around $1 \mu \mathrm{m}$ to $20 \mu \mathrm{m}$ thick but the coatings which are 
layers of splats can be hundreds of micrometers thick [54]. Typically, the splats that form during the thermal spray process are elongated and not perfectly round pancakes. The molten particles and subsequent splats that solidify on the surface are various shapes and sizes [38]. The variation in splat sizes results in the forming of a coating with undulations in the lamellar structure. The lamellar structure forms to the shape of the uneven substrate.

The porosities in the coating are viewed as a defect and can affect coating quality. Characteristically, plasma transferred wire arc coatings have low porosity content because of how well the process can be controlled. Porosities in the coating result from insufficient interlock on the substrate surface [38]. Insufficient interlocking usually occurs with particles that have low velocities or in particles that are semi or un-melted. Other defects which are found in spray coatings include interlamellar cracking, delamination, and inclusions [38]. These defects can either be connected in an open void network or separated in a closed void network. Minimizing the number of defects in the coating will improve its quality and performance.

\subsubsection{Spray Coating Mechanical Properties}

The adhesion strength between a coating and substrate can be defined by fracture mechanics as the energy required to initiate and propagate a crack until failure occurs. The quality of the thermal spray coating influences its adhesion or bond strength with the substrate material. A poor-quality coating will easily de-bond and result in failure. Parameters such as operating conditions, feedstock material, substrate material, residual stresses, and environmental conditions all influence the quality of the coating [38].

Bonding between the coating and substrate is also dependent on the characteristics of contact between the surfaces. Rougher surfaces which have more surface area to promote 
friction based mechanical interlocking show improved bond strength compared to smooth surfaces [33]. The mechanical interlocking mechanism was observed by Zaat [55] who also stated that bonding between the coating and substrate can occur metal to metal bonding and chemical bonding. Metal to metal bonding is when diffusion between the coating and substrate occurs while chemical bonding is the formation of an intermetallic compound between the coating and substrate [55].

The interface bond between the coating and substrate is important for adhesion strength. Surface roughening is commonly used to activate and promote mechanical interlocking of the coating on the substrate surface. The mechanical interlocking improves bond strength. Many different surface activation profiles have been developed to modify bond strength with a few of them presented in Figure 2.18.
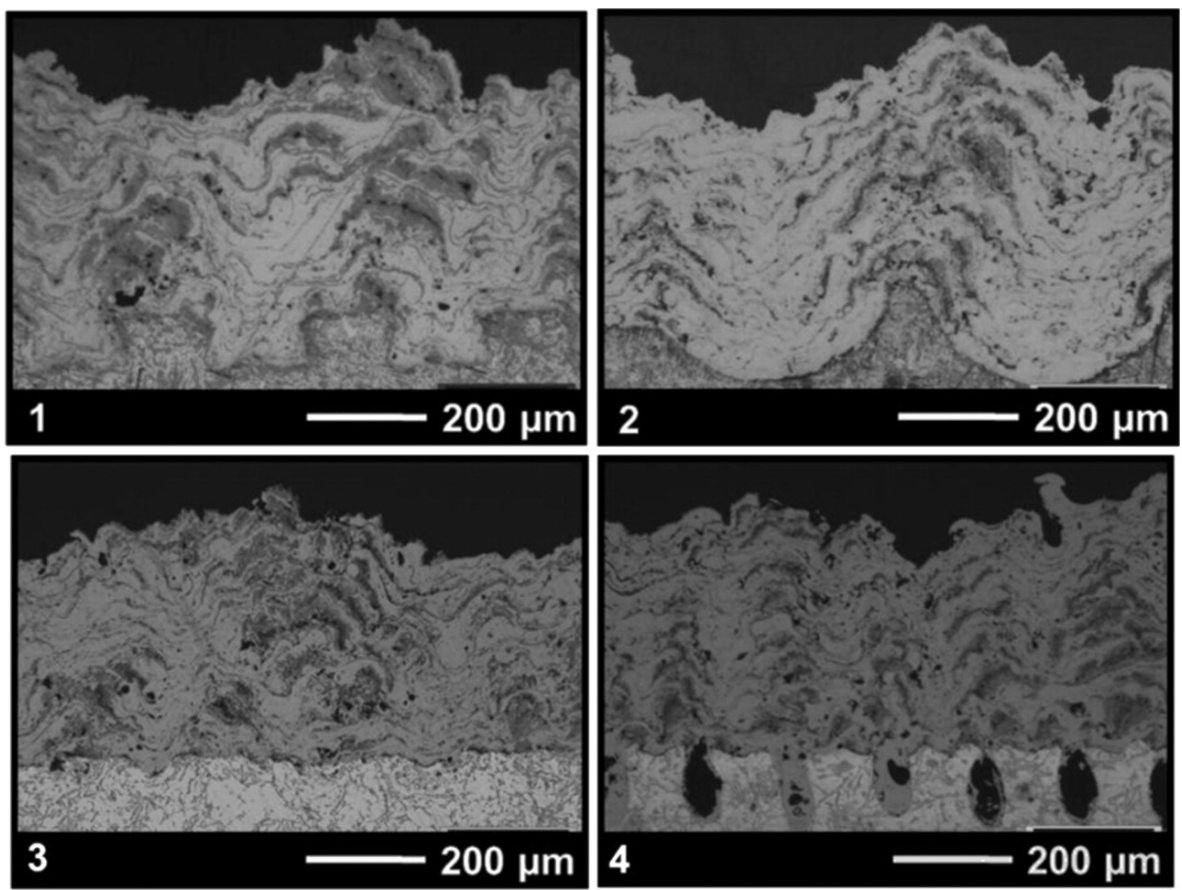

Figure 2.18: Different surface activation profiles to modify coating bond strength: 1) dove tail profile, 2) mechanical roughening, 3) grit blasting, and 4) laser texturization [41]. 
Studies have been conducted to determine the adhesion bond strength of specific mechanically interlocked spray coatings and substrates. Samson et al. [17] investigated the bond strength of pure aluminum powder cold sprayed onto polished, grit blasted, and pulsed waterjet roughened aluminum 6061-T6511 substrate. Figure 2.19 shows SEM images of the polished, grit blast, and pulsed waterjet surface morphology. They determined that the polished surface attained a respectable bond strength of $25.5 \mathrm{MPa}$, while the bond strength decreased to $12.8 \mathrm{MPa}$ for the grit blast sample and increased for the pulsed waterjet up to $51.1 \mathrm{MPa}$. Figure 2.12 graphically presents and compares this data. It was also established in their study that increasing the pulsed waterjet substrate surface roughness improved coating adhesion strength. They proposed that the increased adhesion strength between the coating and substrate may be a result of increased anchoring features and increased roughness.

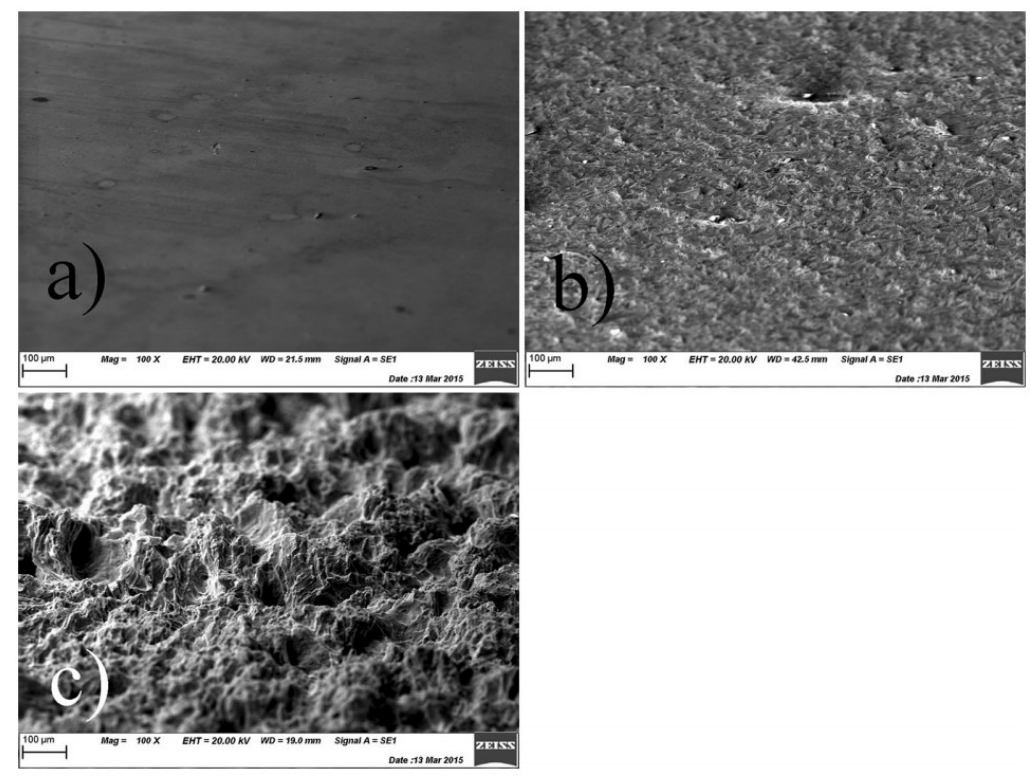

Figure 2.19: SEM images taken at a $20^{\circ}$ angle to the surface showing morphology of a a) polished b) grit blast and c) pulsed waterjet surface [17]. 


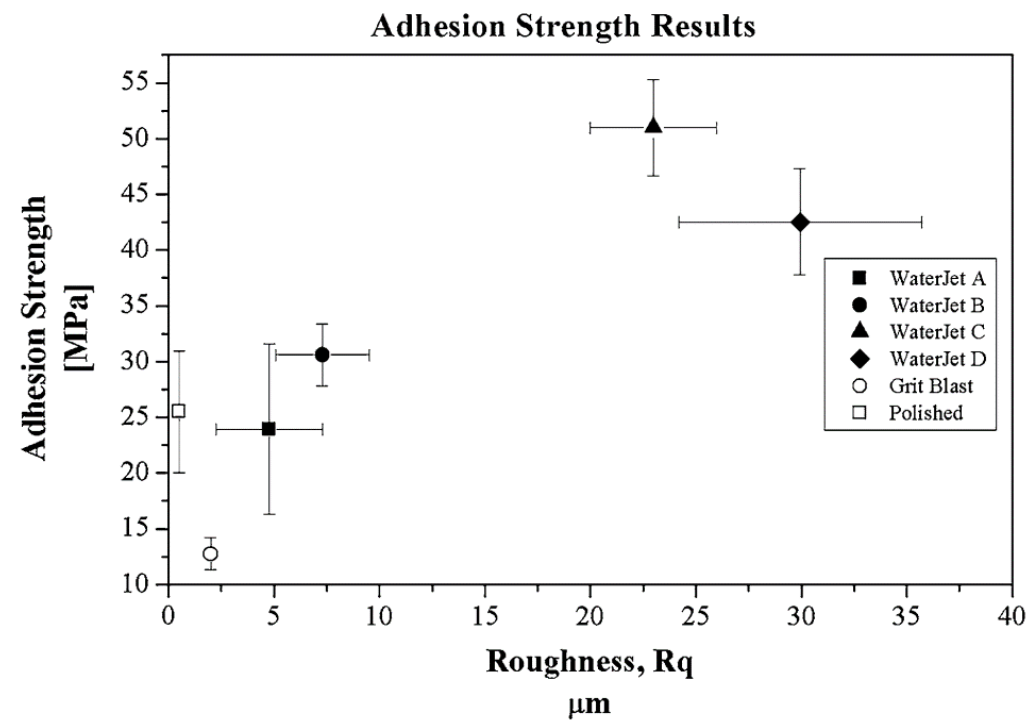

Figure 2.20: Adhesion strength values as a function of surface roughness for multiple surface preparation techniques [17].

Knapp et al. [56] compared the bond strength of plasma sprayed MCrAlY on pulsed waterjet and grit blasted Inconel 718 and Mar-M 509 to determine which one produced more favorable results. They determined that the bond strength capabilities of pulsed waterjet roughened substrates are superior to those of grit blasted substrates. They reported that the plasma sprayed MCrAlY coating-substrate bond strength only reached 58MPa for the grit blasted samples while the bond strength of the pulsed waterjet roughened Inconel 718 and Mar-M 509 substrates exceeded $70 \mathrm{MPa}$. They described that the grit blast particles were left on the surface after mechanical roughening and were responsible for the lower bond strength. Interestingly in their findings there was no trend between pulsed waterjet surface roughness and coating-substrate bond strength. Bobzin et al. [45] compared the adhesion strength between a PTWA low carbon steel coating on Al-6060 surfaces geometrically cut and high pressure waterjet roughened. Two different cutting profiles were used in the study. These cutters were the IWF MRP cutter and the IMF MRP dove tail cutter. The IWF MRP cutter resulted in a coating bond strength of 40MPa while 
the IMF MRP dove tail cutter produced a bond strength of 58MPa. These bond strengths are comparable to the bond strength of $48 \mathrm{MPa}$ measured for the pulsed waterjet process used in their study. Images of the surface profile for the three mechanical roughening techniques are presented in Figure 2.21, while the graph in Figure 2.22 shows the bond strengths for the three mechanical roughening techniques. Grit blasting with $\mathrm{Al}_{2} \mathrm{O}_{3}$ particles has also been used to roughen the surface of cast iron and Al-Si alloys to promote mechanical interlocking between PTWA coating and the substrate [57]. The authors reported the adhesion strength between the PTWA steel coating and grit blasted substrates ranged from 40-60 $\mathrm{MPa}$ and 50-70 $\mathrm{MPa}$ for aluminum and cast iron, respectively.
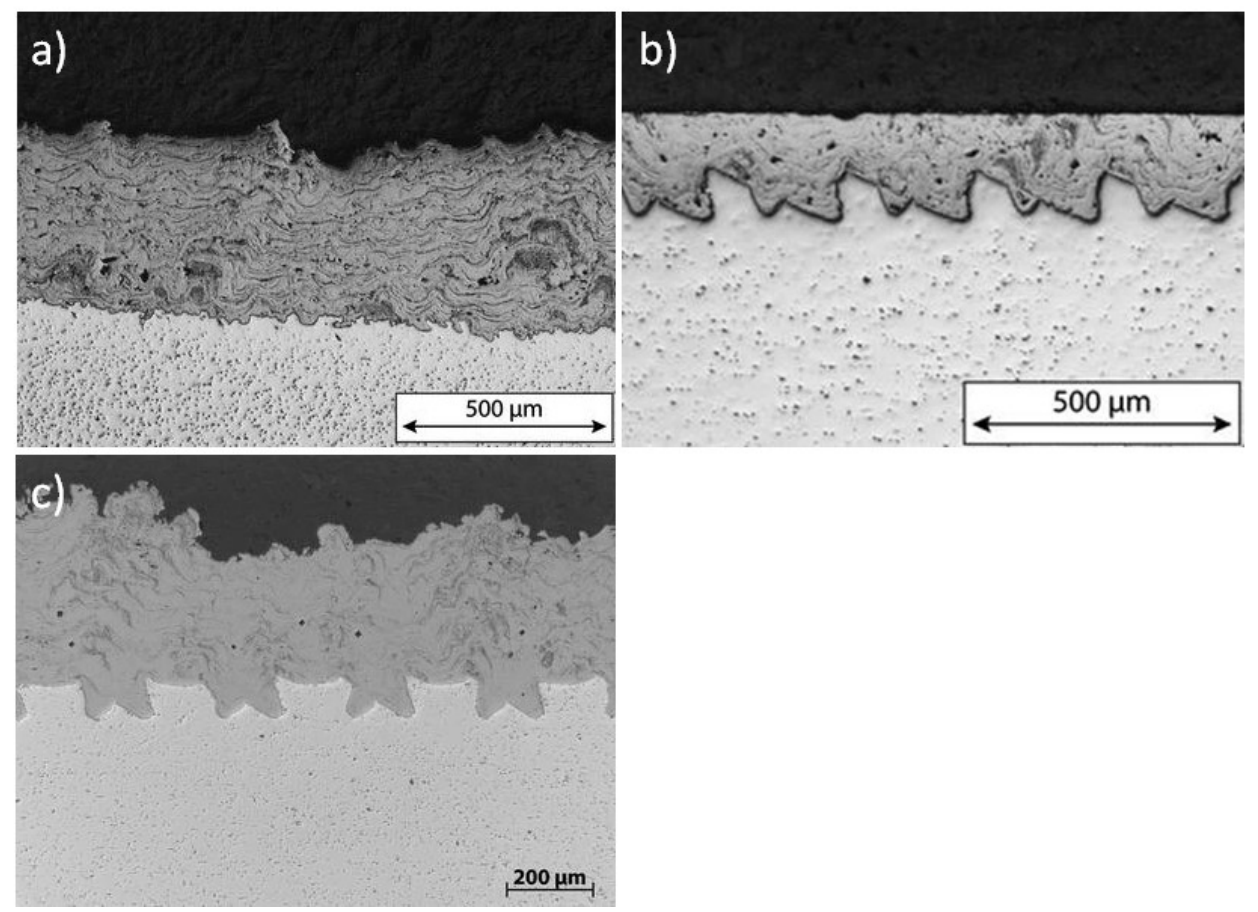

Figure 2.21: Surface profiles of the a) pulsed waterjet b) IWF MRP and c) IWF MRP dove tail [39]. 


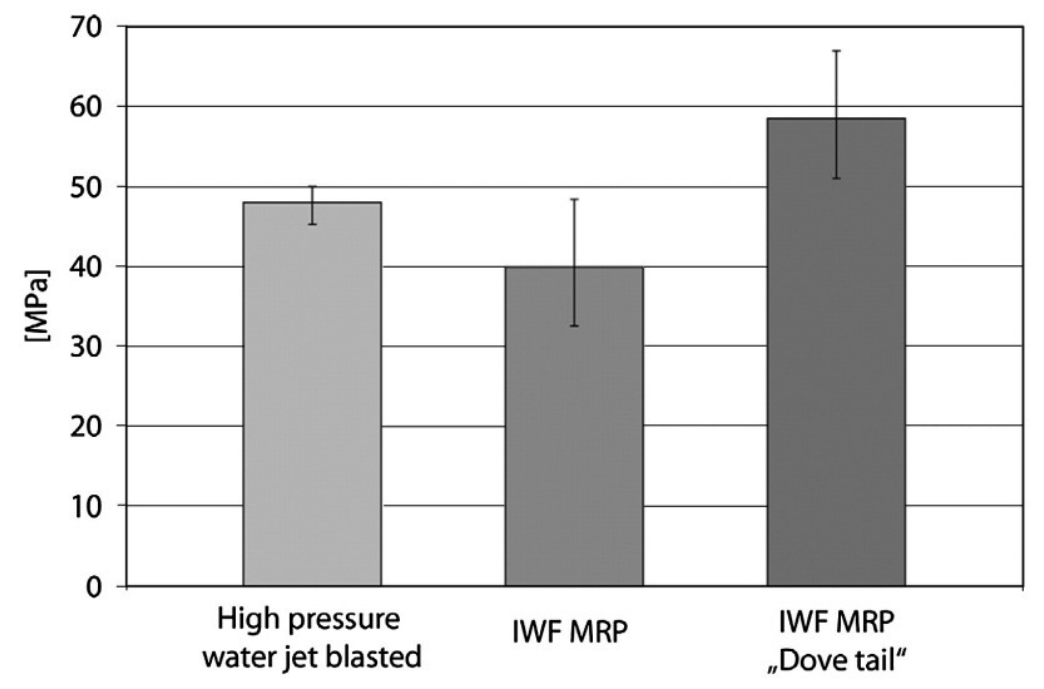

Figure 2.22: Bond strength of PTWA sprayed low carbon streel on mechanically roughened aluminum Al-6060 substrates [45].

The adhesion strength of the thermal spray coating is a performance property and can be measured to determine the greatest perpendicular tensile force a coating can bear before the material detaches or determine if the coating remains intact under a defined load [58]. Failure during pull-off adhesion testing can occur in the glue which binds the dolly to the coating, adhesively at the mechanical interlocking between the coating and substrate, cohesively between the splat layers of the coating, or mixed mode which is a combination of glue, adhesive, and cohesive based failure [59]. In order for the adhesion strength between the coating and substrate to be measured failure must only occur at the interface between the two. Failure in the glue, coating, or substrate is not desirable. As well, if failure occurs along multiple planes in the system this is considered mixed mode and is also not wanted. The diagram in Figure 2.23 represents the three types of material failure modes. 


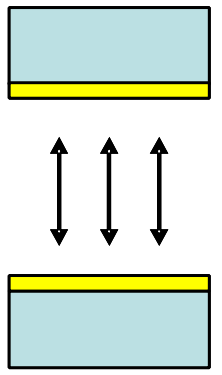

Cohesive

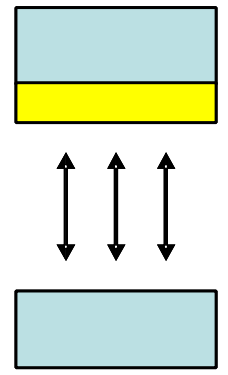

Adhesive or

Interface

Failure

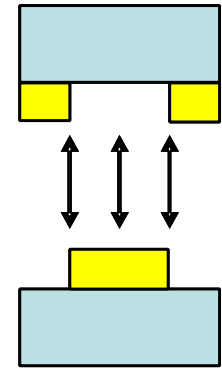

Mixed

Failure

Figure 2.23: Schematic of different failure modes present in bond strength testing [59].

\subsection{Heat Treatment of Aluminum A380}

Altering the properties of aluminum A380 with heat treatment techniques may improve the performance of spray coating adhesion. Normally, heat treatment of cast materials is ill advised due to the presence of pores containing trapped gasses. The gasses trapped in the pores expand causing the pores to grow which results in dimensional changes and surface blistering of the material. However, by reducing heat treatment time and temperature Lumley et al. [60] developed a solution treatment technique to heat treat A380 and avoid dimensional changes and surface blistering. Two most popular heat treatment cycles for aluminum alloys are $\mathrm{T} 4$ and $\mathrm{T} 6$. In T4 heat treatment, the alloy is heated to a solution treatment temperature for a certain extent of time followed by water quenching. Then the alloy is left at room temperature for natural aging. In T6, the aging process is accelerated by heating the alloy at a relatively lower temperature for a certain extent of time followed by water quenching. Figure 2.23 shows the change in mechanical properties with various heat treatment cycles. 


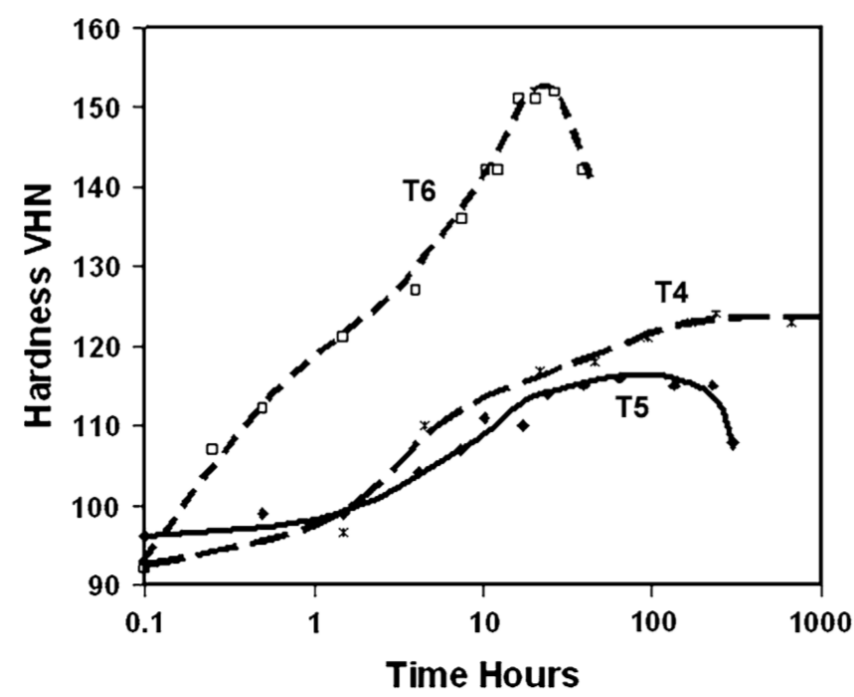

Figure 2.24: Hardness curves for A380 comparing samples given a T5 and T6 aging treatment at $150^{\circ} \mathrm{C}$ for $24 \mathrm{hrs}$ to a T4 aged sample at $25^{\circ} \mathrm{C}$ for $25 \mathrm{hrs}$. the heat treatment parameters were $490^{\circ} \mathrm{C}$ at 15 minutes [60].

\subsection{Gaps in the Literature}

Though work has been conducted on the use of pulsed waterjet technology to produce a roughness profile, and the mechanical interlock of a PTWA coating has been studied on machined and grit blast surface profiles, information concerning the pairing of the two with the engine cylinder bore liner application in mind is nonexistent. This paper addresses the combining of the two techniques to develop the pulsed waterjet process as a viable surface roughening solution prior to the PTWA coating with the engine cylinder bore liner application in consideration. The aim is to optimize the pulsed waterjet surface roughening process for maximum adhesion strength between the coating and the substrates while considering the coating final surface finish. 


\section{Chapter 3 Materials and Experimental}

\section{Procedure}

The methods and experimental procedures used to prepare and characterize the substrate materials and the plasma transferred wire arc coatings are discussed in this chapter. The techniques used to describe and understand the material microstructures, morphologies and compositions include optical microscopy, scanning electron microscopy with electron dispersion x-ray spectroscopy, and a profilometer. The flow chart in Figure 3.1 represents the methodology used to determine the optimal pulsed waterjet roughened surface for suitable adhesion of the plasma transferred wire arc coating.

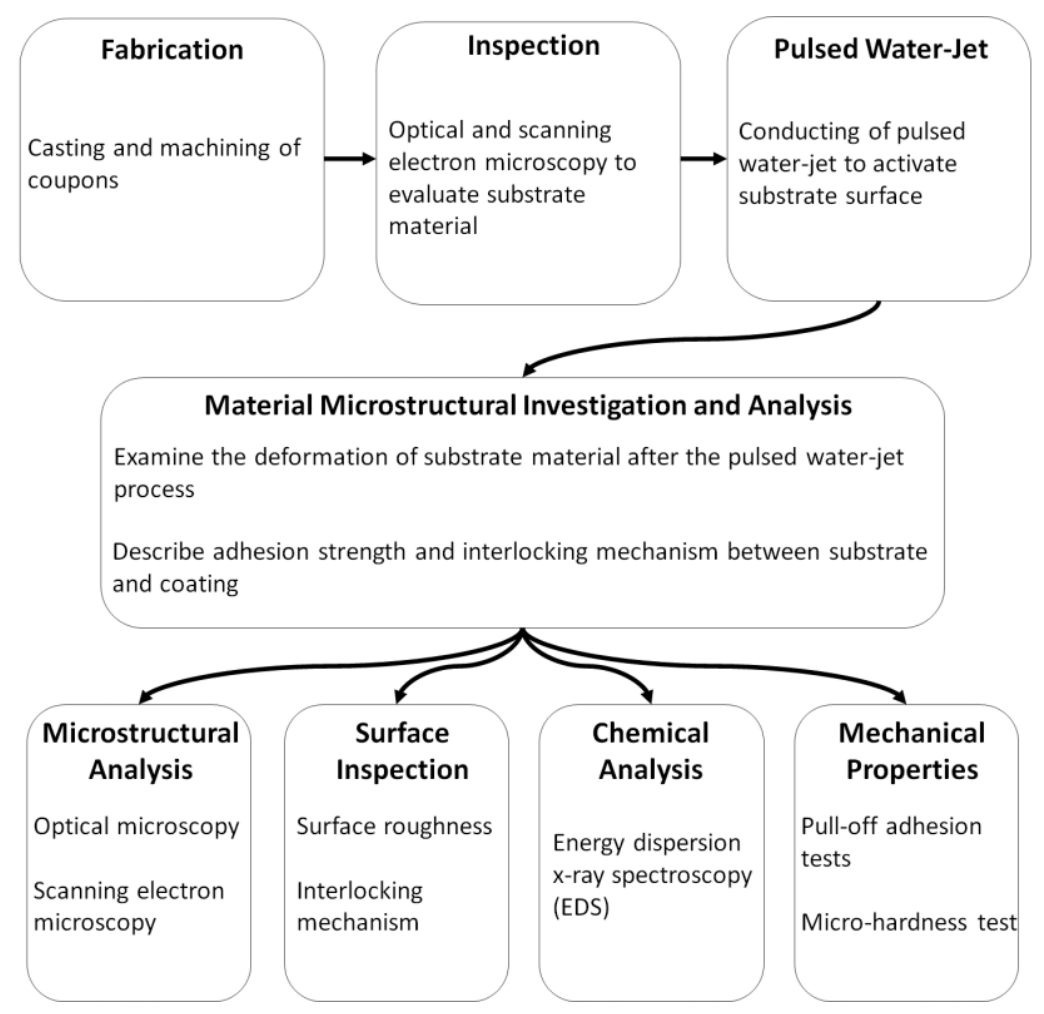

Figure 3.1: Flow chart outlining the methodology used to determine the optimal surface roughness for adhesion of plasma transferred wire arc coating. 


\subsection{Materials}

\subsubsection{Substrate Material}

Cast aluminum and gray cast iron are materials commonly used to manufacture automotive engines due to their low cost and frictional performance.

The coatings were deposited on aluminum alloy A380 and grey cast iron (GCI) with the plasma transferred wire arc spray process. These two substrate materials are commonly used alloys for automotive engines and were selected based on previously conducted engine bore adhesion strength research which provided promising and reliable information to use as a reference. The cast iron and aluminum substrate materials were cast in larger moulds to eliminate the potential of warping during cool down and to improve mould quality. Prior to waterjet roughening the moulded material was machined to improve the surface finish produced by the crude casting process and to cut them into smaller coupons. Figure 3.2 shows the images of the A380 and GCI samples after surface machining. Each small coupon will have its surface activated for adhesion with different pulsed waterjet surface roughening parameters. The chemical composition of the A380 and GCI is presented in table 1 and table 2 shows a comparison in mechanical properties of the two substrate materials.

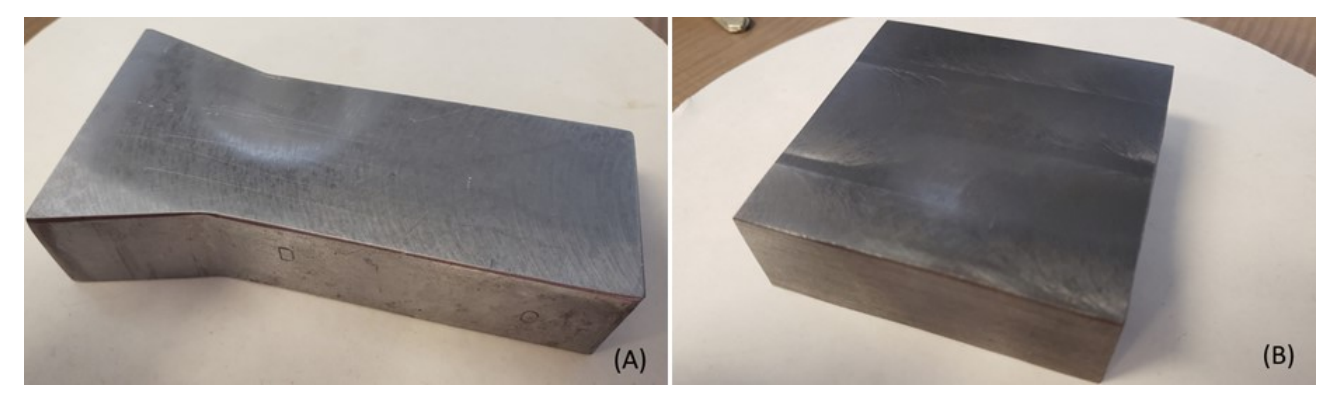

Figure 3.2: Images of substrate material coupons: (A) A380, (B) GCI. 
Table 1: Substrate materials and composition provided by suppliers

\begin{tabular}{cc|cc}
\hline & \multicolumn{2}{|c}{ Composition GCI } & \multicolumn{2}{c}{ Composition A380 } \\
\hline \multirow{2}{*}{ Element } & Weight Percentage (wt\%) & Element & Weight Percentage (wt\%) \\
\hline $\mathbf{C}$ & $2.8-3.3$ & $\mathbf{S i}$ & $7.5-9.5$ \\
$\mathbf{S i}$ & $1.2-1.7$ & $\mathbf{C u}$ & $3.0-4.0$ \\
$\mathbf{M n}$ & $0.8-1.2$ & $\mathbf{F e}$ & $\max 1.3$ \\
$\mathbf{P}$ & $\max 0.15$ & $\mathbf{M n}$ & $\max 0.5$ \\
$\mathbf{S}$ & $\max 0.12$ & $\mathbf{N i}$ & $\max 0.5$ \\
& & $\mathbf{M g}$ & $\max 0.1$ \\
& & $\mathbf{Z n}$ & $\max 3.0$ \\
\hline
\end{tabular}

Table 2: A380 and GCI mechanical properties.

\begin{tabular}{|l|c|c|}
\hline \multicolumn{1}{|c|}{ Mechanical Properties } & A380 & GCI \\
\hline Elastic Modulus $(\mathrm{GPa})$ & 71.0 & 115.0 \\
\hline Density $\left(\mathrm{g} / \mathrm{cm}^{3}\right)$ & 2.71 & 7.15 \\
\hline Hardness (Brinell) & 80 & 212 \\
\hline Ultimate Tensile Strength $(\mathrm{MPa})$ & 290 & 252 \\
\hline Yield Strength $(\mathrm{MPa})$ & 145 & - \\
\hline Shear Strength $(\mathrm{MPa})$ & 185 & 334 \\
\hline Endurance Limit $(\mathrm{MPa})$ & 140 & 110 \\
\hline Elongation to Failure $(\%)$ & 3 & 0.5 \\
\hline
\end{tabular}

\subsubsection{Plasma Transferred Wire Arc Coating Material}

The feedstock material used to plasma transferred wire arc coat the A380 and GCI was SS 420. It is a low carbon, high chrome stainless steel wire with a composition of $0.35 \%$ C, $13 \% \mathrm{Cr}, 0.5 \% \mathrm{Si}$, and $0.5 \% \mathrm{Ni}(\mathrm{wt} \%)$. Its properties consist of high strength, high elongation, low shrink, excellent wear qualities, and good corrosion resistance. The material is commonly used in applications such as cylinder liners, pistons, valve stems, pump plungers, and crankshaft bearings [61]. 


\subsection{Pulsed Waterjet Procedure}

The surface of the substrate cast material was roughened using the pulsed waterjet apparatus supplied by VLN Advanced Technologies Inc. The pressure and standoff distance for the experiment were determined using a drop test and by assessing trials conducted on excess material. The substrate surface roughness was altered by varying the transverse speed of the nozzle such that, as the nozzle, transverse speed decreased the substrate surface roughness increased. Each of the coupons was subjected to the pulsed waterjet at a different transverse speed.

\subsubsection{Pulsed Waterjet Test Setup}

The pulsed waterjet system used in this study is presented in Figure 3.3 and consisted of a test cell, pump system, control system. The cell comprised of the pulsed nozzle, robot, sample holding fixture, and enclosure. An image of the pulsed nozzle and sample holding fixture used during the experiment is presented in Figure 3.4. The pump system was used to supply the water and generate water pressure. The system can deliver water pressures ranging from $34.5 \mathrm{MPa}$ to $138 \mathrm{MPa}$. Finally, the control unit controlled the robot, nozzle standoff distance, nozzle transverse speed, pulsed frequency, unit power, and water pressure. 


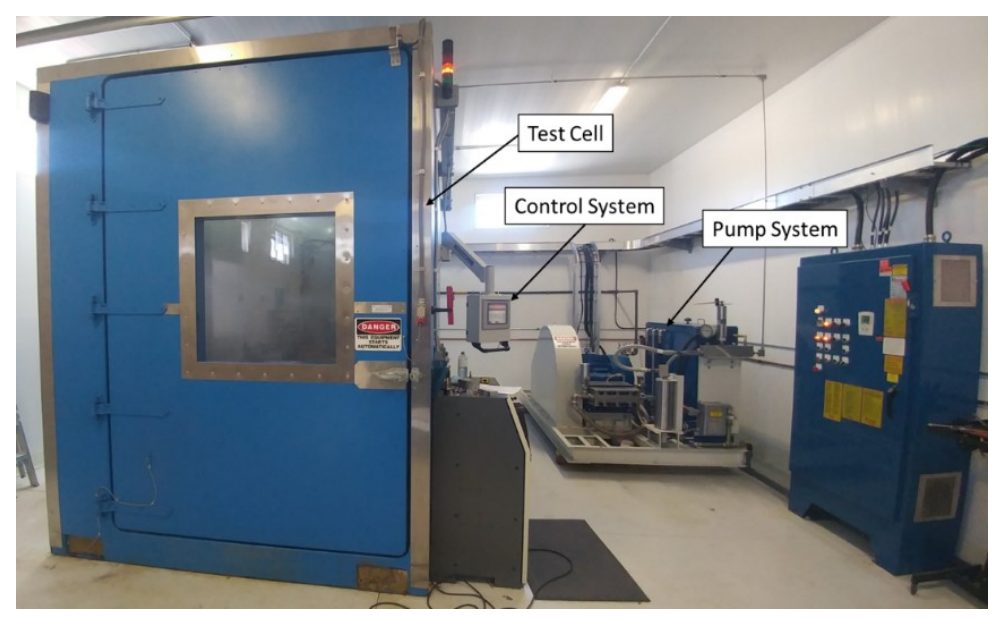

Figure 3.3: Pulsed waterjet test system containing the test cell, control system, and pump system.

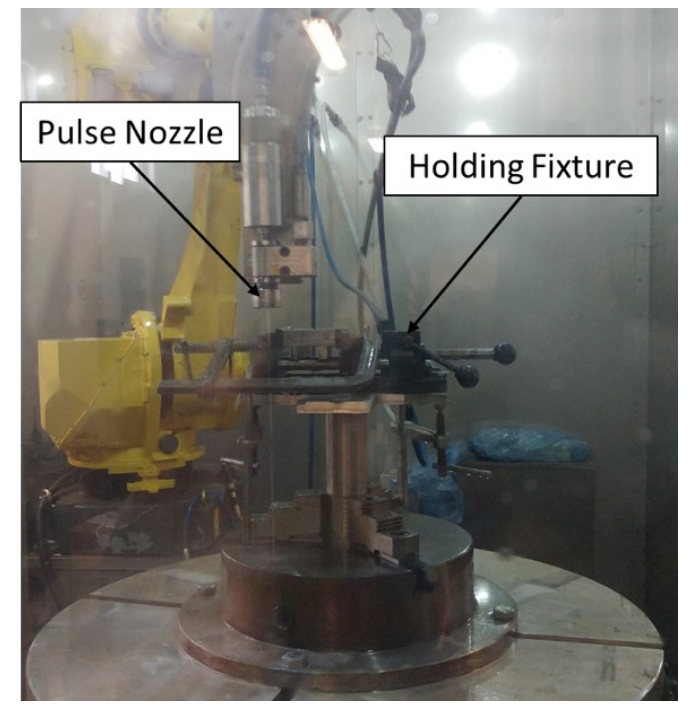

Figure 3.4: Pulsed nozzle and sample holding fixture used during the experiment.

\subsubsection{Parameters of Pulsed Waterjet Process}

The initial pulsed waterjet parameters were established using the drop test method discussed in section 2.1.3 and 2.1.4. The drop test assisted in determining a baseline for the operating parameters which were fine-tuned by conducting trials on excess substrate material. Once the operating parameters were set the nozzle transverse speed was varied to develop a range of substrate roughness profiles. 
The parameters selected to conduct the pulsed waterjet roughening of the A380 and GCI substrates for testing of the optimal adhesion strength between plasma spray coating and substrate are presented in table 3. These parameters were used for all the tests conducted during the study.

Table 3: Pulsed waterjet parameters used to roughen the A380 and GCI.

\begin{tabular}{cccccccc}
\hline $\begin{array}{c}\text { Substrate } \\
\text { Material }\end{array}$ & $\begin{array}{c}\text { Frequency } \\
\mathbf{( k H z )}\end{array}$ & Amplitude & $\begin{array}{c}\text { Overlap } \\
\text { Between } \\
\mathbf{P a s s} \\
\mathbf{( m m})\end{array}$ & $\begin{array}{c}\text { Nozzle } \\
\text { Diameter } \\
\mathbf{( m m )}\end{array}$ & $\begin{array}{c}\text { Water } \\
\text { Pressure } \\
\mathbf{( M P a )}\end{array}$ & $\begin{array}{c}\text { Standoff } \\
\text { Distance } \\
\mathbf{( m m})\end{array}$ & $\begin{array}{c}\text { Nozzle } \\
\text { Transverse } \\
\text { Speed } \\
(\mathbf{m m} / \mathbf{s})\end{array}$ \\
\hline A380 & 40 & $75 \%$ & 0.1 & 1 & 34.5 & 31.75 & $100-350$ \\
\hline GCI & 40 & $75 \%$ & 0.1 & 1 & 34.5 & 25.4 & $100-1000$ \\
\hline
\end{tabular}

\subsection{Measurements of Substrate Dimensional Changes}

Dimensional changes may result from substrate material removal or displacement during the pulsed waterjet process. A caliper was used to determine if any significant dimensional changes occurred in the substrate material. If dimensional changes did occur, an additional process would need to be developed to ensure the sample still met the outlined dimensional criteria.

\subsection{Stylus Profilometer Surface Roughness Measurements}

The roughness value of each coupon after the pulsed waterjet process was measured using the Bruker Dektak XT profilometer shown in Figure 3.5. Three-dimensional area scans were taken for each coupon and the surface roughness for each sample was calculated using the Vision64 software. 


\subsubsection{Stylus Profilometer System Overview}

The Dektak XT system works by taking measurements electromechanically from a moving diamond tipped stylus over the defined sample surface. The system allows the user to program the scan length, speed, and stylus force. The stylus is attached to a linear variable differential transformer, which produces and processes electrical signals that correspond to sample surface variations. Following this the signals are converted and stored in a digital format.

The Vision64 software is responsible for analysing the digitally stored data, conducting calculations, and displaying results. This software was used to determine the average roughness for the pulsed waterjet roughened coupon samples and to develop three dimensional maps of the surface profile.

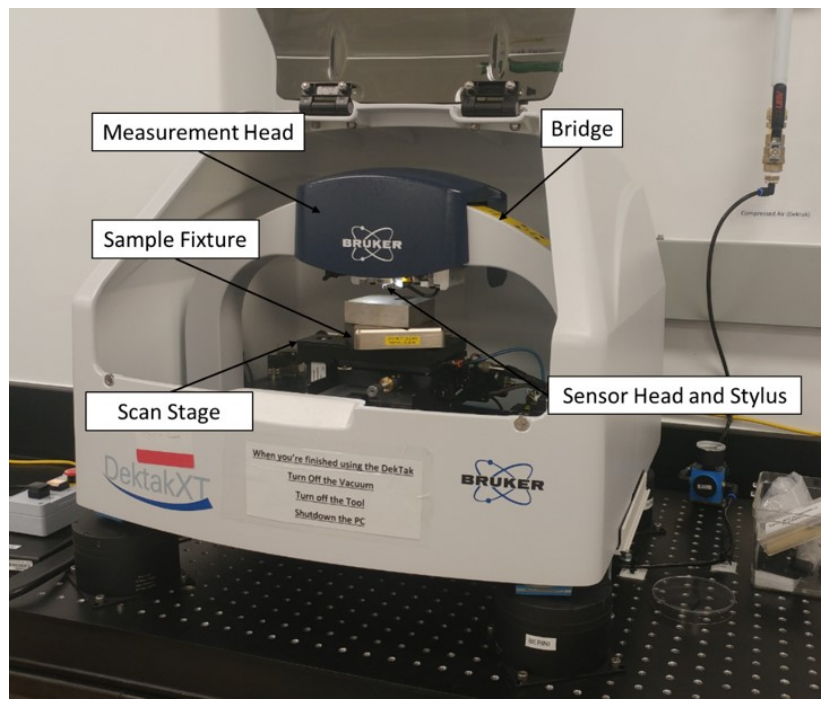

Figure 3.5: Dektak XT stylus profilometer.

\subsubsection{Parameters Selected for Stylus Profilometer}

The user programmed parameters used to measure the average surface roughness of the coupons are as follows: the scan area was set to $10 \mathrm{~mm}$ by $10 \mathrm{~mm}$, the scan speed was 
$500 \mu \mathrm{m} / \mathrm{s}$, the stylus force was $3 \mathrm{mg}$, the stylus tip radius was $2 \mu \mathrm{m}$, and the roughness value measurement range was $+/-524 \mu \mathrm{m}$. A scan area of $10 \mathrm{~mm}$ by $10 \mathrm{~mm}$ was selected to accurately represent the coupon surface roughness as the roughness profiles are uniform, and the dollies are $10 \mathrm{~mm}$ in diameter. It would be impractical to scan the entire coupon surface because of the uniform roughness profiles and one scan would take weeks to complete. Also, the values selected for the scan speed, stylus force, and measured roughness value range were set based on surface feature size and scan resolution. The average scan time for one sample was 3 hours and the distance between each stylus pass was $1.7 \mu \mathrm{m}$. Also, a leveling function in the Vision64 software was used to level the sample data.

\subsection{A380 Heat Treatment Procedure}

T4 and T6 heat treatments were conducted on a couple of the A380 samples under atmospheric conditions using the furnace presented in Figure 3.6. The purpose of the heat treatment was to potentially improve the surface activation produced by the pulsed waterjet process. If the ductility or hardness of the substrate material changed the surface profile produced by the pulsed waterjet process may also change and adhesion between the coating and substrate might improve. 


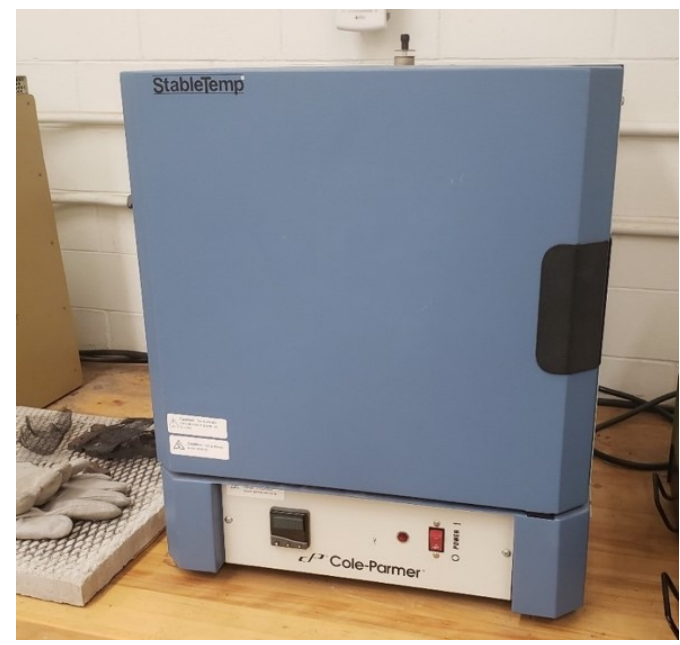

Figure 3.6: Furnace used for T4 and T6 heat treatment of A380 samples.

\subsubsection{Cast Aluminum T4 Heat Treatment Process}

The T4 heat treatment process for A380 is intended to increase the ductility of the sample which will result in an improved ability to plastically deform. The plastic deformation occurs during the pulsed waterjet process as high pressure water deforms the substrate surface. The T4 heat treatment process consisted of heating the furnace to $490^{\circ} \mathrm{C}$ and then placing the sample in the furnace for 15 minutes. After 15 minutes, the sample was removed and quickly quenched in cold water. Following this, the sample was naturally aged for 14 days at $25^{\circ} \mathrm{C}$.

\subsubsection{Cast Aluminum T6 Heat Treatment Process}

T6 heat treatment process for A380 is intended to increase the hardness of the sample which will result in decreased plastic deformation during the pulsed waterjet process. Cast aluminum is a softer material and because of the violent pulsed waterjet process, the material may experience major surface deformation. Increasing the materials hardness may decrease surface deformation and improve the homogeneity of the roughened 
surface. The T6 heat treatment process consisted of heating the furnace to $490^{\circ} \mathrm{C}$ and then placing the sample in the furnace for 15 minutes. After 15 minutes, the sample was removed and quickly quenched in cold water. Following this, the sample was artificially aged for 24 hours at $150^{\circ} \mathrm{C}$ and finally water quenched.

\subsection{Hardness Tests}

The ASTM standard E92-17 of test methods for Vickers hardness and Knoop hardness of metallic materials was used to determine the subsurface Vickers hardness of the A380 and GCI samples post pulsed waterjet. The purpose of this test was to determine if the samples subsurface hardness changed as a result of pulsed waterjet induced roughening. Features in the subsurface which may impact its hardness are cracks and plastic deformation. The Vickers hardness tester used was a Clemex shown in Figure 3.7. The device used a diamond indenter with an indentation force of $200 \mathrm{~g}$ and a dwell time of 10 seconds. For each pulsed waterjet roughened sample five indents were made at each subsurface depth. A total of five depth measurements were used. The indentations were measured using a 400x optical microscope. While performing the tests the distance between each indentation was at least three times the diameter of the previous indentation to avoid strain hardened areas which would have greater hardness values. 


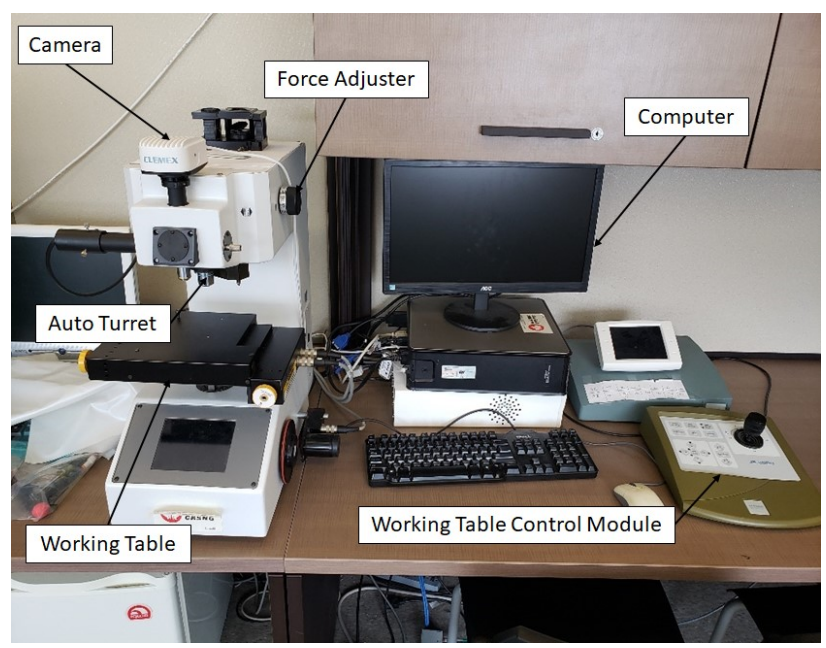

Figure 3.7: Image of the Clemex Vickers hardness tester.

\subsection{Plasma Transferred Wire Arc Coating Procedure}

A Sulzer Metco System machine was used for the PTWA coating on the roughened surfaces. The feedstock material used for the PTWA spray coating process was a high chrome low carbon stainless steel (SS 420) wire with a composition of C $0.25, \mathrm{Cr} 13, \mathrm{Si}$ 0.5, and Ni 0.5 (wt.\%), which is commonly used in applications such as cylinder liners, pistons, valve stems, pump plungers, and crankshaft bearings [61]. The plasma spray coating process developed by Metalmorphosis for this project was as follows: the standoff distance of the plasma spray nozzle during coating was $150 \mathrm{~mm}$ and was applied in $12-15$ passes to obtain a final coating thickness was $0.6 \mathrm{~mm}$.

\subsection{Pull-off Adhesion Strength Measurements}

The adhesion strength between the thermal spray coating and substrates was determined to be the force needed for the coating to fail in a pull-off adhesion test. An Elcometer 510 Automatic Portable Pull-off Adhesion Gauge machine will be used to determine the bond strength between the substrates and low carbon steel coating according 
to the ASTM standard D4541-17 method for pull-off strength of coatings using a portable adhesion tester. Later, a comparison was made between the adhesion strength and roughness values for the two substrates. The target bond strength is between $45-55 \mathrm{MPa}$ but a value above $30 \mathrm{MPa}$ is acceptable [4]. Three pull-off tests were conducted on a single substrate to show bond strength repeatability.

\subsubsection{Pull-off Adhesion Strength Procedure}

During testing $10 \mathrm{~mm}$ dollies were evenly distributed and adhered to the thermal spray coating of each test coupon. The dollies were glued to the thermal spray coated surface using the FM-1000 glue. The FM-1000 when tested resulted in an adhesive and cohesive based failure between the coating and substrate. Therefore, based on these results the FM 1000 was selected as the glue used for the pull off strength testing between the coating and substrates.

The adhesion strength for each coupon was determined by taking the average of the three pull-off tests. The surface of the dollies was roughened for maximum mechanical bonding of the adhesive. Roughening was performed using 240 Grit sandpaper. The tensile load during the pull-off test was applied at a constant speed of $2.80 \mathrm{MPa} / \mathrm{s}$. A schematic

illustrating the dolly adhesion test setup for portable pull-off testing is presented in Figure 3.8 . 

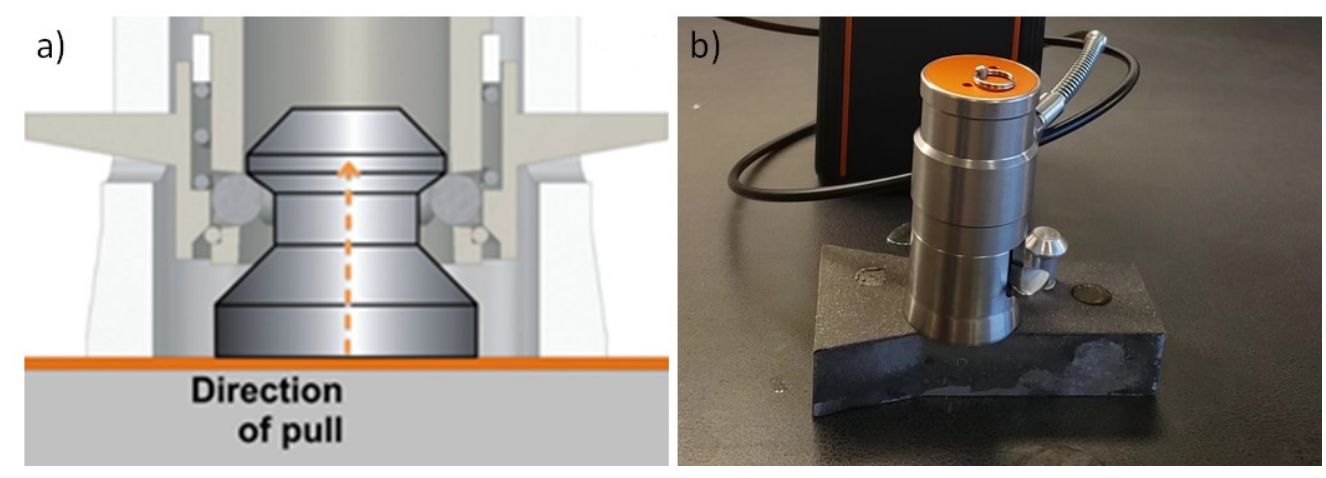

Figure 3.8: Images of a) Dolly adhesion test setup and b) Pull Tester Set On Sample.

Additionally, the cure cycle used for the FM-1000 adhesive during bond strength pull off testing was as follows:

\section{Mounting procedure of FM-1000 on samples}

1. Remove the FM-1000 glue from refrigerator and put in an oven at $160-180^{\circ} \mathrm{F}(70$ $80^{\circ} \mathrm{C}$ ) for $45 \mathrm{~min}$ to $1 \mathrm{~h}$. This will ensure there is no humidity in the glue.

2. Preheat secondary oven to $190^{\circ} \mathrm{C}$.

3. Sand the faces of the dolly with 240 grit paper without applying pressure in a slow Figure-eight shape. Clean the face with compress air to remove all dust and residue. The goal of this step is to maximize the surface area for mechanical interlocking. Do not touch the surface with fingers.

4. Carefully place disk of glue on the sample.

5. Put the opposite dolly gently on the FM-1000 glue.

6. Ensure that the dolly is aligned perfectly on the glue.

7. Use a clamp to apply $20 \mathrm{~N}$ of force to tighten the fixture.

8. Place the fixture in the oven for at least 2 hours at $190^{\circ} \mathrm{C}$.

9. After 2 hours of curing, turn oven off and let it cold down while keeping the door closed. 
10. When the fixtures are cool, remove the samples from the oven. The glue should have changed to yellow. Disassemble the sample from the fixture without imposing forces on the samples (take them gently by the two sides and without tension, compression, or shear force).

11. Test the samples.

\subsection{Microstructural Analysis}

The metallography of the substrate material and interlocking interface were analysed using optical microscopy and scanning electron microscopy. An AmScope microscope was used for optical imaging and a Zeiss GeminiSEM was used for scanning electron imaging. A $20 \mathrm{kV}$ voltage was used for SEM imaging and images were taken at a magnification of $250 \mathrm{X}$ and $1000 \mathrm{X}$. These two magnifications were selected to show a general view of interlocking between the surfaces, and a closer more detailed location of anchor. The purpose of analysing the interface between the spray coating and substrates was to determine how interlocking between the two transpired. It also assisted in determining why the pull-off adhesion strength varied with roughness profile and which roughness profiles provided the most favourable interlocking. 


\section{Chapter 4 Results and Discussion}

In this chapter, the results obtained during experimental testing are presented.

\subsection{Stylus Profilometer Surface Roughness Results}

This section will discuss the information obtained about the substrate and surface

profile of the pulsed waterjet roughened A380 and GCI substrates. This information includes thickness changes to the substrate, the measured roughness values, the change in roughness value with pulsed waterjet transverse speed, the microstructural features responsible for producing the roughness profile, and an assessment of the roughness profiles generated on the heat treated A380 samples. The images presented in Figures 4.1 and 4.2 show the roughness profiles produced on the A380 and GCI coupons by the pulsed waterjet. 

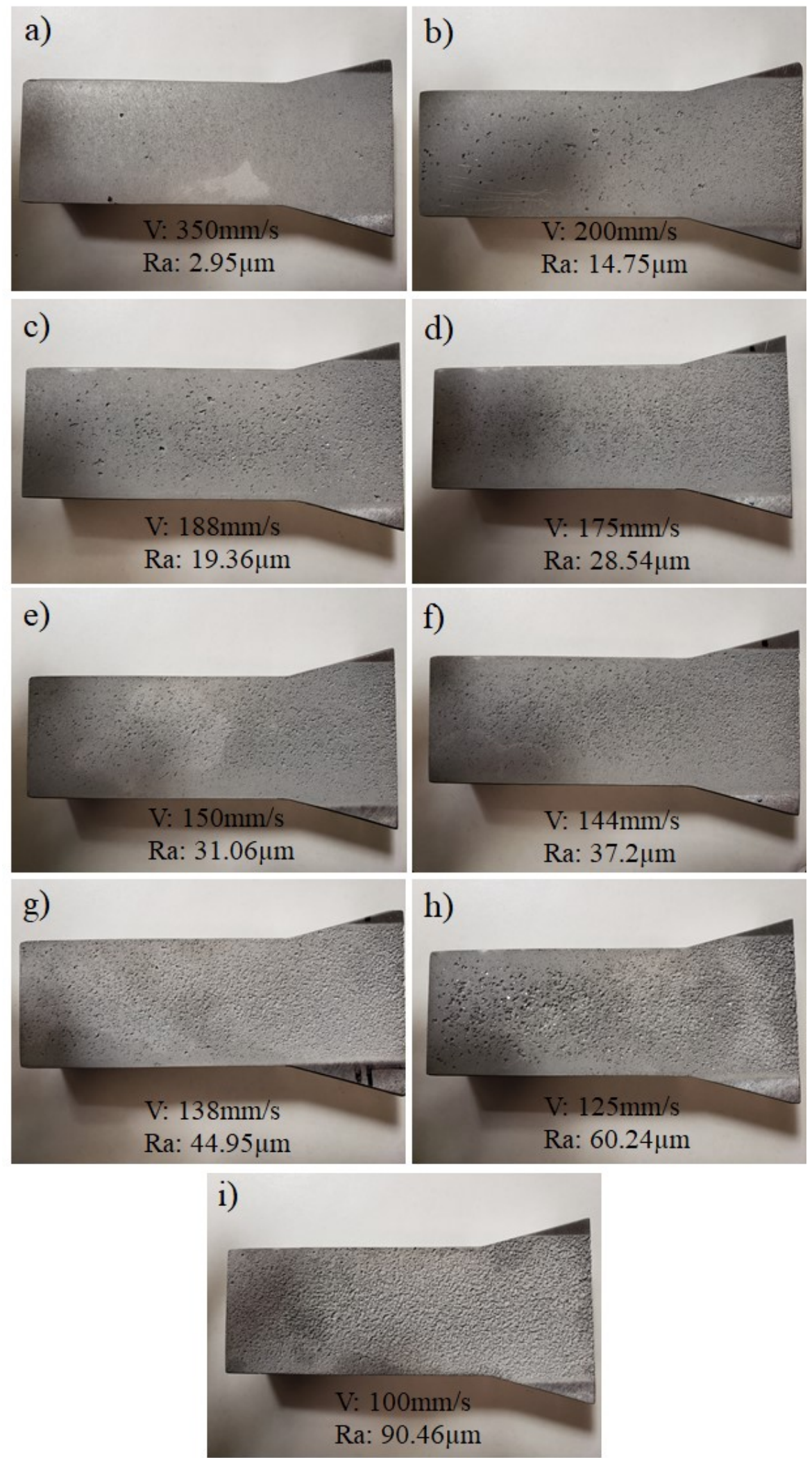

Figure 4.1: Images of pulsed waterjet A380 roughness. The corresponding nozzle speed and average roughness values are presented on each image. 


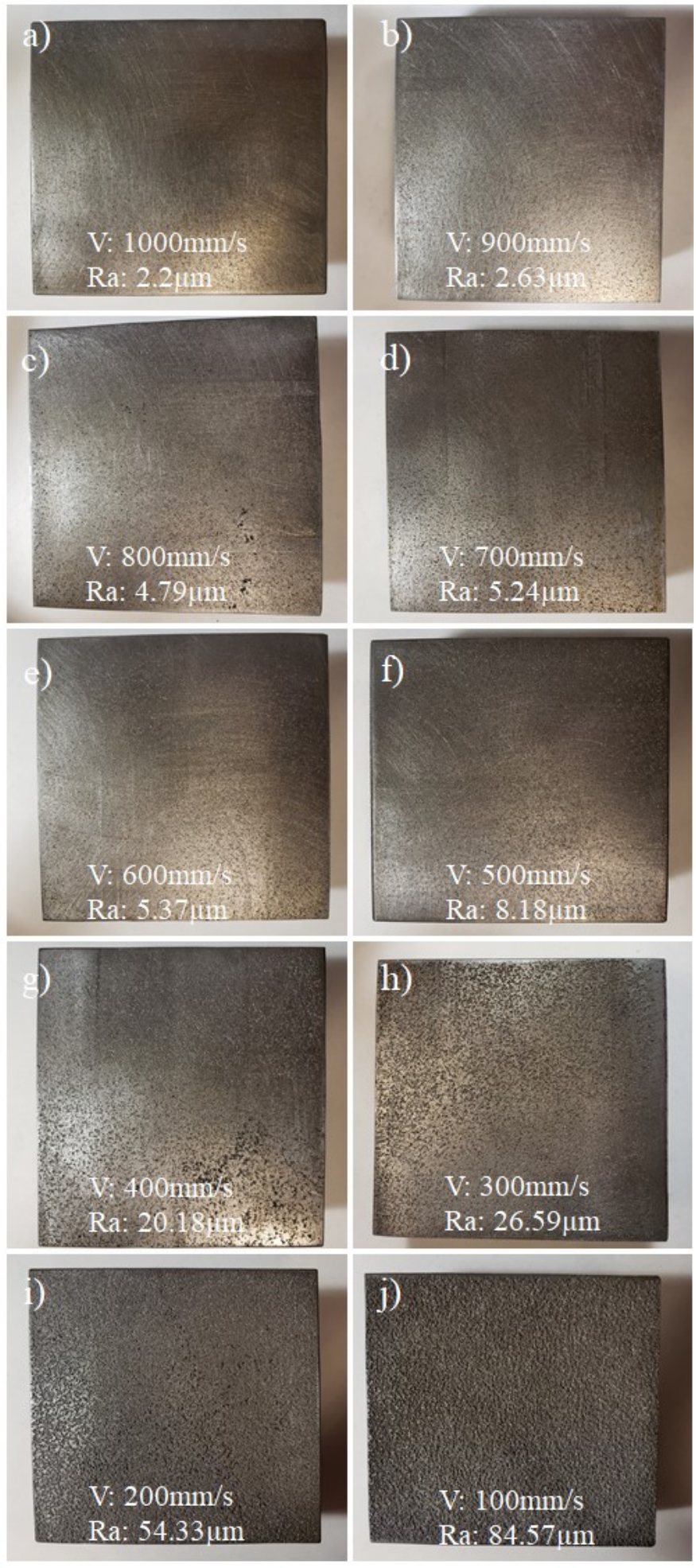

Figure 4.2: Images of pulsed waterjet GCI roughness profiles. The corresponding nozzle speed and average roughness values are presented on each image. 


\subsubsection{Changes in Substrate Thickness}

During the pulsed waterjet roughening process, the surface of the substrate material is deformed and removed. This results in minor dimensional thickness changes of the substrate. In engine cylinder bores and other applications where dimensional constraints are crucial dimensional changes brought on by the pulsed waterjet process may be significant. Therefore, it was important to determine if and how much the thickness of the A380 and GCI substrates changed as a result of the pulsed waterjet roughening process.

The change in substrate thickness of the pulsed waterjet roughened A380 and GCI material was measured for the nozzle transverse speed range. Using the measured thickness values, it was established that pulsed waterjet roughening the A380 or GCI material resulted in material removal and a subsequent decrease in substrate thickness. The decrease in substrate thickness was small ranging between $0 \mu \mathrm{m}-20 \mu \mathrm{m}$ and may be deemed insignificant as the applied coating thickness is $600 \mu \mathrm{m}$ and therefore much greater and capable of rebuilding the substrate. Additionally, it was also concluded that for the roughness profiles generated during this study, the changing nozzle transverse speed had no effect on the change in substrate thickness. The graphs presented in Figures 4.3 and 4.4 show that the substrate thickness decreased as a result of the pulsed waterjet roughening process and that the change in substrate thickness is independent of the transverse speed. 


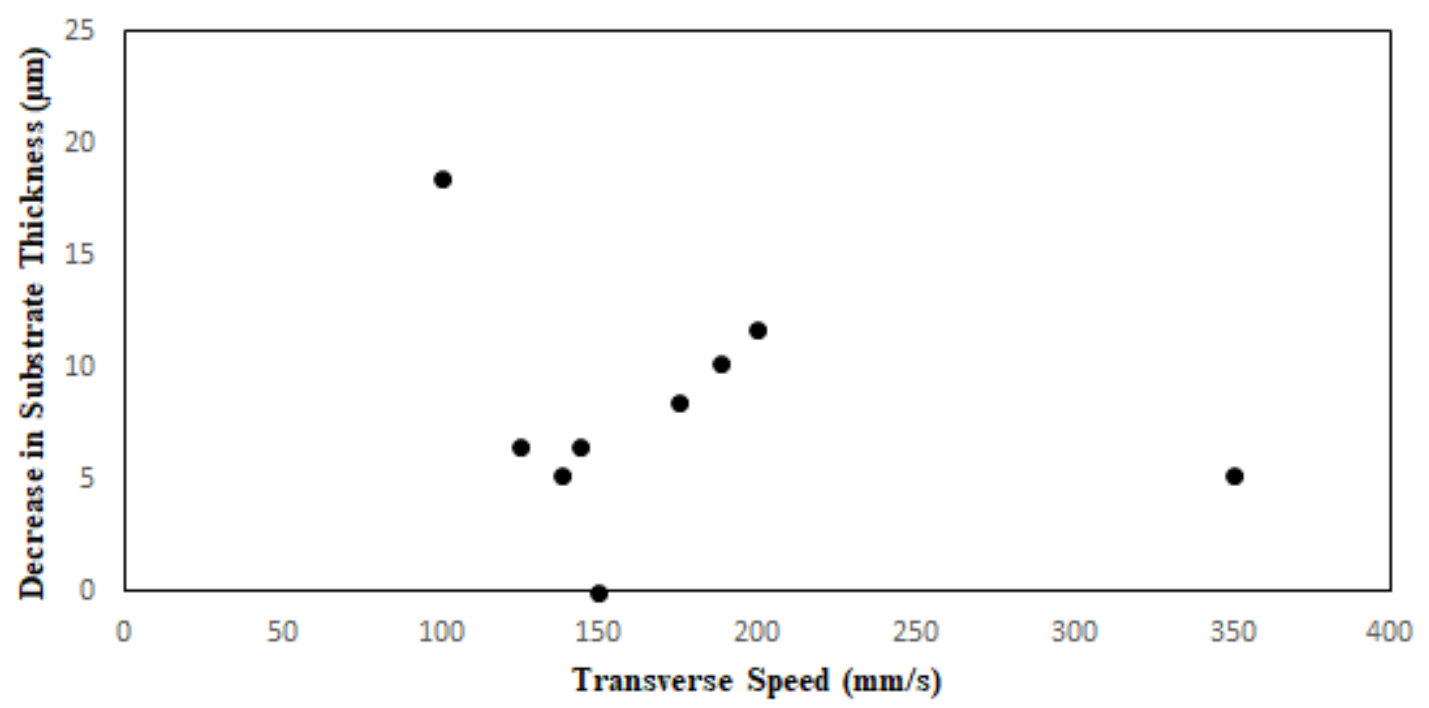

Figure 4.3: Decrease in A380 substrate thickness with nozzle transverse speed for a pulsed waterjet system with a constant pressure of $34.5 \mathrm{MPa}$ and a constant standoff distance of $31.75 \mathrm{~mm}$.

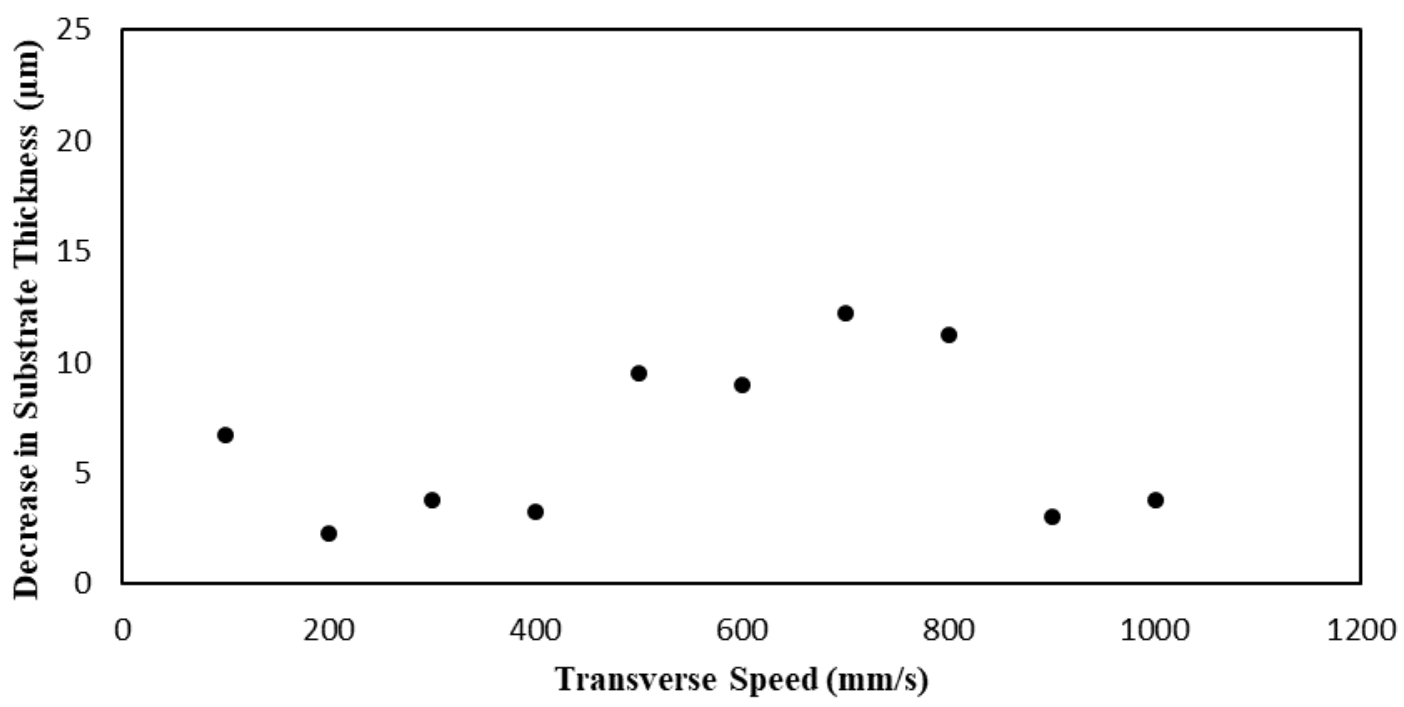

Figure 4.4: Decrease in GCI substrate thickness with nozzle transverse speed for a pulsed waterjet system with a constant pressure of $34.5 \mathrm{MPa}$ and a constant standoff distance of $25.4 \mathrm{~mm}$. 


\subsubsection{Measured Roughness Profiles}

Three-dimensional area scans were taken of the roughened surfaces using the Dektak profilometer. These scans allowed for the determination and evaluation of features on the roughened surface such as pit size and distribution, and the average roughness value. The parameters used to conduct the scans on the cast aluminum and GCI substrates are those discusses in 3.4.2. The images that follow are the three-dimensional surface profile scans of the roughened substrates and are used to define the optimal adhesion strength of the spray coating.

The scans of the roughened cast aluminum samples are presented in Figure 4.5. These images show the roughened surface profile, the range of average roughness values, and how the roughness value changed with nozzle transverse speed. 

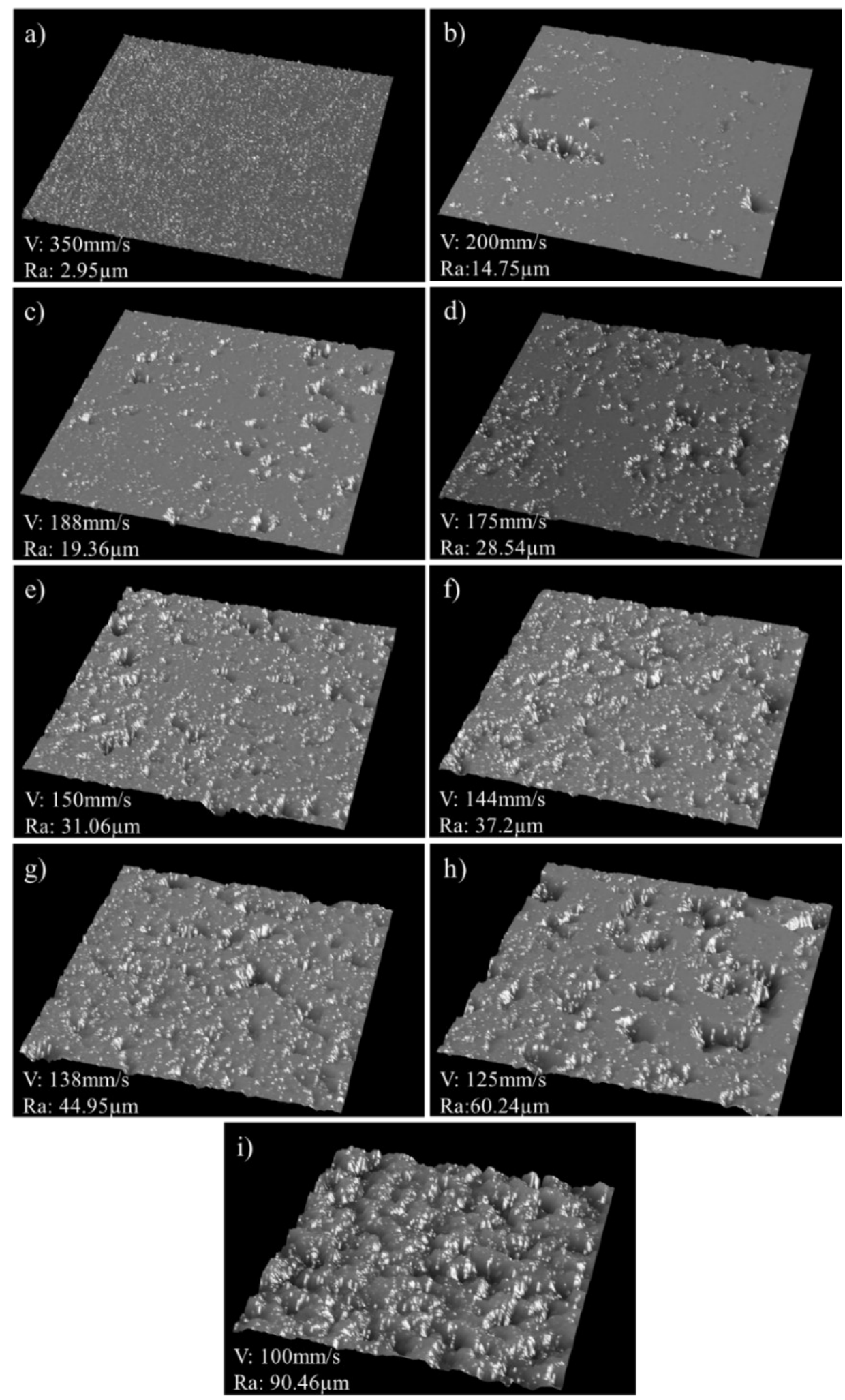

Figure 4.5: Pulsed waterjet A380 roughness profiles for a $10 \mathrm{~mm}$ by $10 \mathrm{~mm}$ area. The corresponding nozzle speed and average roughness values $\left(R_{a}\right)$ are presented on each image. 
In the case of A380, the pulsed waterjet process formed pits on the substrate surface through plastic deformation, crack coalescing, and erosion. The average roughness value $\left(\mathrm{R}_{\mathrm{a}}\right)$ of the pulsed waterjet surface increased as the pit depth and density increased. The pits are blunt in shape and isolated from each other. The nozzle transverse speed was varied to alter the amount of plastic deformation and erosion on the surface. As the transverse speed of the pulsed waterjet nozzle decreased the dwell time of the pulsed waterjet stream on the target area increased. The increased dwell time resulted in more high-pressure water hammer pulses bombarding the target area which in turn caused an increased amount of plastic deformation and erosion on the surface. Thus, the increased plastic deformation and erosion resulted in an increased average roughness of the surface. Additionally, the longer dwell time also increased the stresses produced by the radial flow of water in the pits. The produced radial flow stresses further increased the amount of plastic deformation and erosion. Finally, it is important to note that the distribution of the pits was random due to the randomness associated with developed water hammer head in the pulsed waterjet, and the randomness of the phases and other microstructural features in the material.

Three-dimensional area scans were also taken for the roughened GCI samples. The images of the scans are presented in Figure 4.6. These images show the change in surface profile and average surface roughness as the nozzle transverse speed was varied. 

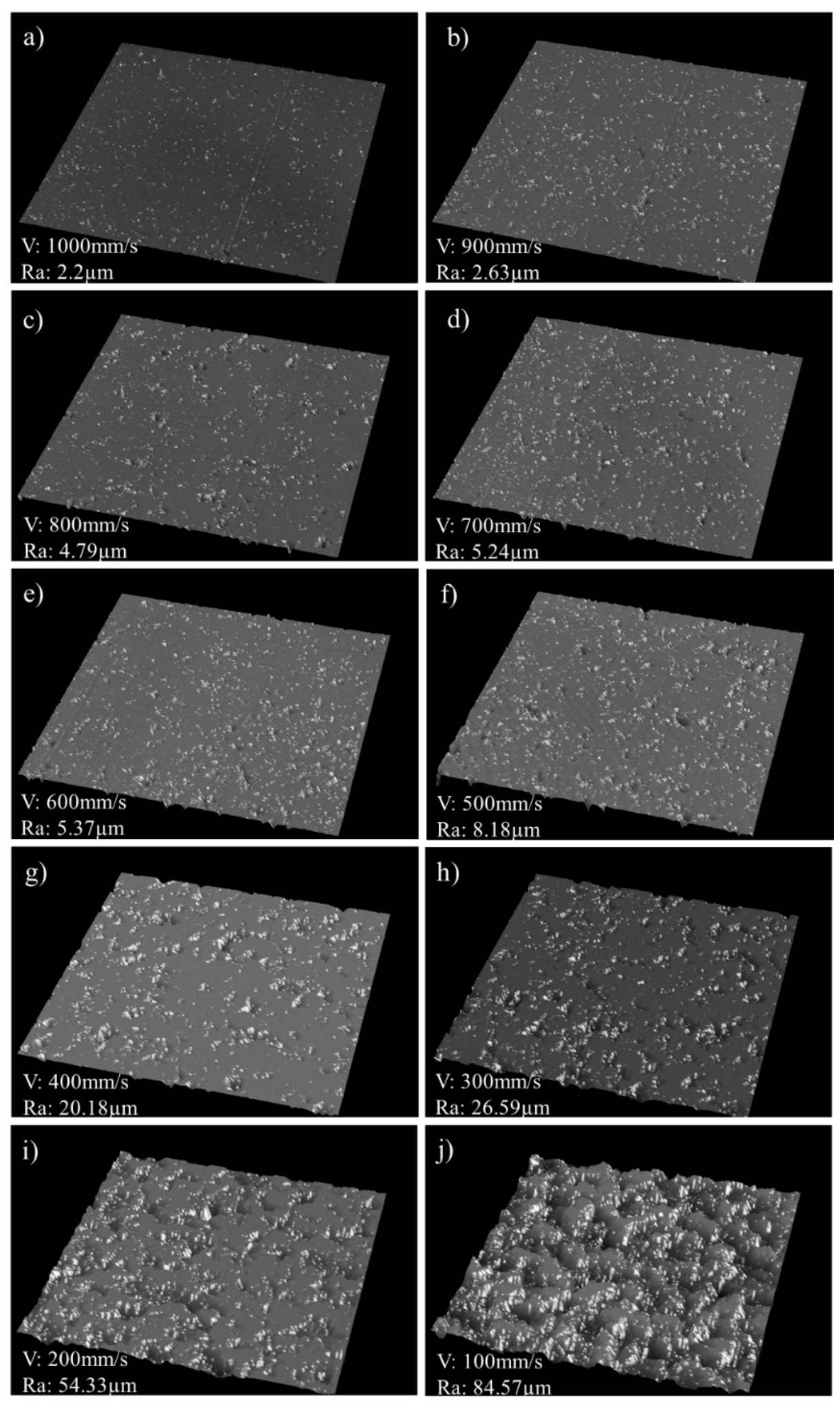

Figure 4.6: Pulsed waterjet GCI roughness profiles for a $10 \mathrm{~mm}$ by $10 \mathrm{~mm}$ area. The corresponding nozzle speed and average roughness values are presented on each image. 
Similar to the pulsed waterjet roughened aluminum substrates the roughened GCI substrates experienced an increase in average roughness value as pit depth and density increased. However, these pits did not develop due to plastic deformation, but by the formation and growth of cracks in the brittle GCI graphite flakes (next section). The cracks in the graphite flakes continued to grow until they coalesced with the cracks in the neighbouring graphite flakes. Crack coalescing caused the removal of material from the GCI substrate surface which resulted in the formation of pits. This idea is supported by the grey colouration of the substrate surface after the pulsed waterjet roughening process. This grey surface colouration is formed by fracture along and exposure of the graphite flakes. The nozzle transverse speed was altered to determine the extent of surface roughening due to crack coalescing between graphite flakes. As the nozzle transverse speed decreased the dwell time, crack density, and crack length increased. Thus, the amount of material removal by crack coalescing increased. Further, unlike the isolated pits formed on the A380 roughened surface the pits formed on the GCI surface were linked. This aligns with the idea that the pits formed due to crack coalescing between the graphite flakes. Lastly, it should be mentioned that like the $\mathrm{A} 380$ substrate the pit distribution in the GCI was random. This randomness was due to the unpredictability of the developed water hammer head in the pulsed waterjet, as well as, the randomness associated with the distribution of the graphite flakes in the GCI substrate.

The A380 and GCI microstructure and mechanisms of surface roughening for pit formation are further explored in section 4.1.4. 


\subsubsection{Change in Roughness with Transverse Speed}

The change in surface roughness of the A380 and GCI substrates was graphed in relation to the varied nozzle transverse speed. These graphs are presented in Figures 4.7 and 4.8. The trends in the graphs reveal an inverse relationship between the surface roughness and the nozzle transverse speed. As the transverse speed decreased the substrate surface average roughness value increased. This was due to longer dwell times which allowed for an increased number of high pressure waterjet pulses to impact an area. The values of the average surface roughness ranged from $2.95 \mu \mathrm{m}$ to $90.46 \mu \mathrm{m}$ for the A380 and $2.2 \mu \mathrm{m}$ to $84.57 \mu \mathrm{m}$ for GCI. The standard deviations on the graphs were provided by the Bruker Dektak XT profilometer and are calculated using data points gathered during the three-dimensional scan. Each of the substrates roughened and plotted on these graphs was subjected to plasma spray coating to determine the optimal roughness for adhesion strength.

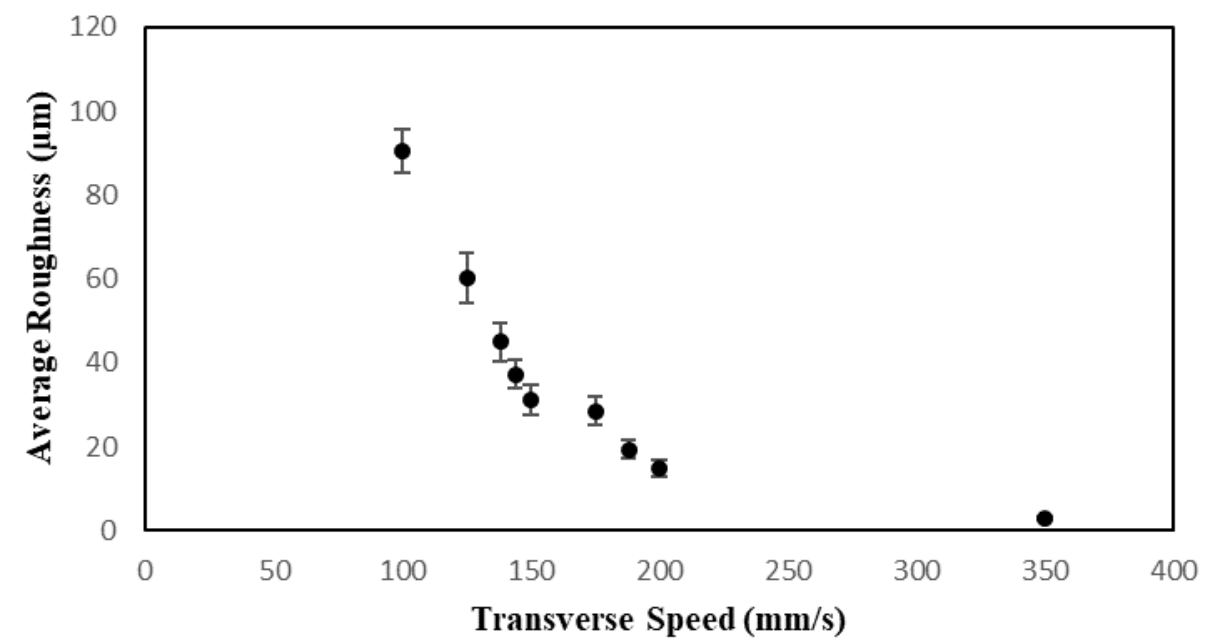

Figure 4.7: The effects of nozzle transverse speed on surface roughness of A380. 


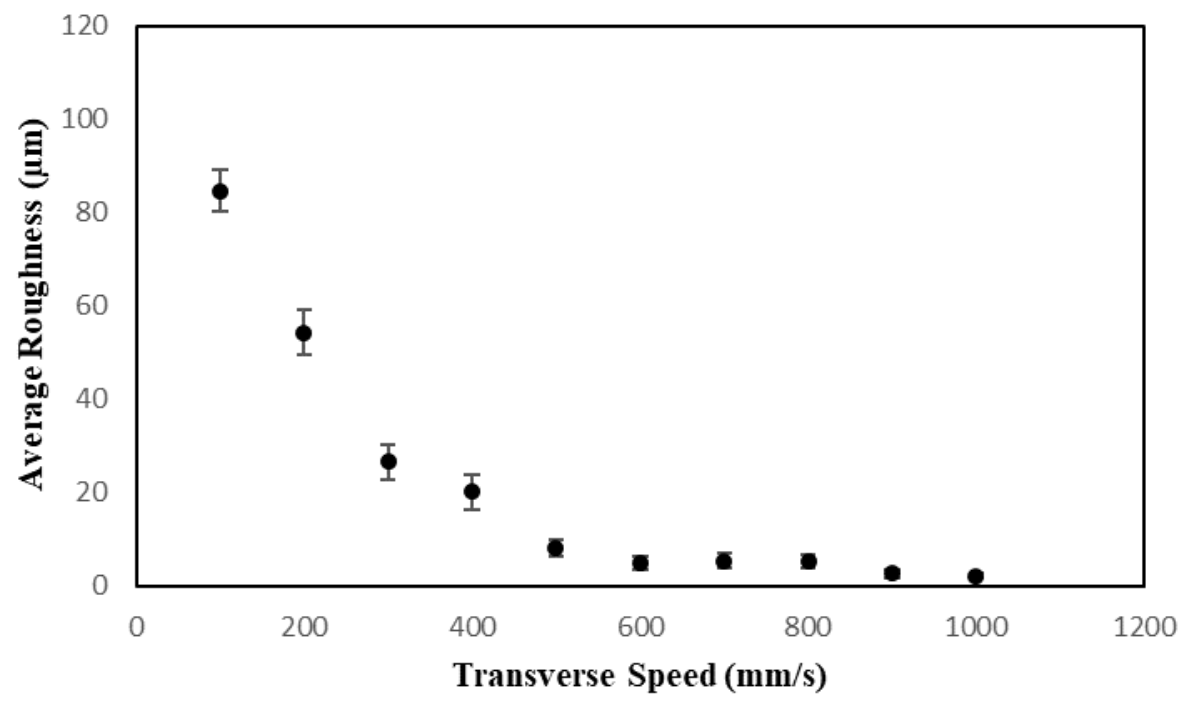

Figure 4.8: The effects of nozzle transverse speed on surface roughness of GCI.

\subsubsection{Microstructural Features Responsible for Roughness Profiles}

The SEM was used to determine the microstructure features responsible for producing the observed surface profiles. Comparing these features with other waterjet deformed samples presented in the literature it was possible to determine what characteristics were responsible for producing the roughened surface finishes.

Figure 4.9 shows the SEM microstructure of the A380 base material. The surface profile which formed during pulsed waterjet of the A380 is a result of the energy transferred from the pulsed waterjet stream to the substrate surface. The pulsed waterjet effectively caused pits to form on the aluminum substrate surface through plastic deformation, crack formation, and growth which resulted in material detachment, and erosion. 


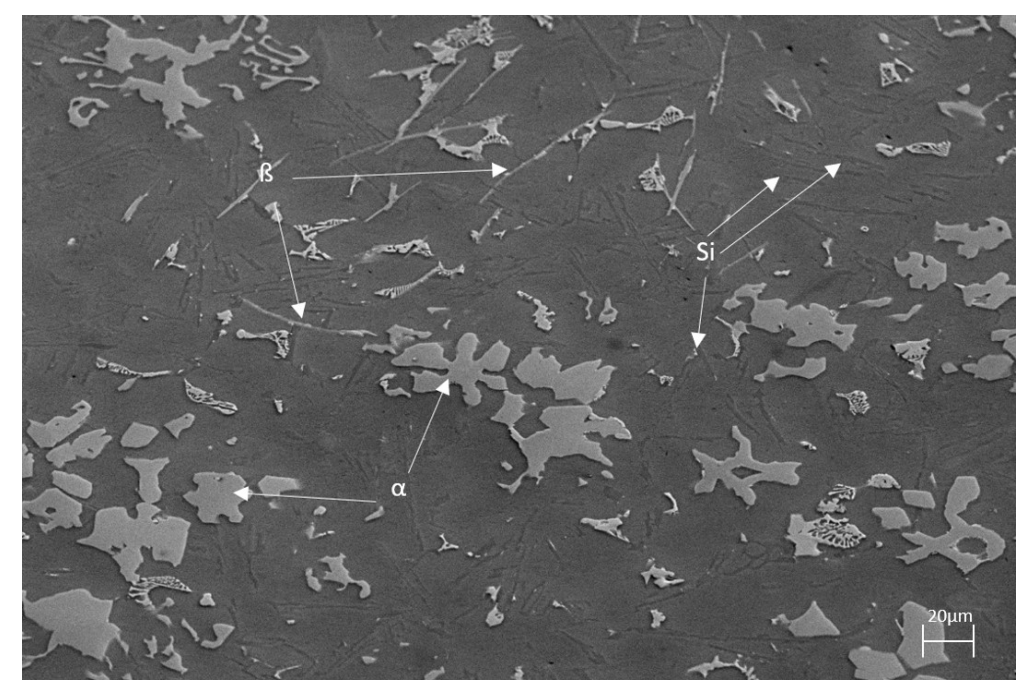

Figure 4.9: SEM image of the A380 surface.

It was believed that the pits may have formed due to pores in the microstructure but based on the image in Figure 4.10 the pores are too small of a feature to affect the surface profile. These features were determined to be pores by EDX analysis. The EDX analysis was used to conduct a point scans on these spots and concluded that they have the same composition as the matrix material. The deformation of the roughened surface occurred because of the ductility of the A380 material, crack coalescing, and erosion.

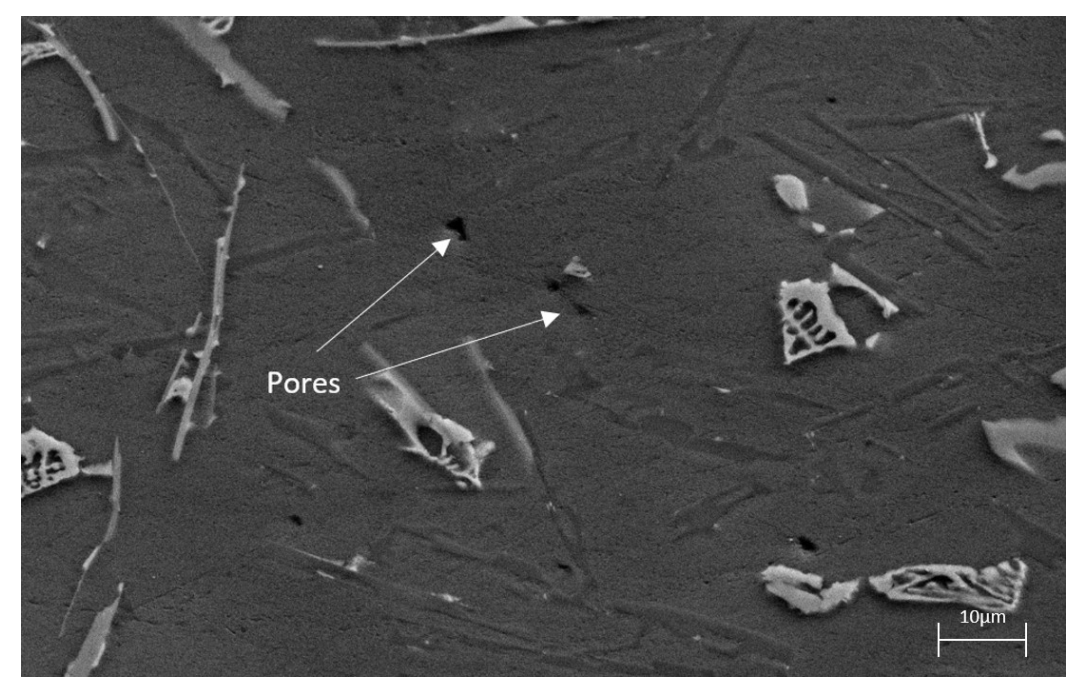

Figure 4.10: SEM image of pores in the A380 material. 
In the case of the GCI microstructure, the pits in the roughened surface are a result of cracks forming, growing, and coalescing in the graphite flakes. GCI is a brittle material and it is known that load induced fracture occurs by crack formation and propagation in the graphite flakes. Therefore, it makes sense that when the pulsed waterjet applied stress on the GCI surface it fractured in a similar manner. Figure 4.11 shows the graphite flake dispersion in the GCI.

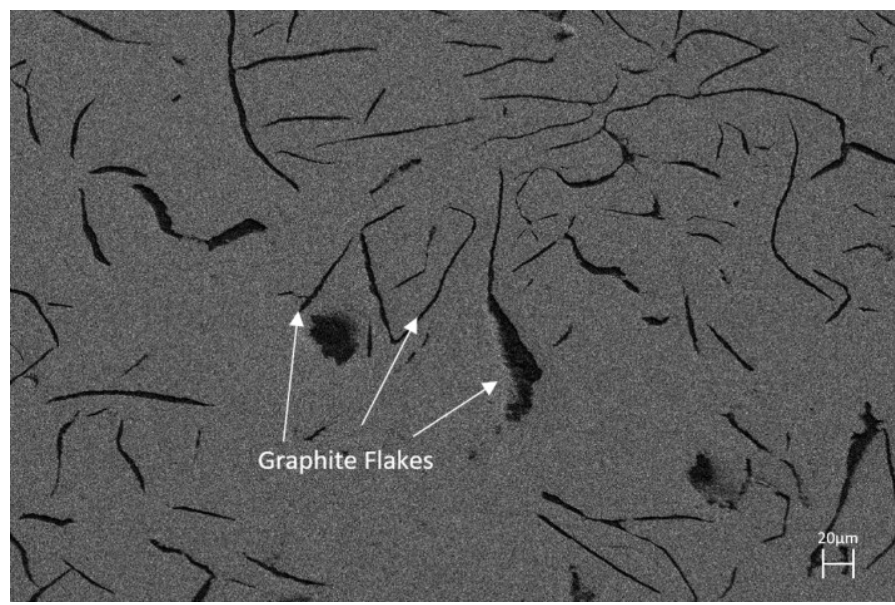

Figure 4.11: SE image of GCI showing the dispersion of graphite flakes normal and perpendicular to the surface.

Similar to the A380, the GCI sample pores were believed to play a role in the formation of the GCI roughened surface. However, EDX analysis assisted in determining the pores were too small of a feature to play a role in pulsed waterjet surface roughening. The pore size in the GCI is presented in Figure 4.12. 


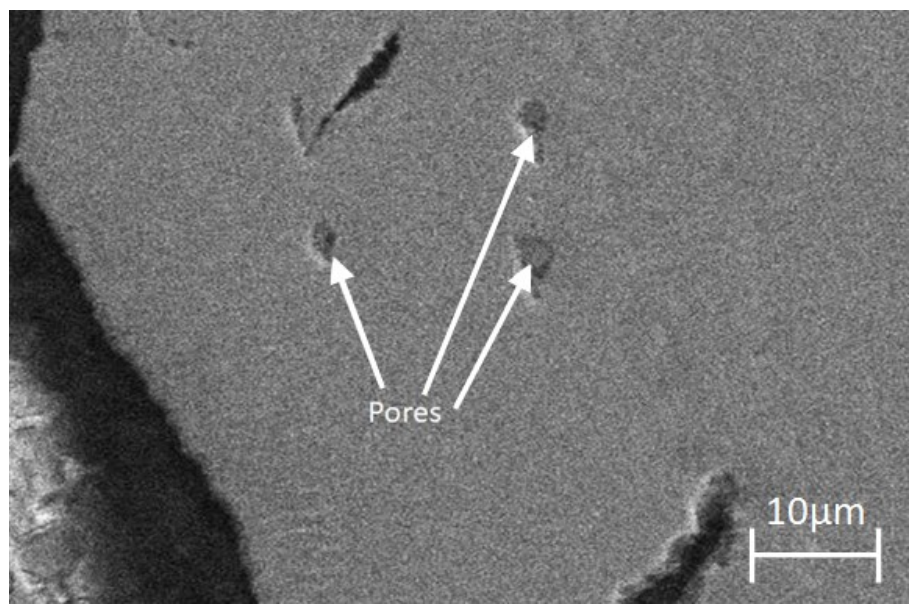

Figure 4.12: SE image of pores in the GCI material.

The A380 and GCI substrate materials both experienced a roughened surface profile when subjected to the pulsed waterjet process. However, the mechanisms in which the roughness profiles formed for the two were different. The A380 profile formed because of plastic deformation, crack coalescing, and erosion while the GCI resulted from mainly material removal through crack coalescing. These two different surface roughening mechanisms of the cast materials can be attributed to their mechanical properties outlined in section 3.1.1 table 2, with the Young's modulus and hardness values being the key difference between them.

\subsubsection{Assessment Heat Treated A380 Roughness Profiles}

A380 samples that underwent the T4 and T6 heat treatments outlined in section 3.5 were also pulsed waterjet. The parameters selected to pulsed waterjet the two heat treated samples were those which produced a favourable roughness profile and bond strength for the as-cast tested samples. The parameters used were a standoff distance of $31.75 \mathrm{~mm}$, a transverse speed of $150 \mathrm{~mm} / \mathrm{s}$, and an operating pressure of $34.5 \mathrm{MPa}$. These parameters produced an average surface roughness of $31.06 \mu \mathrm{m}$ for the as-cast sample. A comparison 
between the roughness values measured for the heat treated and as-cast samples were made to determine if the heat treatment process affected the average roughness values.

Three-dimensional area scans were developed for the roughened surfaces of the T4 and T6 heat treated samples. The characteristics of the surface profile and measured roughness values for the two samples are as follows: the T4 sample had sizeable isolated pit features which resulted in an average roughness value of $79.33 \mu \mathrm{m}$, while the T6 heat treated sample had a sizeable continues pit trench which produced an average roughness value of $99.88 \mu \mathrm{m}$. Images of the as-cast and two heat treated roughness profiles are presented in Figure 4.13. If the collected roughness profiles and measured average roughness values are compared to the untreated sample at the same roughening parameters some variations are noticed. Specifically, for both roughened heat-treated samples the surface pit features are larger which resulted in lower pit density. Also, the average roughness of both heat-treated samples is almost 3 times greater than the untreated sample. A potential explanation for the greater average surface roughness of the heat treated samples was outlined and discussed by Lumley et al. [60] in their findings. The reasoning being that heat treating the $\mathrm{A} 380$ samples promotes the expansion of gas trapped in the material which increases pore size. The larger pores near the surface may have been exposed by pulsed waterjet erosion. Further testing is still required to better understand why heat treating the A380 samples resulted in an increased average surface roughness, but that topic is outside the scope of this study. 


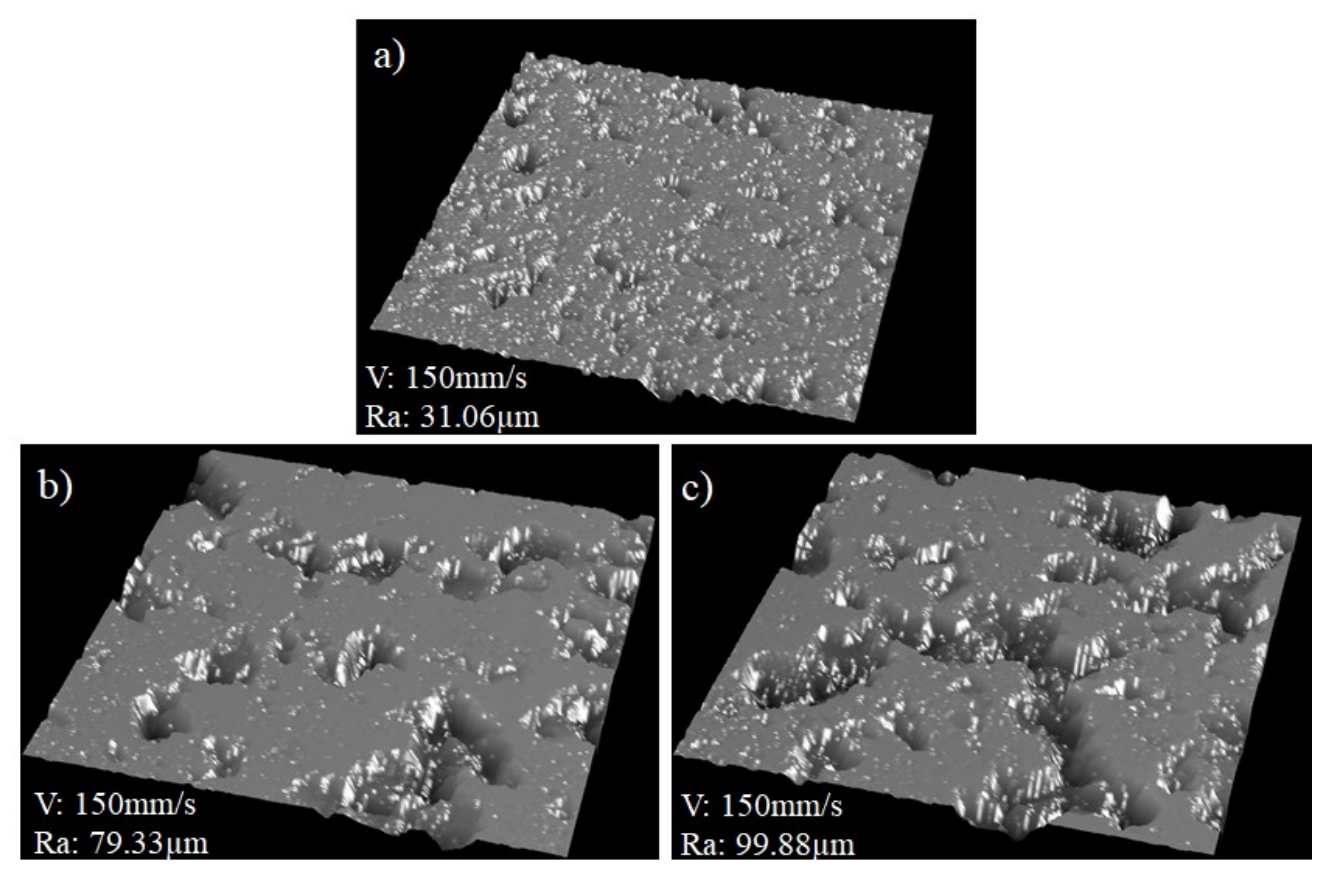

Figure 4.13: Pulsed waterjet as-cast, T4, and T6 A380 roughness profiles for a $10 \mathrm{~mm}$ by $10 \mathrm{~mm}$ area where: a) is the as-cast sample b) is the T4 heat treated sample and c) is the T6 heat treated sample.

An attempt was made to PTWA coat the T4 temper and T6 temper samples but due to the large average surface roughness of the samples the coating produced was very uneven and mirrored the roughness profile of the substrate. Pull testing to determine adhesion strength could not be conducted on these samples as a flat surface is needed for the dolly.

\subsection{Subsurface Hardness Results}

Vickers microhardness measurements were taken at the subsurface of the pulsed waterjet roughened A380 and GCI samples. A total of five hardness measurements were taken at the selected subsurface depth. Plots were generated for the roughened A380 and GCI samples showing the change in hardness as a function of depth below the roughened 
surface. Additionally, comparisons were made between how the surface roughness impacted the subsurface hardness.

\subsubsection{Change in Subsurface Hardness with Depth}

The graphs presented in Figures 4.14 and 4.15 display the change in hardness as a function of depth below the roughened surface for the A380 and GCI samples.

The A380 graph presented in Figure 4.14 depicts the change in hardness with depth. Analysis of the graphed data revealed that for all the A380 samples the initial Vickers hardness measurements taken closest to the roughened surface at a depth of $25 \mu \mathrm{m}$ were the smallest value. This is consistent with the findings of Azhari et al. [32] who stated that the hardness is lower near the roughened surface because of crack formation and propagation. The hardness of the material recovered at a depth of $175 \mu \mathrm{m}$ and below showing a near constant measurement throughout the rest of the sample. Additionally, increasing the surface roughness and deformation produced by compressive stresses generated during the pulsed waterjet process had no benefits of increasing the hardness of the material.

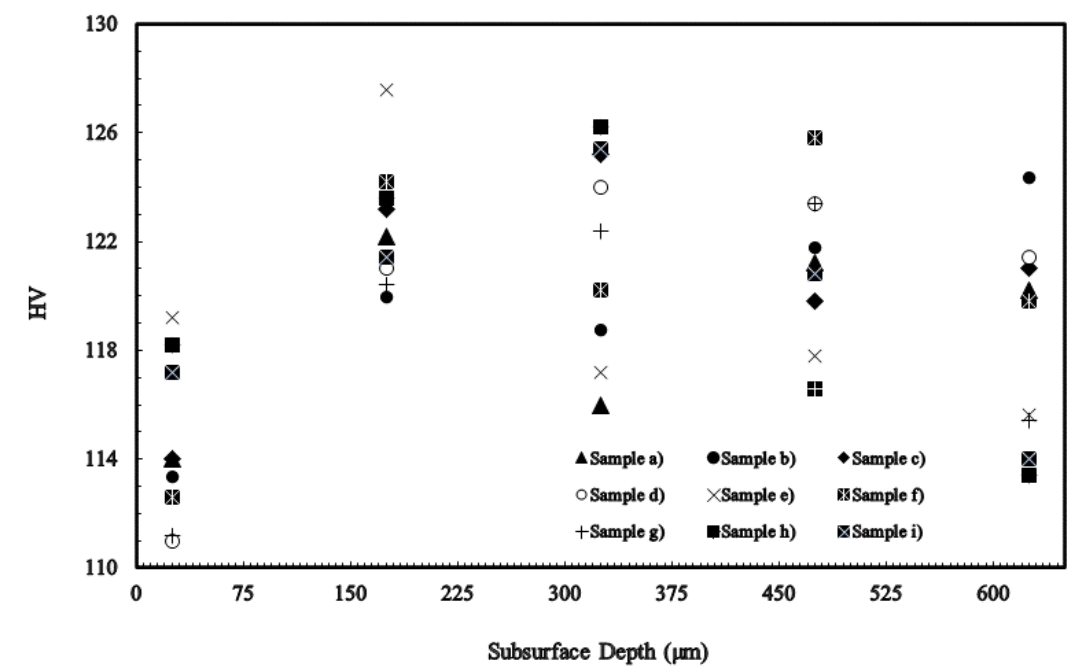

Figure 4.14: Hardness as a function of subsurface depth for pulsed waterjet roughened A380. The sample letter corresponds with the images in Figure 4.1. 
The GCI graph presented in Figure 4.15 also depicts the change in material hardness with depth. Unlike the A380 graph, the pulsed waterjet process does not decrease the material hardness near the surface. This can be explained by the idea that cracks grow and propagate in the graphite flakes and not in the matrix material. The pulsed waterjet appears to have no impact on the hardness of the GCI and the hardness is more dependent on the phase present in the microstructure.

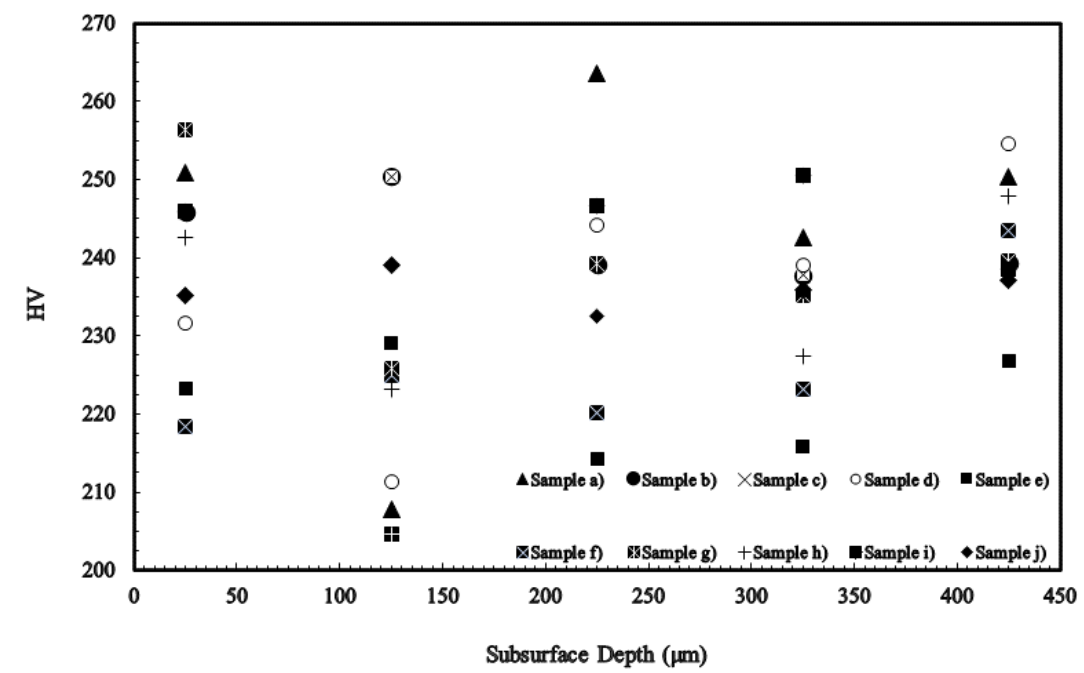

Figure 4.15: Hardness as a function of subsurface depth for pulsed waterjet roughened GCI. The sample letter corresponds with the images in Figure 4.2.

\subsection{Pull-off Adhesion Strength Results}

Adhesion testing was conducted between the SS 420 plasma transferred wire arc coating, and the pulsed waterjet roughened GCI and A380 substrates. The testing was conducted in accordance with ASTM standard D4541-17 using a portable pull-off machine. Images of prepared A380 and GCI samples are presented in Figure 4.16 and follow that of the schematic outlined in Figure 3.8. 

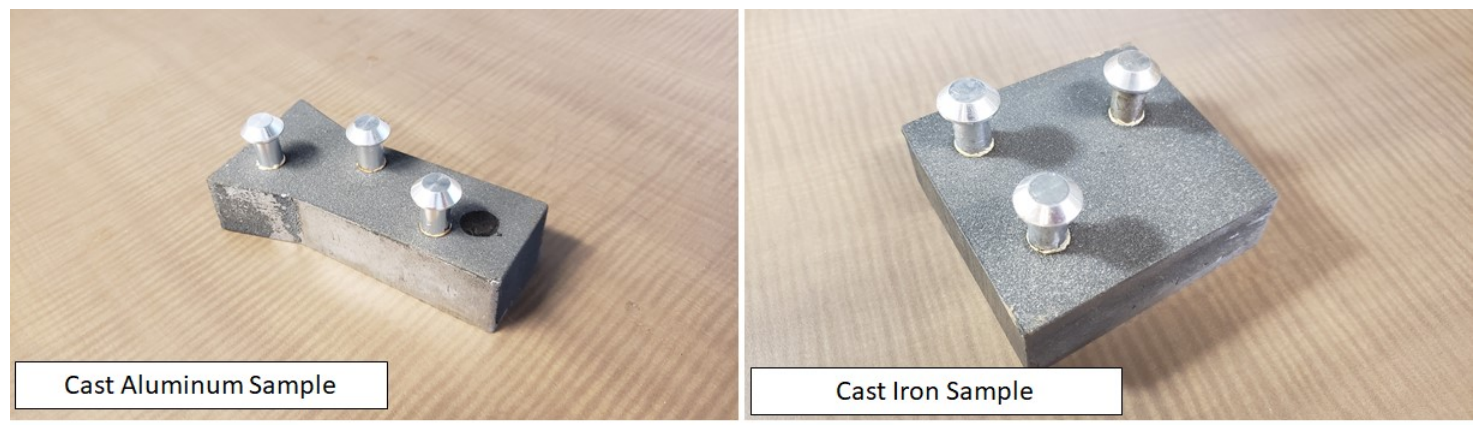

Figure 4.16: Images of A380 and GCI samples prepared for pull-off strength testing.

The adhesion testing of these samples revealed how average surface roughness affected the bond strength between the spray coating and substrate. Additionally, the impact of varied average surface roughness on the failure mechanism of the coating system was also examined. The following sections will discuss the experimental findings.

\subsubsection{Relationship between Substrate Average Surface Roughness and Adhesion}

\section{Strength}

Multiple pull-off tests were taken to ensure consistency in the recorded values are there is uncertainty associated with pulsed waterjet induced surface deformation. The graphical relationship between average surface roughness and coating adhesion strength for the A380 and GCI materials is presented in Figure 4.17 and 4.18. The error bars associated with the pull-off strength are the standard deviation calculated using the numbers recorded for the three pull-off tests conducted on each sample. 


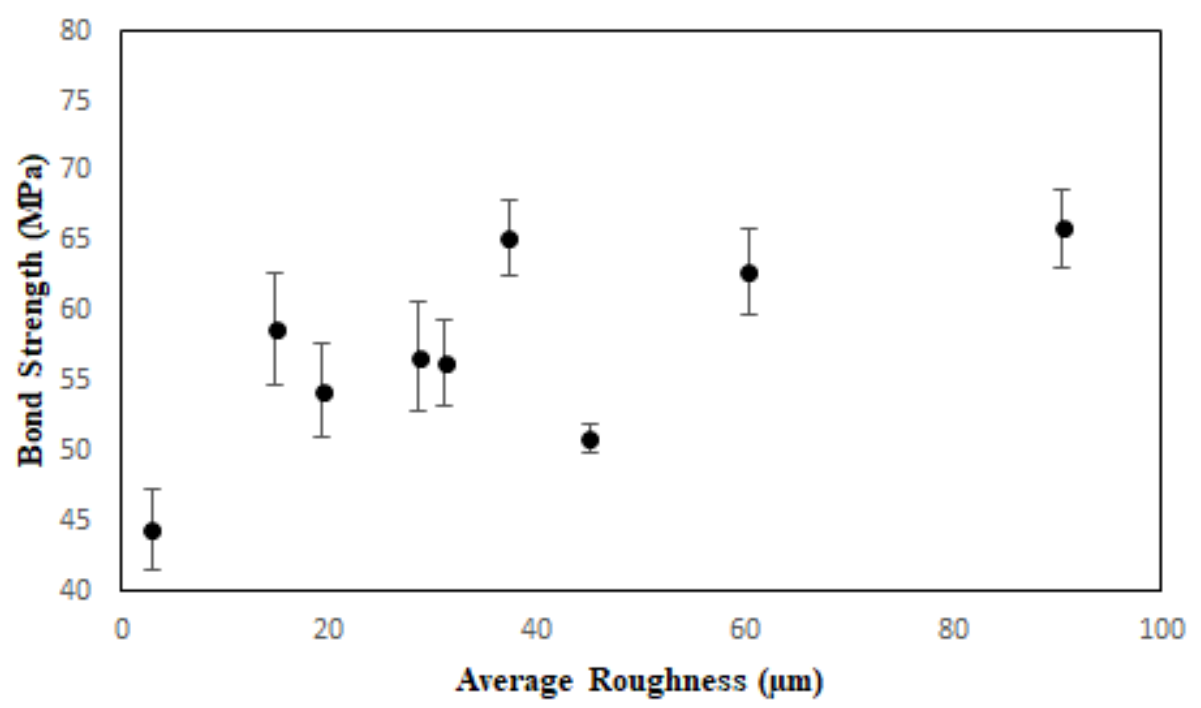

Figure 4.17: The adhesion strength of the SS 420 plasma spray coating on the A380 substrate.

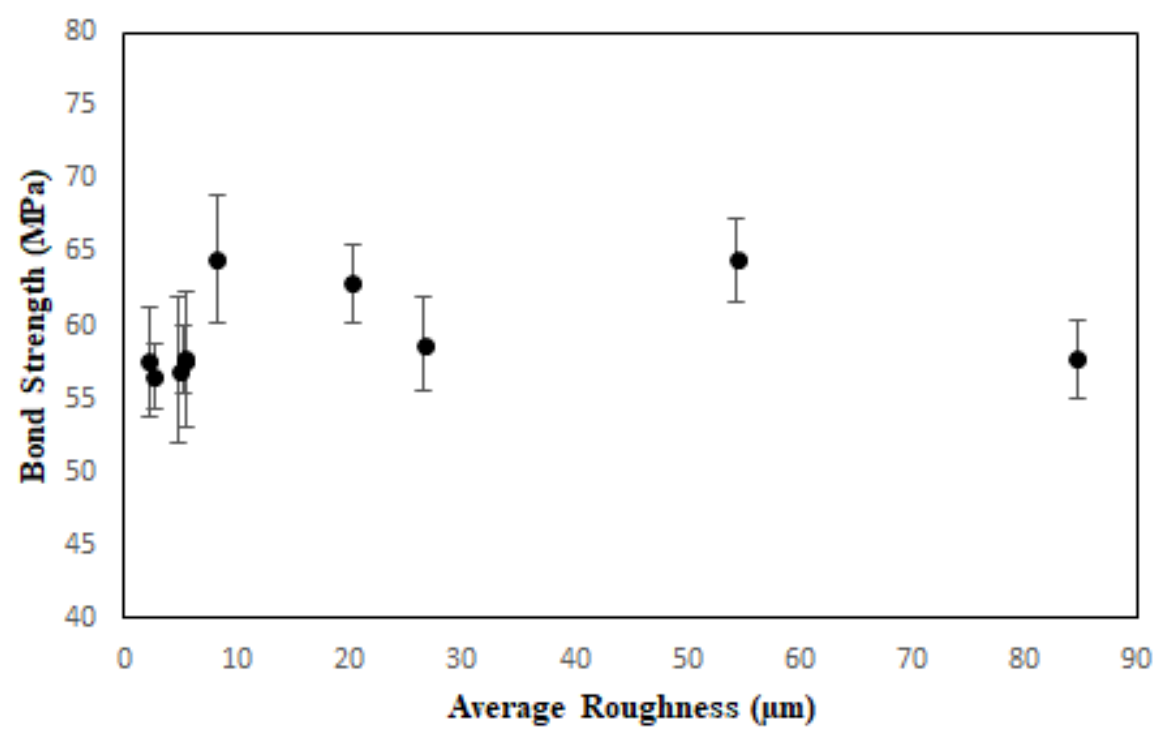

Figure 4.18: The adhesion strength of the SS 420 plasma spray coating on the GCI substrate.

For the case of the A380 plasma spray coated system, the bond strength between the coating and substrate saw a gradual increase with average roughness value. The minimum recorded bond strength occurred for the average roughness value of $2.95 \mu \mathrm{m}$ and was $44.4 \mathrm{MPa}$ while the maximum was at an average surface roughness value of $90.46 \mu \mathrm{m}$ 
and was $65.9 \mathrm{MPa}$. In all the pulsed waterjet A380 samples the coating-substrate adhesion strength met the required bond strength outline by Barbezat et al. of $30 \mathrm{MPa}$ [4]. Therefore, based on bond strength only all the roughened A380 samples have the potential to be applied to the engine cylinder bore liner application. The pulsed waterjet roughened GCI samples also met the $30 \mathrm{MPa}$ requirement for the engine cylinder bore liner application and exhibited a higher bond strength between the coating and substrate than the A380 samples. Examining the graph in Figure 4.18 of the relationship between coating-substrate bond strength and average surface roughness for the GCI samples revealed there was little variation in bond strength as the average surface roughness values changed. The minimum recorded bond strength was $56.83 \mathrm{MPa}$ for the sample with an average roughness value of $2.63 \mu \mathrm{m}$ and the maximum bond strength was $64.6 \mathrm{MPa}$ for the sample with an average surface roughness of $8.18 \mu \mathrm{m}$. Therefore, all samples tested were above the required bond strength needed for the engine cylinder bore liner application.

\subsubsection{Coating System Failure and Surface Profile}

The coating-substrate combinations studied in this work experienced failure characteristics depending on the surface roughness profile. The failure modes for all the pull-off tests are presented in table 4. It was noted that for both substrates, when the average surface roughness value was below $\sim 20 \mu \mathrm{m}$, the adhesion strength test resulted in an adhesive failure of the coating layer. However, above $20 \mu \mathrm{m}$ the failure was no longer a clean coating removal and failure mode was cohesive occurring between the coating splat layers. Images of the complete coating removal and splat layer failure types for the GCI and A380 samples are presented in Figure 4.19. The change in failure mode occurred because as the average roughness of the sample increased the number of favourable anchor 
sites for mechanical interlocking increased. If there are no favourable anchoring sites in an area, then the result is complete coating removal. However, if there are favourable anchoring sites the coating is not completely removed but instead there is splat layer separation of the PTWA coating. Therefore, based on these findings an average surface roughness of $20 \mu \mathrm{m}$ or greater should be considered optimal for adhesion strength between the pulsed waterjet roughened surface and spray coating. This is because if failure does occur, the remaining coating would protect the substrate from the environment.

Table 4: GCI and A380 adhesion strength measurements and failure modes.

\begin{tabular}{ccc|ccc}
\hline \multicolumn{2}{c|}{ GCI Adhesion Results } & \multicolumn{3}{c}{ A380 Adhesion Results } \\
\hline $\begin{array}{c}\text { Average } \\
\text { Roughness } \\
(\boldsymbol{\mu m})\end{array}$ & $\begin{array}{c}\text { Pull-off } \\
\text { Adhesion } \\
\text { Strength }(\mathbf{M P a})\end{array}$ & $\begin{array}{c}\text { Failure } \\
\text { Mode }\end{array}$ & $\begin{array}{c}\text { Average } \\
\text { Roughness } \\
(\boldsymbol{\mu m})\end{array}$ & $\begin{array}{c}\text { Pull-off Adhesion } \\
\text { Strength (MPa) }\end{array}$ & $\begin{array}{c}\text { Failure } \\
\text { Mode }\end{array}$ \\
\hline 2.2 & 53.25 & Adhesive & 2.95 & 44.40 & Adhesive \\
2.63 & 59.12 & Adhesive & 14.75 & 58.73 & Adhesive \\
4.79 & 55.79 & Adhesive & 19.36 & 54.32 & Cohesive \\
5.24 & 59.97 & Adhesive & 28.54 & 56.74 & Cohesive \\
5.37 & 61.82 & Adhesive & 31.06 & 56.29 & Cohesive \\
8.18 & 60.39 & Adhesive & 37.2 & 65.28 & Cohesive \\
20.18 & 61.14 & Cohesive & 44.95 & 50.91 & Cohesive \\
26.59 & 57.69 & Cohesive & 60.24 & 62.81 & Cohesive \\
54.33 & 65.62 & Cohesive & 90.46 & 65.90 & Cohesive \\
84.57 & 59.77 & Cohesive & & & \\
\hline
\end{tabular}




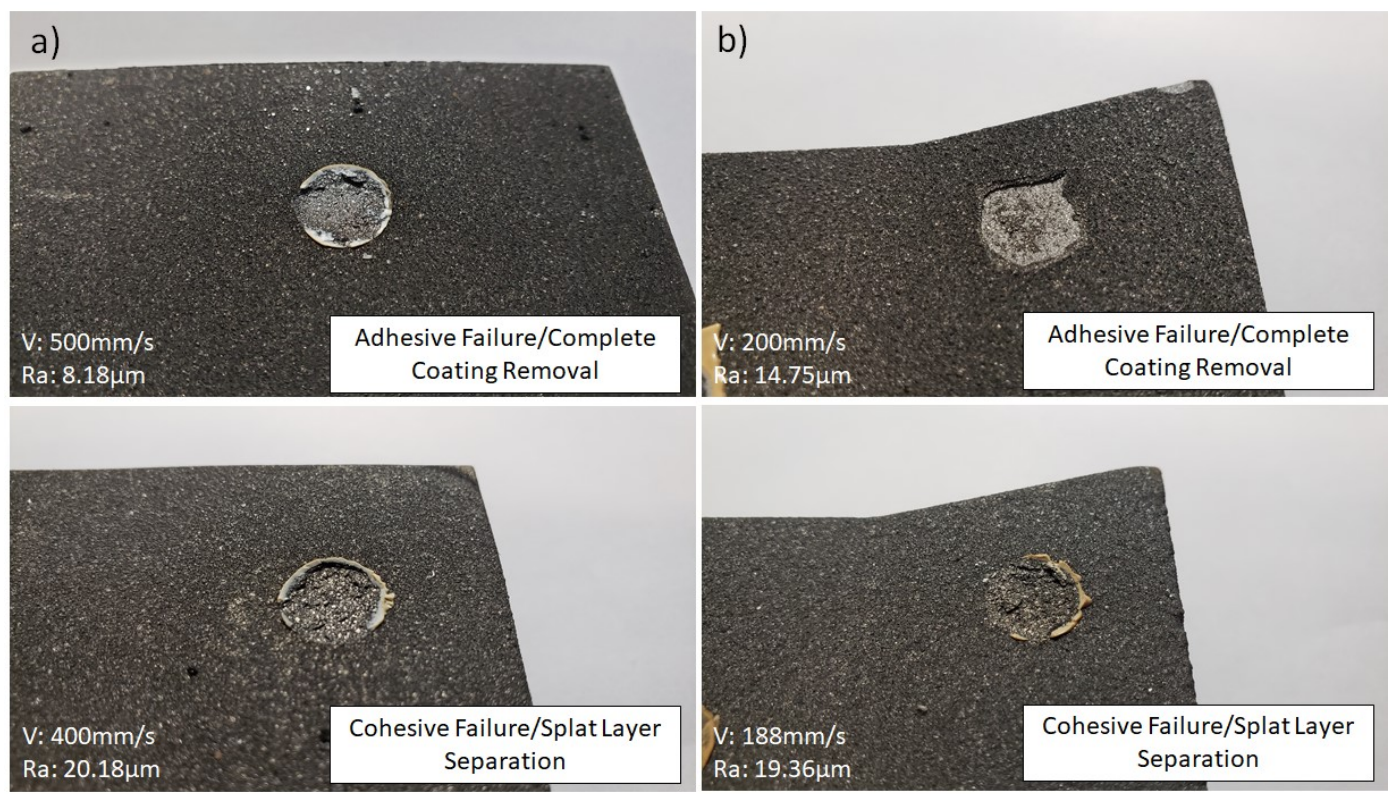

Figure 4.19: Surfaces after pull-off test of the SS 420 plasma spray coating on the a) GCI and b) A380 substrates showing complete coating removal and partial splat layer removal.

Another important aspect of the coating system is the surface profile after the coating process. Observing the surface roughness profiles after PTWA coating revealed that in cases where the average surface roughness exceeded $60 \mu \mathrm{m}$ the coating mirrored the roughness profile of the substrate. Adhesion strength testing could not be conducted on rough surface coatings as it was not possible to obtain a flat area to glue the dolly. Images of the T4 and T6 spray coated samples in Figure 4.20 are an example of rough surface coatings. However, as the average roughness values dropped below $60 \mu \mathrm{m}$ a flatter surface coating was attained. With the cylinder bore liner application in mind a coating with a rough surface profile is costly because of additional spray time, material, and machining needed to produce an acceptable finish. Therefore, the optimal conditions of a surface roughened using pulsed waterjet for adhesion strength of PTWA coating is a surface with an average roughness profile below $60 \mu \mathrm{m}$. 


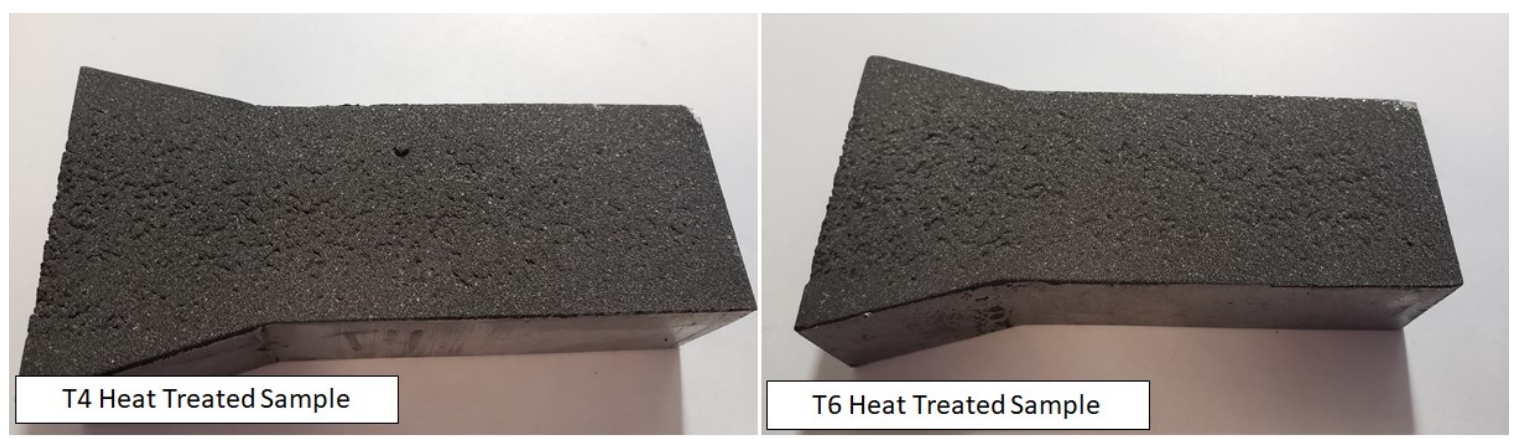

Figure 4.20: T4 and T6 heat treated samples coated with the SS 420 plasma spray.

\subsection{Microstructural Analysis}

This section discusses the characteristics of the samples cross-sectional microstructure after the pulsed waterjet roughening and the plasma transferred spray coating processes.

\subsubsection{Cross-sectional microstructure of SS 420 Plasma Spray Coating}

The image in Figure 4.21 shows the cross-section microstructure of the SS 420 coating. The pores, micro cracks, oxides, and un-melted particles are presented and labeled in the Figure. Also, the stacking and interlocking of the lamellar splat layers are visible.

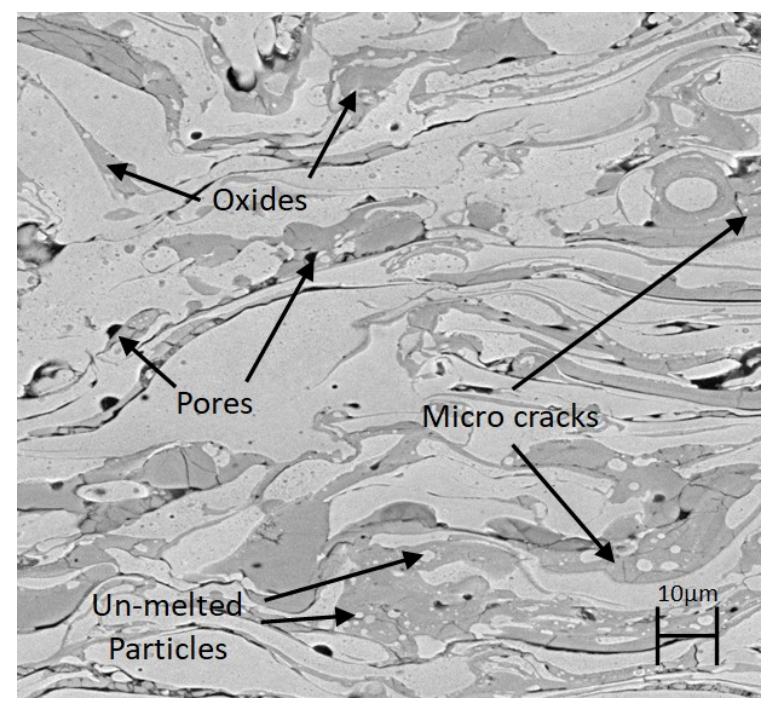


Figure 4.21: SE image of SS 420 coating showing the cross-sectional microstructure. The scan was conducted using a WD of $20.5 \mathrm{~mm}$, EHT of $20.00 \mathrm{kV}$, and a magnification of $1000 X$.

\subsubsection{Interlocking of Pulsed Waterjet Substrate and Plasma Spray Coating}

The pulsed waterjet roughening processes activated the substrate surface by produced pits which provided a site for mechanical interlocking of the plasma spray coating. The tensile load applied perpendicular to the coating surface attempts to break the mechanical interlock between the coating and substrate. The pulsed waterjet process does not produce a homogeneous roughened surface so the ability of a pit to anchor the coating varies on pit shape and size. Microscopy of the interface between the substrate and coating showed that at a microscopic level that the average surface roughness increased as a result of increased pit depth and density. The increased pit depth and density may lead to improved adhesion strength as the surface area and number of favourable mechanical anchoring sites increases. Interestingly, the increased surface roughness does not produce features which disrupt the deposition of the splat material. The images in Figures 4.22 and 4.23 illustrate the mechanical interlocking of the roughened A380 and GCI and the SS 420 spray coating. A comparison of interlocking mechanisms can be made between the two sets of images as both sample combinations had an average surface roughness of around $20 \mu \mathrm{m}$. Upon further examination of the images the differences between the two roughened substrate surface profiles are identifiable. These differences include pit shape, where the pits in the A380 seem more jagged or aggressive, while the pits in the GCI seem more rounded. Pit continuity where the pits in the GCI are more continuous compared to those in the cast aluminum. Finally, pit sizes such that the pits in the A380 appear to have small width but reach a greater depth than those in the GCI. The increased pit depth leads to improved adhesion strength by increasing the surface area which improves the potential 
for favorable anchoring sites and increases the extent of the surface which needs to shear for failure to occur.

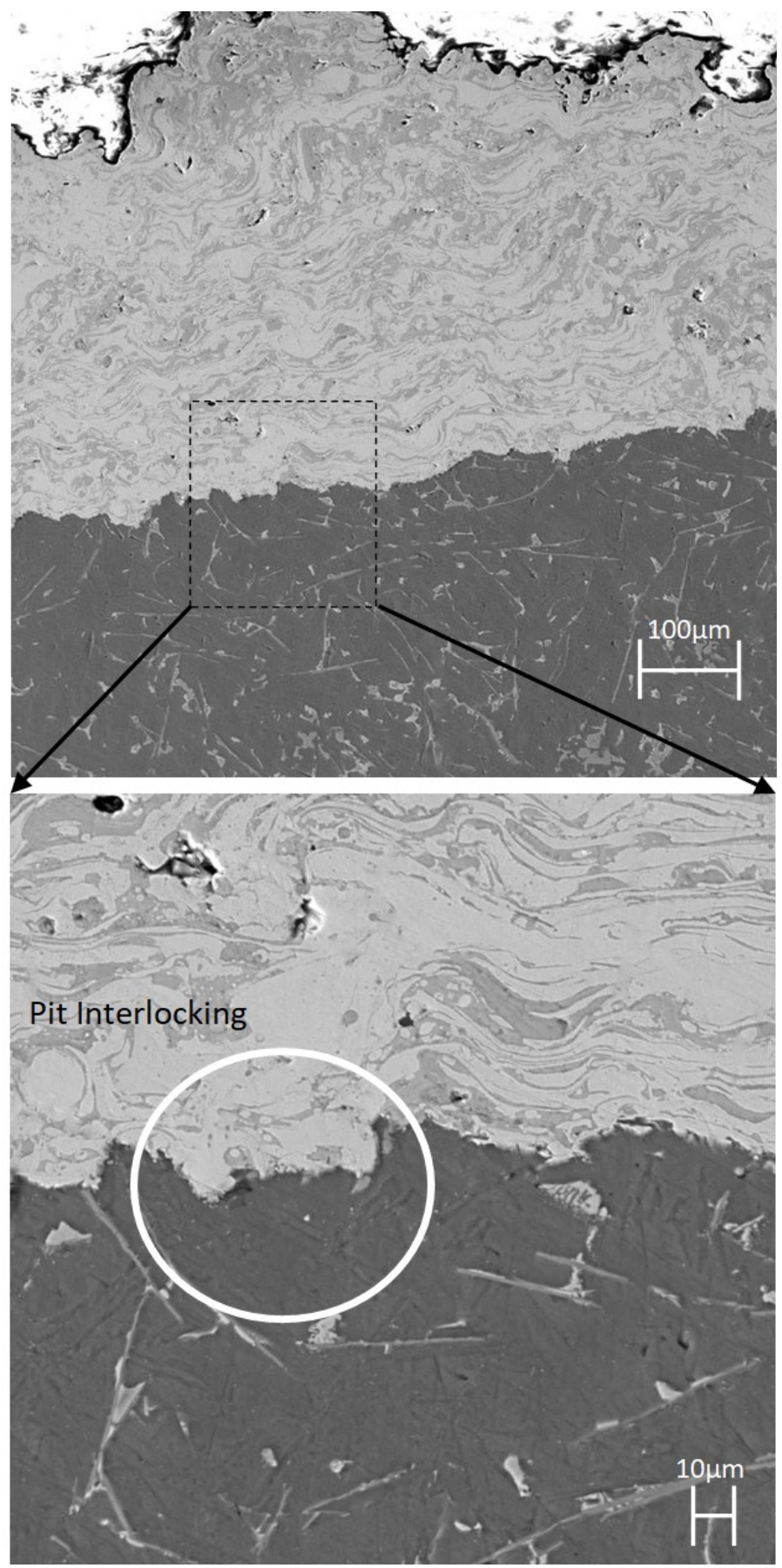

Figure 4.22: SE images showing pit interlocking between cast aluminum substrate with an average surface roughness of $19.36 \mu \mathrm{m}$ and the SS 420 coating. 


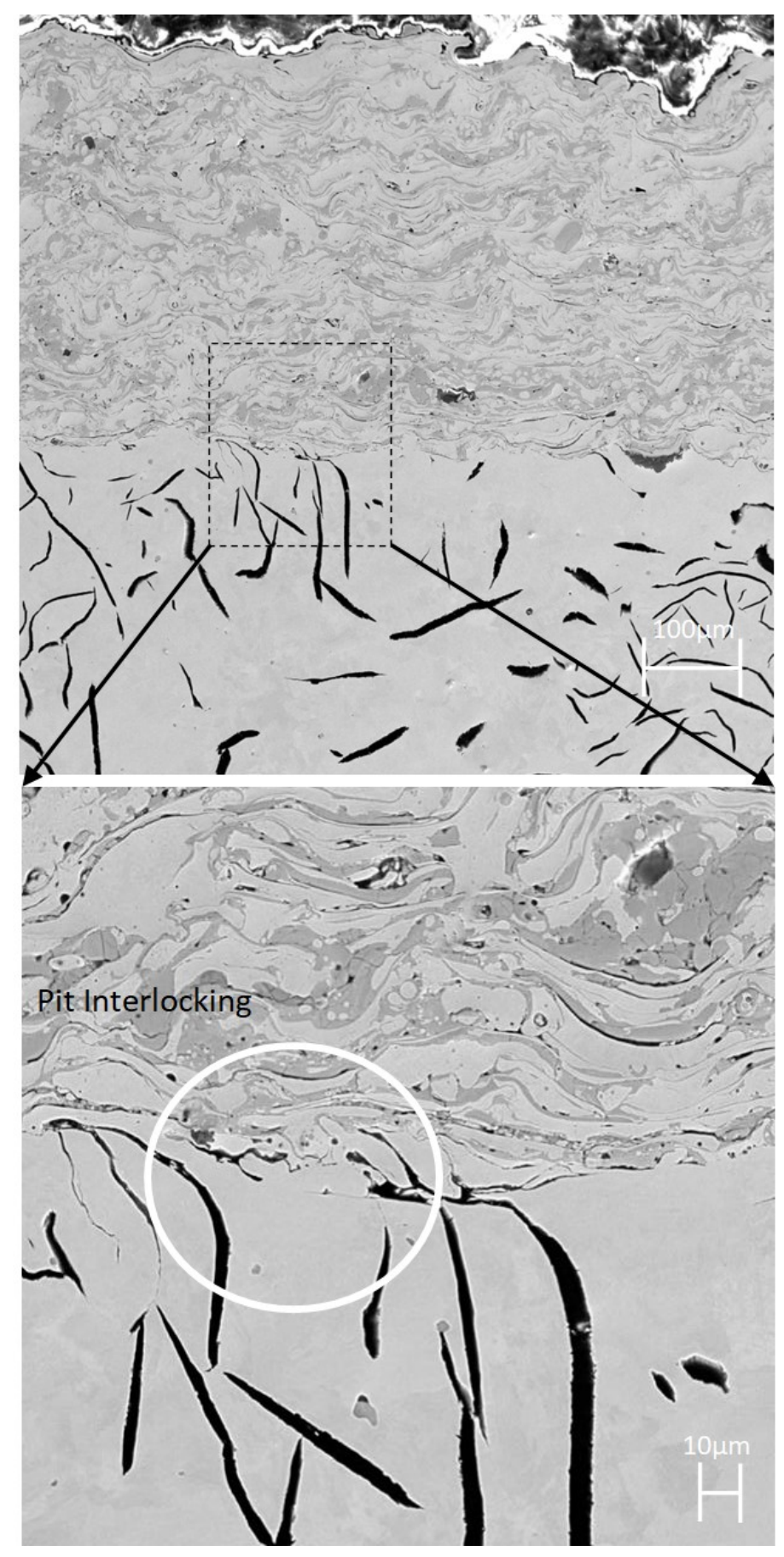

Figure 4.23: SE images showing pit interlocking between cast iron substrate with an average surface roughness of $20.18 \mu \mathrm{m}$ and the SS 420 coating. 


\section{Chapter 5 Conclusions}

The pull-off adhesion strength between pulsed waterjet roughened aluminum A380 and grey cast iron (GCI) samples, and the plasma transferred wire arc (PTWA) coating of SS 420 was studied to determine optimal surface parameters. The microstructure of the material, surface, and interface was analyzed for the samples. The conclusions derived from the study are as follows:

- The average surface roughness of the A380 and GCI increased with decreasing pulsed waterjet nozzle speed. This is a result of the increased dwell time of the jet in an area which resulted in more impacts of the water hammer and larger amount of water flowing radially. The average surface roughness values for the A380 ranged from minimum of $2.95 \mu \mathrm{m}$ to a maximum of $90.46 \mu \mathrm{m}$. The average surface roughness value for the GCI ranged from a minimum of $2.2 \mu \mathrm{m}$ to a maximum of $84.57 \mu \mathrm{m}$.

- The roughened surface profile produced by the pulsed waterjet on the A380 is a result of crack propagation and coalescing, surface erosion, and plastic deformation. The roughened surface profile produced by the pulsed waterjet on the GCI is a result of surface erosion, and crack propagation and coalescing through the brittle graphite flakes.

- The subsurface Vickers hardness of the A380 samples decreased near the pulsed waterjet roughened surface at a depth of $25 \mu \mathrm{m}$ as a result of crack formation and recovered at a depth of $175 \mu \mathrm{m}$. The GCI Vickers hardness was consistent at all depths and supports the idea that cracks are present predominantly in the graphite 
flakes. The only variation in Vickers hardness for the GCI was due to the different phases in its microstructure.

- The bond strength for all A380 and GCI samples with the SS 420 coating was 47\% to $117 \%$ higher than the recommended bond strength of $30 \mathrm{MPa}$ for the engine cylinder bore liner application. This means independent of the average surface roughness value the pulsed waterjet process is an effective surface activator to improve mechanical bonding between the substrate and coating.

- It was observed that for samples with an average surface roughness value greater the $60 \mu \mathrm{m}$ the PTWA spray coating mirror the substrate surface profile. This is disadvantageous as there would be more post processing steps required to produce a satisfactory surface. It was also noticed that above an average surface roughness value of $20 \mu \mathrm{m}$ the amount of coating which remained on the surface after detachment-based failure increased. This is because the number of favorable anchor points for mechanical interlocking between the substrate and coating increased. This is beneficial because if failure does occur the remaining coating would protect the substrate from the environment. Thus, the optimal average surface roughness for adhesion strength between the substrate and coating is between $20 \mu \mathrm{m}$ and $60 \mu \mathrm{m}$.

- The T4 and T6 heat treatment processes drastically increased effectiveness of the pulsed waterjet process to roughen the substrate surface. The resultant surface roughness of the pulsed waterjet $\mathrm{T} 4$ and $\mathrm{T} 6$ samples was $79.33 \mu \mathrm{m}$ and $99.88 \mu \mathrm{m}$ compared to $31.06 \mu \mathrm{m}$ for the untreated sample. The major increase in surface roughness proved to be a challenge when attempting to plasma spray coat the 
samples as the produced coating was uneven and mirror the substrate surface profile. 


\section{Chapter 6 Contributions and Future}

\section{Work}

\subsection{Contributions to Engineering}

- For the first time, pulsed waterjet process has been recognized as a suitable surface roughening process for grey cast iron and cast aluminum A380 alloy to be used prior to PTWA coating with the engine cylinder bore liner application in consideration.

- Surface roughness ranges have been optimized to get the maximum adhesion strength between the coating and the substrates considering the final surface finish.

- For the first time, T4 and T6 heat treatment cycles have been used to compare the roughness profiles for aluminum alloy A380.

\subsection{Suggested Future Work}

There were concerns with the coefficient of thermal expansion (CTE) mismatch between the material used for the engine block and the material used for the liner. The different thermal expansion coefficients for the engine block and liner materials can cause deformation of the liner and heat transferred concerns. The liners have been shown to disengage from the engine block causing heat pockets. Deformation of the liner may also lead to increased oil and fuel consumption, blowby, and increased emission [39]. The NiAl bond coat currently being used for adhesion strengthening between the engine block 
and spray coating helps with the CTE mismatch between the topcoat and engine block material. A study should be conducted to determine how the deformation due to CTE mismatch affects the mechanical bonding between the PTWA coating and pulsed waterjet roughened substrate. An emphasis should be put on studying how much deformation is needed to result in disengagement between the coating and substrate anchor points.

Wear studies are also being conducted on engine cylinder bore liners and protective coatings due to the low wear resistance of hypoeutectic Al-Si alloys such as A380. A wear study should be conducted on the wear resistant PTWA coating deposited on the pulsed waterjet roughened cast substrates. An analysis should be conducted to determine the wear mechanisms of the coating and how abrasive particles and splat delamination contribute to its wear.

Additionally, a study should be completed on the performance of the coatingsubstrate system under thermal loading. Elevated temperatures may result in microstructural phase change of the coating and substrate materials resulting in degradation of the coating-substrate system. Surface treatment techniques such as cross-hatching which reduces friction and heat build up by promoting oil retention may be a viable solution if the system does not fair well under thermal loading. 


\section{References}

[1] K. Bobzin, F. Ernst, J. Zwick and T. Schlaefer, "Thermal Spraying of Cylinder Bores with the PTWA Internal Coating System," in Proceedings of the ASME Internal Combustion Engine Division, Charleston, South Carolina, USA, 2007.

[2] R. Lund, "Remanufacturing: the experience of the USA and implications for the developing countries," World Bank Technical Paper, no. No. 3, p. No. 3, 1984.

[3] D. Cook, C. Verpoort, K. Kowalsky and R. Dicks, "Thermal spray of cylinder bores with the ford PTWA process," VDI Berichte, pp. 151-158, 2003.

[4] G. Barbezat, S. Keller and G. Wuest, "Internal Plasma Spray Process for Cylinder Bores in Automotive Industry," in ASM International - 15th International Thermal Spray Conference, Ohio, 1998.

[5] T. J. Kim and T. J. Labus, "Influence of basic jet parameters and physics of abrasive water jet cutting," WJTA 3, p. 45, 1995.

[6] M. Hashish, "Abrasive jets," WJTA, pp. 4.1-4.52, 1995.

[7] C. C. Longridge, "Hydraulic Mining," Mining Journal, 1910.

[8] D. A. Summers, Waterjetting Technology, New York: Taylor \& Francis, 1995.

[9] E. L. Bryan, "High Energy Jets as a new concept for wood machining," Forest Products Journal, vol. 13, no. 8, p. 305, 1963.

[10] J. E. Field, "Stress Waves, Deformation and Fracture Casued by Liquid Impact," Phul. Trans. Royal Society, vol. 260A, pp. 86-93, 1966.

[11] R. M. Fairhurst, R. A. Heron and D. H. Saunders, "Diajet' - a new abrasive waterjet cutting technique," in 8th International Symposium on Jet Cutting Technology, Durham, UK, Brit.Hydromechanics Research Assn., 1986, pp. 395-402.

[12] M. M. Vijay and J. Foldyna, "Ultrasonically modulated pulsed jets: Basic study, Jet Cutting Technology," Mechanical Engineering Pub, pp. 15-35, 1994.

[13] S. Shimizu, Tribology in Water Jet Process, Japan: IntechOpen, 2011. 
[14] M. Zelenak, J. Foldyna, J. Scucka, S. Hloch and Z. Riha, "Visualisation and measurement of high-speed pulsating and continuous water jet," Elsevier, vol. 72, pp. 1-8, 2015.

[15] M. M. Vijay, A. H. Tieu, W. Yan and B. R. Daniels, "Method and apparatus for prepping surfaces with a high-frequency forced pulsed waterjet". United States of America Patent 8,550,873, 08 October 2013.

[16] VLN Advanced Technologies Inc., "Fundamentals \& Applications of Cavitating and Forced Pulsed Waterjet Technologies," pp. 1-17.

[17] T. Samson, D. MacDonald, R. Fernández and B. Jodoin, "Effect of Pulsed Waterjet Surface Preparation on the Adhesion Strength of Cold Gas Dynamic Sprayed Aluminum Coatings," Journal of Thermal Spray Technology, vol. 24, no. 6, pp. 126, 2015.

[18] T. D. B. Jacobs, K. E. Ryan, P. L. Keating, D. S. Grierson, J. A. Lefever, K. T. Turner, J. A. Harrison and R. W. Carpick, "The Effect of Atomic-Scale Roughness on the Adhesion of Nanoscale Asperities: A Combined Simulation and Experimental Investigation," Tribology Letters, vol. 50, no. 1, pp. 81-93, 2013.

[19] A. Momber, Structures, Hydroblasting and Coating of Steel, Elsevier, 2003.

[20] T. J. Mason, "Ultrasonic cleaning: An historical perspective," Ultrasonics Sonochemistry, vol. 29, pp. 519-523, 2016.

[21] J. Foldyna, L. Sitek, J. Ščučka, P. Martinec, J. Valíček and K. Páleníková, "Effects of pulsating water jet impact on aluminium surface," Journal of Materials Processing Technology, vol. 209, no. 20, pp. 6174-6180, 2009.

[22] A. S. Grinspan and R. Gnanamoorthy, "Surface modification by oil jet peening in Al alloys, AA6063-T6 and AA6061-T4: Part 2: Surface morphology, erosion, and mass loss," Applied Surface Science, vol. 253, no. 2, pp. 997-1005, 2006.

[23] S. Hloch, P. Adamčík, A. Nag, M. Srivastava, D. Čuha, M. Müller, M. Hromasová and J. Klich, "Hydrodynamic ductile erosion of aluminium bya pulsed water jet moving in an inclined trajectory," Wear, Vols. 428-429, pp. 178-192, 2019.

[24] S. Yoshida, "Wave nature in deformation of solids and comprehensive description of deformation dynamics," Proceedings of the Estonian Academy of Sciences, vol. 64, no. 3, pp. 438-448, 2015. 
[25] S. Yoshida, "Comprehensive description of deformation and fracture of solids as wave dynamics," Mathematics and Mechanics of Solids, vol. 22, no. 5, pp. 10941115, 2017.

[26] J. E. Field, M. B. Lesser and J. P. Dear, " Studies of two-dimensional liquid-wedge impact and their relevance to liquid-drop impact problems," Proceedings of the Royal Society A: Mathematical, Physical and Engineering Sciences, vol. 401, no. 1821, pp. 225-249, 1985.

[27] M. Srivastava, R. Tripathi, S. Hloch, S. Chattopadhyaya and A. R. Dixit, " Potential of using water jet peening as a surface treatment process for welded joints," Procedia Engineering, vol. 149, pp. 472-480, 2016.

[28] A. W. Momber, R. Kovacevic and H. Kwak, "Alternative method for the evaluation of the abrasive water-jet cutting of grey cast iron.".

[29] T. Okada, Y. Iwai and A. Yamamoto, "A study of cavitation erosion of cast iron," Wear, vol. 84, no. 3, pp. 297-312, 1983.

[30] G. Laird II, W. K. Collins and R. Blickensderfer, "Crack propagation and spalling of white cast iron balls subjected to repeated impacts," Wear, vol. 124, no. 2, pp. 217-235, 1988.

[31] M. Srivastava, S. Hloch, N. Gubeljak, M. Milkovic, S. Chattopadhyaya and J. Klich, "Surface integrity and residual stress analysis of pulsed water jet peened stainless steel surfaces," Measurement, vol. 143, pp. 81-92, 2019.

[32] A. Azhari, C. Schindler and B. Li, "Effect of waterjet peening on aluminum alloy 5005," International Journal of Advanced Manufacturing Technology, vol. 67, no. 1-4, pp. 785-795, 2012.

[33] P. L. Fauchais, J. V. Heberlein and M. I. Boulos, Thermal Spray Fundamentals From Powder to Part, Boston, MA: Springer, 2014.

[34] N. Espallargas, Future Development of Thermal Spray Coatings: Types, Designs, Manufacture and Applications, Waltham: Woodhead Publishing, 2015.

[35] M. U. Schoop, "Apparatus for spraying molten metal and other fusible substances". United States of America Patent US1133507A, 30 March 1915. 
[36] C. Hopmann, K. Bobzin, M. Weber, M. Öte, P. Ochotta and X. Liao, "IMKS and IMMS-Two Integrated Methods for the One-Step-Production of Plastic/Metal Hybrid Parts," Advances in Production Technology, 2015.

[37] T. J. Levingstone, M. Ardhaoui, K. Benyounis, L. Looney and J. T. Stokes, "Plasma sprayed hydroxyapatite coatings: Understanding process relationships using design of experiment analysis," Surface and Coating Technology, vol. 283, pp. 29-36, 2015.

[38] J. Zou, "Characterization of thermal spray coatings on aluminum engine bore," University of Windsor, Windsor, 2016.

[39] K. Bobzin, F. Ernest, J. Zwick, T. Schlaefer, D. Cook, K. Nassenstein, A. Schwenk, F. Schreiber, T. Wenz, G. Flores and M. Hahn, "Coating bores of light metal engine blocks with a nanocomposite material using the plasma transferred wire arc thermal spray process," Journal of Thermal Spray Technology, vol. 17, no. 3, pp. 344-351, 2008.

[40] T. A. Taylor, D. F. Bettridge and R. C. Tucker Jr, "Coating composition having good corrosion and oxidation resistance". United States of America Patent 5455119, 03 October 1995.

[41] G. Darut, H. Liao, C. Coddet, J. M. Bordes and M. Diaby, "Steel coating application for engine block bores by Plasma Transferred Wire Arc spraying process," Surface and Coating Technology, vol. 268, pp. 115-122, 2015.

[42] J. R. Davis, Handbook of thermal spray technology, Material Park: ASM International, 2004.

[43] C. Verpoort, W. Blume, R. Ehrenpreis, M. Silk, W. Polich, D. Cook, K. Kowalsky, K. Bobzin, T. Schlaefer, J. Zwick, F. Ernst, A. Schwenk and K. Nassenstein, "Thermal Spraying of Aluminium Cylinder Bores by the Ford PTWA Spray Process," in ASME Internal Combustion Engine Division Spring Technical Conference, Aachen, 2006.

[44] L. Wang, "Erosion testing and surface preparation using abrasive water-jetting," Journal of Materials Engineering and Performance, vol. 1, no. 13, pp. 103-106, 2004. 
[45] K. Bobzin, F. Ernst, T. Schlaefer, C. Verpoort and G. Flores, "Thermal spraying of cylinder bores with the Plasma Transferred Wire Arc process," Surfaces \& Coatings Technology, no. 202, pp. 4438-4443, 2008.

[46] S. Chandra and P. Fauchais, "Formation of Solid Splats During Thermal Spray Deposition," Journal of Thermal Spray Technology, vol. 18, no. 2, pp. 148-180, 2008.

[47] M. Pasandideh-Fard, V. Pershin, S. Chandra and J. Mostaghimi, "Splat shapes in a thermal spray coating process: Simulations and experiments," Journal of Thermal Spray Technology, vol. 11, no. 2, pp. 206-217, 2002.

[48] J. Vetter, "Surface Treatments for Automotive Applications," Coating Technology for Vehicle Applications, pp. 91-132, 2015.

[59] W. J. Lenling, M. F. Smith and J. A. Henfling, "Beneficial effects of austemper post-treatment on tungsten carbide based wear coatings," in National Thermal Spray Conference and Exposition, Albuquerque, 1990.

[50] L. Bianchi, F. Blein, P. Lucchese, M. Vardelle, A. Vardelle and P. Fauchais, "Effect of particle velocity and substrate temperature on alumina and zirconia splat formation," in Thermal Spray Industrial Applications, Ohio, 1994.

[51] S. Sampath, X. Y. Jiang, J. Matejicek, A. C. Leger and A. Vardelle, "Substrate temperature effects on splat formation, microstructure development and properties of plasma sprayed coatings Part I: Case study for partially stabilized zirconia," Materials Science and Engineering, vol. A272, no. 1, pp. 181-188, 1999.

[52] A. Abedini, A. Pourmousa, S. Chandra and J. Mostaghimi, "Effect of substrate temperature on the properties of coatings and splats deposited by wire arc spraying," Surface and Coatings Technology, vol. 201, no. 6, pp. 3350-3358, 2006.

[53] B. Gérard, "Application of thermal spraying in the automobile industry," Surface and Coatings Technology, pp. 2028-2031, 2006.

[54] A. Edrisy and A. T. Alpas, "Microstructures and sliding wear resistances of $0.2 \%$ carbon steel coatings deposited by HVOF and PTWA thermal spray processes," Thin Solid Films, Vols. 420-421, pp. 338-344, 2002.

[55] J. H. Zaat, " A quarter of a century of plasma spraying," Annual Review of Materials Scinece, vol. 13, no. 1, pp. 9-42, 1983. 
[56] J. K. Knapp and T. A. Taylor, "Waterjet roughened surface analysis and bond strength," Surface and Coatings Technology, Vols. 86-87, pp. 22-27, 1996.

[57] G. Barbezat and G. Wuest, "Advantages for Automotive Indsutry of Plasma Spray Coating of A1-Si Cast Alloy Cylinder Bores," Surface Engineering, vol. 14, no. 2, pp. 113-116, 1998.

[58] "D4541-17 Standard Test Method for Pull-Off Strength of Coatings Using Portable Adhesion Testers," ASTM International, West Conshohocken, PA, 2017.

[59] J. H. Kweon, J. W. Jung, T. H. Kim, J. H. Choi and D. H. Kim, "Failure of carbon composite-to-aluminum joints with combined mechanical fastening and adhesive bonding," Composite Structures, vol. 75, no. 1-4, pp. 192-198, 2006.

[60] R. N. Lumley, R. G. Odonnell, D. R. Gunasegaram and M. Givord, "Heat Treatment of High-Pressure Die Castings," Metallurgical and Materials Transactions A, vol. 38A, pp. 2564-2574, 2007.

[61] "Metcoloy ${ }^{\circledR} \# 2$ Wire - Technical Bulletin \#10-023," Sulzer Metco - The Coatings Company, 2000. 